Florida International University

FIU Digital Commons

3-18-2020

\title{
An Examination of Motivation and Teacher Identity in Minority High School Students Enrolled in a Career and Technical Education Teacher Preparation Program
}

\author{
Elizabeth M. Aguila \\ eagui030@fiu.edu
}

Follow this and additional works at: https://digitalcommons.fiu.edu/etd

Part of the Early Childhood Education Commons, Educational Methods Commons, Secondary

Education Commons, Teacher Education and Professional Development Commons, and the Vocational

Education Commons

\section{Recommended Citation}

Aguila, Elizabeth M., "An Examination of Motivation and Teacher Identity in Minority High School Students Enrolled in a Career and Technical Education Teacher Preparation Program" (2020). FIU Electronic Theses and Dissertations. 4384.

https://digitalcommons.fiu.edu/etd/4384

This work is brought to you for free and open access by the University Graduate School at FIU Digital Commons. It has been accepted for inclusion in FIU Electronic Theses and Dissertations by an authorized administrator of FIU Digital Commons. For more information, please contact dcc@fiu.edu. 


\section{FLORIDA INTERNATIONAL UNIVERSITY}

Miami, Florida

\section{AN EXAMINATION OF MOTIVATION AND TEACHER IDENTITY IN MINORITY HIGH SCHOOL STUDENTS ENROLLED IN A CAREER AND TECHNICAL EDUCATION (CTE) TEACHER PREPARATION PROGRAM}

A dissertation submitted in partial fulfillment of

the requirements for the degree of

DOCTOR OF PHILOSOPHY

in

TEACHING AND LEARNING

by

Elizabeth Martin Aguila 
To: Dean Michael R. Heithaus

College of Arts, Sciences and Education

This dissertation, written by Elizabeth Martin Aguila, and entitled An Examination of Motivation and Teacher Identity in Minority High School Students Enrolled in a Career and Technical Education (CTE) Teacher Preparation Program, having been approved in respect to style and intellectual content, is referred to you for judgment.

We have read this dissertation and recommend that it be approved.

Elizabeth Cramer

Laura Dinehart

Haiying Long

Joyce Fine, Major Professor

Date of Defense: March 18, 2020

The dissertation of Elizabeth Martin Aguila is approved.

Dean Michael R. Heithaus

College of Arts, Sciences and Education

Andrés G. Gil

Vice President for Research and Economic Development and Dean of the University Graduate School

Florida International University, 2020 


\section{DEDICATION}

To God, for giving me the health and the strength to accomplish this dream; putting special people in my path that have carried me along.

To my grandparents who have been guiding me from above every step of the way.

To my husband Levis, my daughter Samantha, and my son Levis Jr., who have believed in me and never let me forget that I am stronger than I think.

To my parents, who raised me to persevere regardless of circumstance.

To my family and friends, who carried me, cried with me, inspired me, and helped me. Finally, and most importantly, to my students, old and new, who are my inspiration to be better, every day. 


\section{ACKNOWLEDGMENTS}

Dr. Fine, who encouraged and supported me throughout this journey.

My committee, who continuously inspired me to reach my fullest potential.

My FIU professors, especially Dr. Cohen, who pushed me to begin this odyssey.

My administration, Dr. Louis Algaze, Mrs. Maritza Jimenez and Mrs. Lesa Slocum for their continuous support and encouragement.

The administration and teacher at my comparison school for their encouragement and support.

Finally, my two co-teachers, Jeselie Martinez and Gysenia Escobar, who took on responsibilities so that I can accomplish my dream. 


\author{
ABSTRACT OF THE DISSERTATION \\ AN EXAMINATION OF MOTIVATION AND TEACHER IDENTITY IN MINORITY \\ HIGH SCHOOL STUDENTS ENROLLED IN A CAREER AND TECHNICAL \\ EDUCATION (CTE) TEACHER PREPARATION PROGRAM
}

by

Elizabeth Martin Aguila

Florida International University, 2020

Miami, Florida

Professor Joyce Fine, Major Professor

This quantitative research describes the measures of motivating factors, through a social learning lens, that empower minority high school students in a CTE program to develop a teacher identity through time in clinical teaching practice. This quasiexperimental study found interactions between student motivation, teacher identity, and student achievement through an early clinical practice intervention used in SCHOOL A ECE 1. A comparison group, SCHOOL B ECE 2, was used to measure any effect of a community of practice framework on these factors. The present study also used a nonteacher education program, SCHOOL A BIO 1 to measure if motivation and teacher identity were content specific. The target population were $9^{\text {th }}-12^{\text {th }}$ grade students enrolled in CTE programs. The independent variables in the current study included the vocational program enrollment and course academic levels (levels 1-4) in the CTE programs, to measure both motivation and identity development and pre and post achievement analysis. The dependent variables included survey responses to find effects on motivation, teacher identity. The study utilizes the Motivated Strategies for Learning 
Questionnaire (MSLQ) survey instrument to measure motivational orientations. A modified version of a teacher identity survey was used to measure different dimensions of a teacher identity framework which includes recognition, interest, performance, and competence. An ex post facto design measures changes in student attendance and GPA to determine changes after time in clinical teaching practice between $9^{\text {th }}$ and $12^{\text {th }}$ grade. The results found no significant difference between the programs in motivation, but a significant difference was found in the development of teacher identity in the students of SCHOOL A ECE 1. A significant difference was also found between the levels (levels 14), with level 4 students in SCHOOL A ECE 1 having the highest mean for teacher identity. 


\section{TABLE OF CONTENTS}

CONTENT

PAGE \#

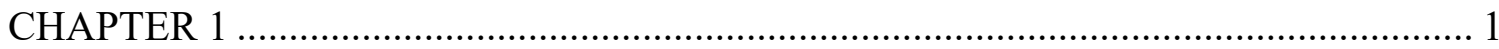

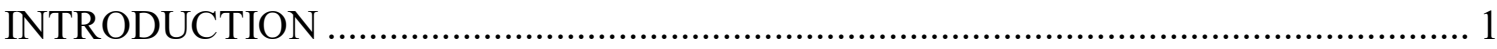

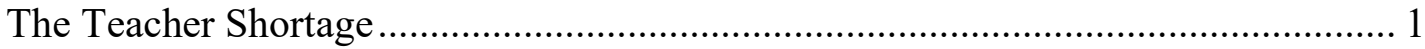

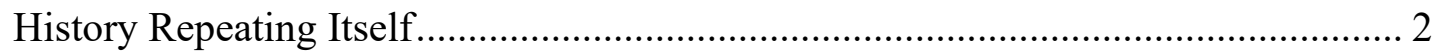

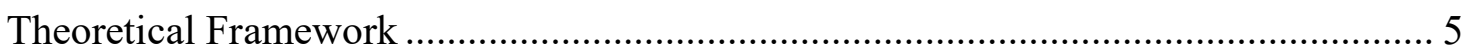

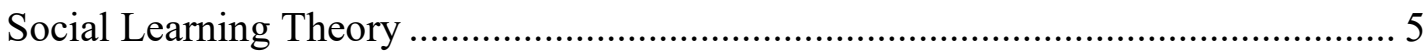

Community of Practice Framework ...................................................................... 6

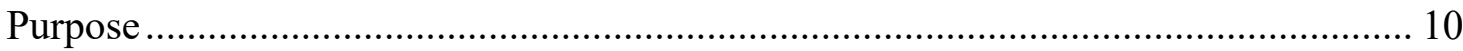

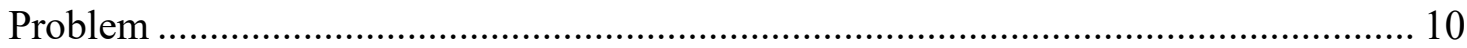

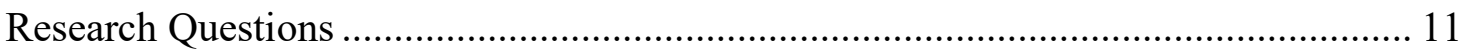

Definition of Relevant Terms............................................................................ 12

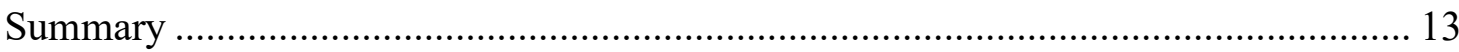

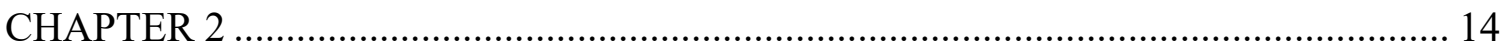

REVIEW OF THE LITERATURE .................................................................. 14

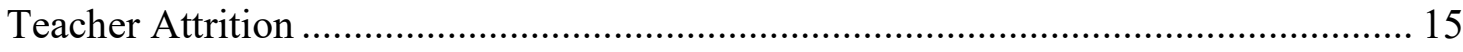

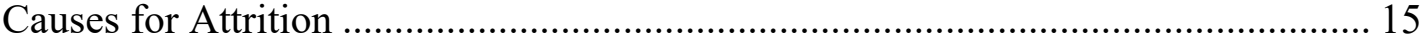

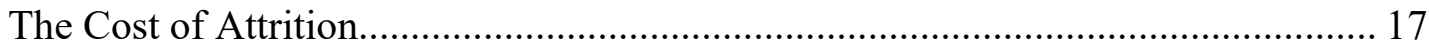

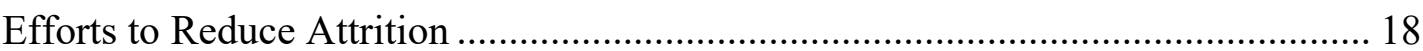

Historical Foundation of Career and Technical Education (CTE) ............................ 22

CTE Vocational Programs: Student Motivation and Achievement ............................ 23

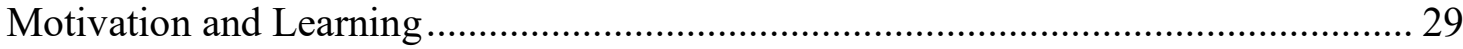

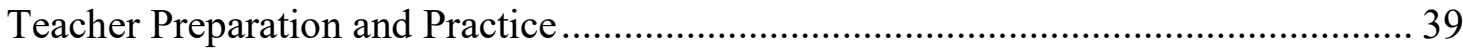

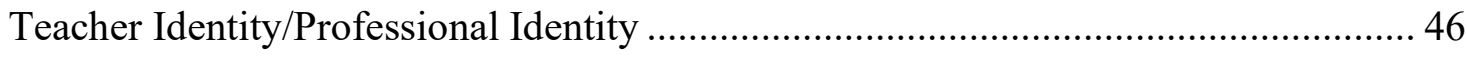

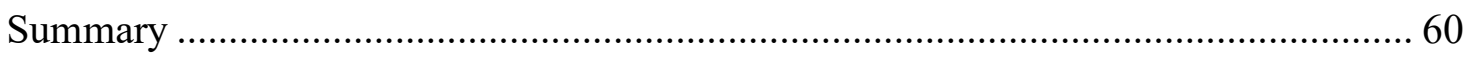

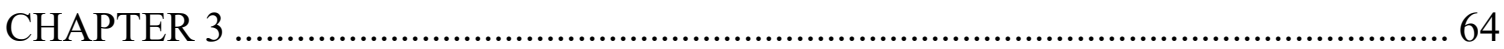

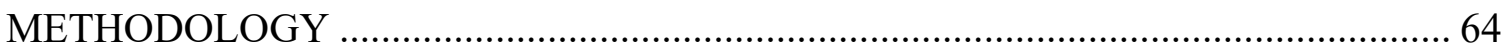




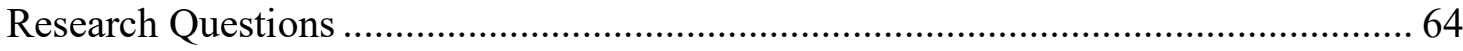

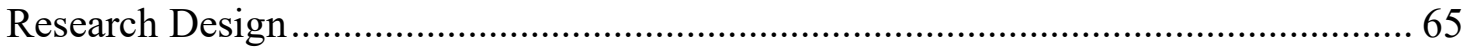

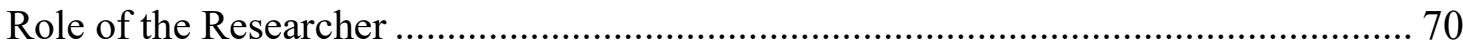

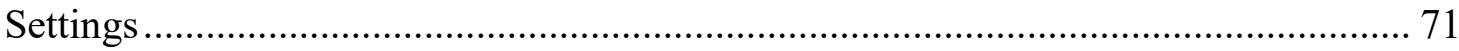

SCHOOL A ECE 1 Academy Program Overview ………………………………..... 72

SCHOOL A ECE 1 Relevant Framework Overview ……………………………..... 75

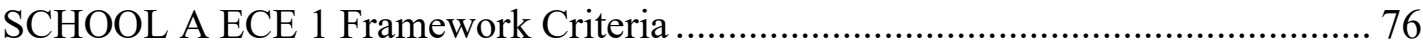

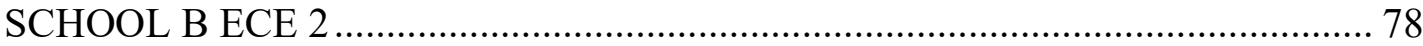

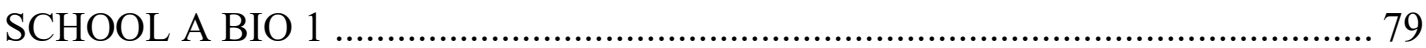

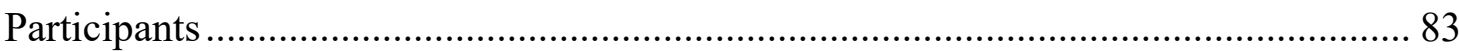

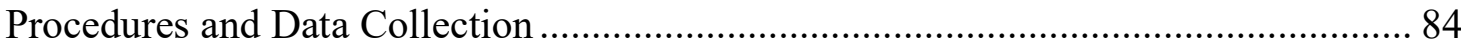

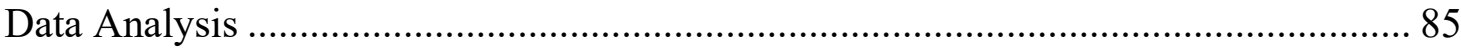

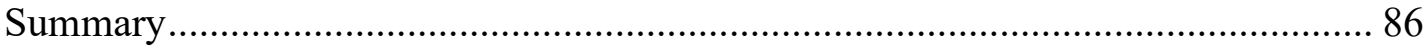

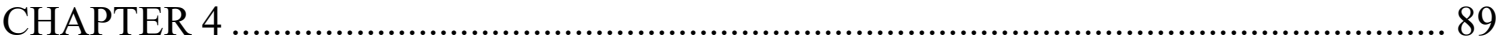

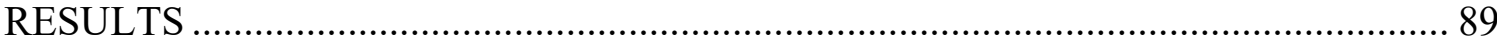

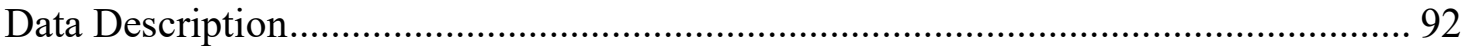

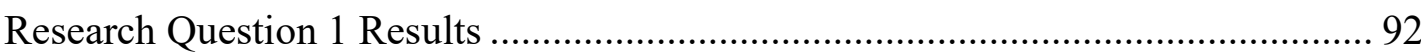

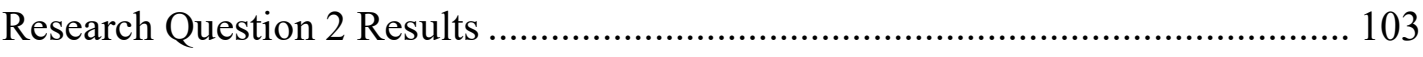

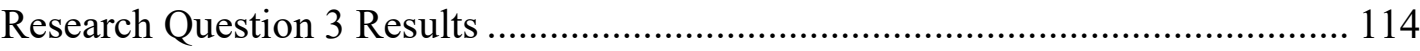

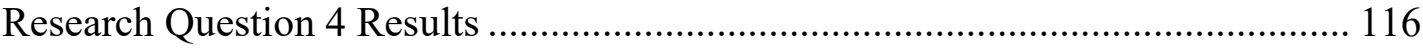

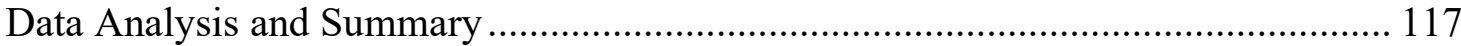

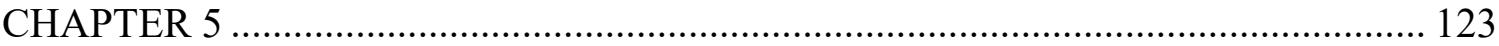

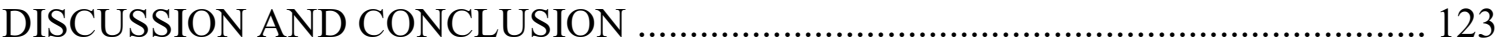

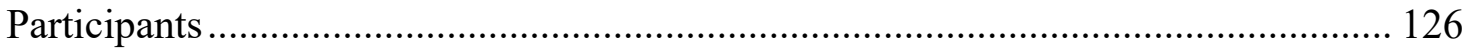

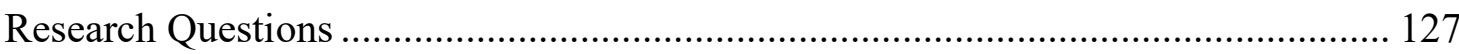

Answering Research Question 1....................................................................... 128

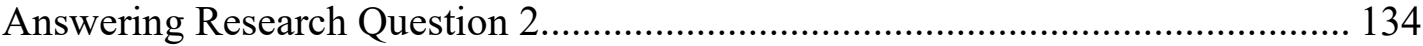

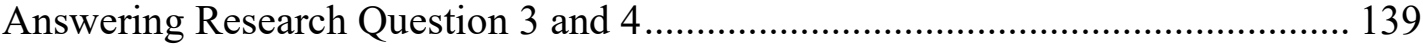

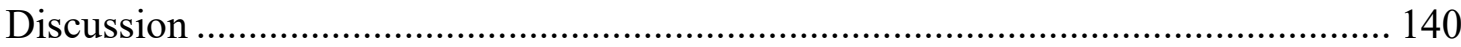


Recommendations for Future Research .

143

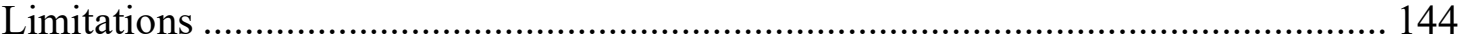

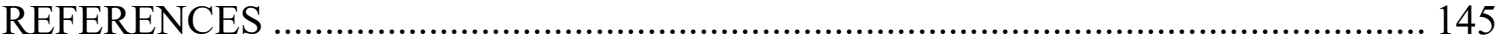

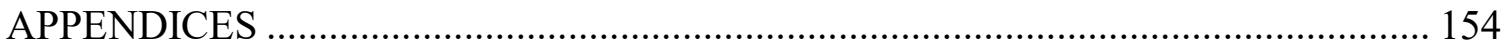

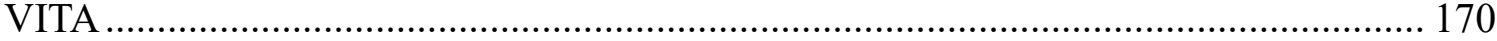




\section{LIST OF TABLES}

TABLE

PAGE

3.1 Motivational Scales and Item information 67

3.2 Teacher Identity framework dimensions and survey item information

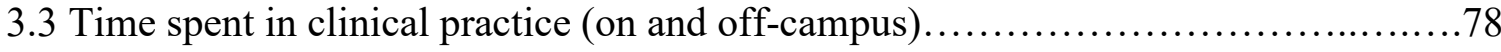

4.1 Multivariate test results for independent variables: Vocational Program and Program Levels on MSLQ .................................................93

4.2 ANOVA Between-Subjects Effects of Interest Goal Orientation...................94

4.3 ANOVA Vocational Program Comparisons of Interest Goal Orientation..............94

4.4 ANOVA Program Level Comparisons of Interest Goal Orientation.................95

4.5 ANOVA Between-Subjects Effects of Extrinsic Goal Orientation........................95

4.6 ANOVA Vocational Program Comparisons of Extrinsic Goal Orientation............96

4.7 ANOVA Program Level Comparisons of Extrinsic Goal Orientation.................96

4.8 ANOVA Between-Subjects Effects of Task Value Effect.............................97

4.9 ANOVA Vocational Program Comparisons of Task Value Effect..................97

4.10 ANOVA Program Level Comparisons of Task Value Effect.......................98

4.11 ANOVA Between-Subjects Effects of Control of Learning Beliefs.................99

4.12 ANOVA Vocational Program Comparisons of Control of Learning Beliefs..........99

4.13 ANOVA Program Level Comparisons of Control of Learning Beliefs...............99

4.14 ANOVA Between-Subjects Effects of Self-Efficacy for Learning and Performance

4.15 ANOVA Vocational Program Comparisons of Self-Efficacy for Learning and Performance.

4.16 ANOVA Program Level Comparisons of Self-Efficacy for Learning and Performance. 
4.17 Independent Samples t-test and group statistics for motivational scales of the MSLQ by Vocational Program........................................... 102

4.18 Multivariate test results for independent variables: Vocational Program and Program Levels on Teacher Identity Survey..................................104

4.19 ANOVA Between-Subjects Effects of Teacher Identity Recognition................105

4.20 ANOVA Vocational Program Comparisons of Teacher Identity Recognition.......105

4.20.1 ANOVA Program Level Comparisons of TID: Recognition....................106

4.21 ANOVA Between-Subjects Effects of Teacher Identity Interest..................107

4.22 ANOVA Vocational Program Comparisons of Teacher Identity Interest.............107

4.22.1 ANOVA Program Level Comparisons of TID: Interest........................108

4.23 ANOVA Between-Subjects Effects of Teacher Identity Performance................109

4.24 ANOVA Vocational Program Comparisons of Teacher Identity Performance.......109

4.24.1 ANOVA Program Level Comparisons of TID: Performance................... 110

4.25 ANOVA Between-Subjects Effects of Teacher Identity Competence...............111

4.26 ANOVA Vocational Program Comparisons of Teacher Identity Competence........111

4.26.1 ANOVA Program Level Comparisons of TID: Competence....................112

4.27 Independent Samples t-test and group statistics for dimensions of the Teacher Identity Survey by Vocational Program......................................113

4.28 Paired Samples T-test to compare $9^{\text {th }}$ and $12^{\text {th }}$ grade GPA Mid-year for

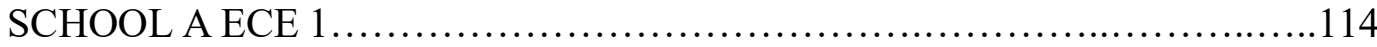

4.29 Paired Samples T-test to compare $9^{\text {th }}$ and $12^{\text {th }}$-grade Mid-year GPA for

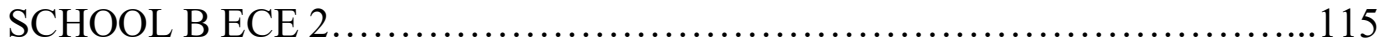

4.30 Paired Samples T-test to compare $9^{\text {th }}$ and $12^{\text {th }}$-grade Mid-year unexcused absences from the school day for SCHOOL A ECE 1 ........................117

4.31 Paired Samples T-test to compare $9^{\text {th }}$ and $12^{\text {th }}$-grade Mid-year unexcused

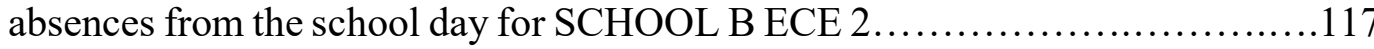


4.32 Correlations, including all three groups, of motivation, mean, teacher identity mean, current mid-year GPA, and current mid-year Attendance (number of

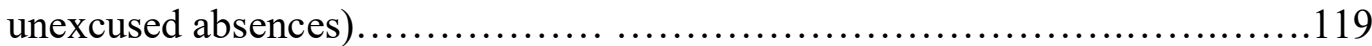

4.33 Correlations, including only the two early childhood programs, of motivation, mean, teacher identity means, current mid-year GPA, and current mid-year Attendance (number of unexcused absences) .............................. 120

5.1 Number of participants per level, per program............................... 127 


\section{CHAPTER 1 \\ INTRODUCTION}

\section{The Teacher Shortage}

The field of education, as well as the teaching profession, has seen many changes over time. Increasingly, demands and expectations have been placed on teachers' already overflowing workload. According to Sutcher, Darling-Hammond, and Carver-Thomas (2016), the teacher's role in the classroom has shifted as a result of the diverse needs of students, emerging technologies, and changes in public policy. Teaching is in a constant state of flux. The imbalance of compensation, political control, and demands of the profession, along with high-stakes testing, and vacillating accountability measures have pushed experienced teachers away, making it challenging to retain passionate and competent teachers (Sutcher et al., 2016). According to the State Department of Economic Opportunity, Bureau of Labor Market Statistics (2018), the need for teachers at every level and content area will rise over $13 \%$ before 2026 . The most significant teacher shortages for the state of Florida for the 2019-2020 school year are in Exceptional Student Education, Math, Reading, English as a Second Language, Career and Technical Education and Science (U.S. Department of Education, 2020). According to Sutcher, Darling-Hammond and Carver-Thomas (2019), because of "data limitations at the national level," it is difficult to report exact national shortage data (p. 3). The gap in data makes analyzing the intensity of the teacher shortage difficult to analyze. According to a report produced from the U.S. Department of Education, the national shortages across the states seem to reflect those of the state of Florida (file:///C:/Users/Lagui.DESKTOP- 
A2K9IUM/Downloads/ViewTSAReport\%20(1).pdf). Sutcher et al. ( 2019) report over 40 states have teacher shortages in similar content areas.

The days of abundant education majors are waning. According to the PUMS (Public Use Microdata Sample), data given by the United States Census Bureau (2015), education majors had decreased from $21.6 \%$ in 1975 to $7.6 \%$ in 2015 . According to a national analysis completed by Sutcher et al. (2019), enrollment in teacher preparation programs have declined 35\% between 2009 and 2014. Because of the many changing variables, the number of students entering the field of education is rapidly decreasing, and current teachers are leaving the classroom as baby boomers retire or leave for higherpaying jobs that require similar skills. According to Sutcher et al. (2016), teacher shortages would improve if teacher attrition received increased attention. Also, the authors claim if teachers were offered a more competitive compensation package, there would be an increase in highly-qualified teachers in areas of need such as special education; there would also be an improvement in the retention of teachers in low-income schools and an improvement in the overall teacher supply market, and teacher attrition would improve (Sutcher et al., 2016).

\section{History Repeating Itself}

As a result of Darling-Hammond's (1997) landmark report, entitled "What Matters Most," published by the National Commission on Teaching America's Future, policymakers agreed to fund initiatives to improve teacher recruitment and retention such as including new teacher mentoring, quality professional development, student loan forgiveness programs, and incentives for continuing education (Berry \& Shields, 2017). Although these initiatives were working to keep teachers in the classroom, policymakers 
gradually pulled away and allowed the programs to terminate (Berry \& Shields, 2017). After the Great Recession in 2008, it was challenging to fill vacant teaching positions because many of the previously established initiatives were nonexistent. States hired anyone who wanted to teach, even when they had not completed a teacher preparation program or met state requirements for certification (Berry \& Shields, 2017). Today, the country is facing the same shortages but with higher stakes. Teachers must now be prepared to meet even higher state standards and rigorous demands. In a more diverse world with sophisticated technology, teachers are less prepared than before (Berry \& Shields, 2017; Redding \& Henry, 2018). Berry and Shields suggested solutions to teacher attrition rates, and the teacher shortage includes strengthening teacher preparation for preservice teachers and ensuring high-value mentorship for beginning teachers (Berry \& Shields, 2017). Finally, the authors suggest that the problem of a teacher shortage and attrition is not a technical one but a political one. They argue that the problem cannot be addressed with a temporary fix, but instead needs effective advocacy for quality teacher preparation and sustainable solutions (Berry \& Shields, 2017).

In summary, the vision of the high school preparation program in the current study, SCHOOL A ECE 1, is to prepare future teachers to become resilient, agentic, selfregulated advocates for the teaching profession through quality preparation and early clinical teaching practice. With a focus on building self-efficacy, the high school program seeks to prepare future teachers using an instructional framework that promotes problemsolving, advocacy, and content knowledge through teaching practice. To recruit and retain quality teachers, they must be adequately prepared for the obstacles they will face in the teaching profession. Research shows that teachers that are not rigorously prepared 
will add to the attrition rate, especially in urban schools. The research also shows that programs that promote clinical opportunities, as well as professional development, see the most significant percentage in teacher retainment. The high school target program in the present study requires over 480 hours of teaching experience with preschool-aged children, between ninth and twelfth grade using a structured, clinical framework that uses a rigorous criterion that includes national and state certifications as well as relevant professional development. The framework includes opportunities for paid internships in their urban community, intending to encourage students to stay in their community as prepared, diverse advocates for their future students after they graduate from college. To further motivate students to remain in their high-need community, dual enrollment opportunities are also offered as well as articulation agreements to help create a pipeline between the local college and university, district, and school.

States are looking to create career pathways that begin in high school and feed into colleges and universities to remedy the shortage and improve teacher attrition rates. In a report by the Learning Policy Institute (2016), Sutcher and colleagues suggest the implementation of "Grow Your Own" programs that recruit high school students to teach in schools in their communities. These programs seek to minimize the diversity gap between teachers and students to improve overall student achievement. Although the schools compared in the current study do not follow the "Grow Your Own" framework, through Career and Technical Education (CTE) Education and Training cluster, these high schools are doing more to encourage and motivate students to enter the field of education to replenish the depleting number of teachers. 
There is limited research on the success or effectiveness of the current framework used for the Education and Training cluster in CTE to motivate students to enter the field of education (Advance CTE, 2019; DeFeo, 2015; Loera et al., 2013). The research provided in the current dissertation shows the need for effective, highly qualified teachers in the years to come

\section{Theoretical Framework}

\section{Social Learning Theory}

The current study views teaching and learning in vocational programs through the lens of the Social Learning Theory. Social Learning Theory allows one to continuously study how the mind understands, interprets, and constructs new knowledge. Various attributes of the present study connected to components of the Social Learning Theory and encompassed behavioral influences on teaching and learning during early clinical teaching practice. The study specifically used Social Learning Theory to guide the analysis of student motivations and teacher identity as well as student achievement and school attendance. The current study also used the sociocultural theory as a lens to analyze the results of social interactions in the development of teacher identity, motivation, and student achievement as well as the effects of the community of practice framework already in place at ECE 1 on these same factors. Vygotskian sociocultural theories of learning facilitated through the concept of the zone of proximal development (ZPD) also informed the present study. The community of practice framework was used to attempt to organize and explain a program that includes a group of students who share a common interest and passion. The researcher relates learning procedures in the 
community of practice framework and gives a clearer understanding of the reflecting, analyzing, and problem-solving contributions to teaching experience. The sociocultural lens was chosen because a broad theoretical framework was needed to address the complex issues and relationships of teacher identity, motivation, and student achievement in a high school teacher preparation program. A sociocultural viewpoint provides a way to organize the concepts and models to explore the research questions.

\section{Community of Practice Framework}

Wenger (1998) believes that learning is socially constructed and developed in a social context. He believes that knowledge is connected to one's values and competence; knowing is the ability to participate and engage in their world; and that the goal of learning is to get meaning from these experiences of engagement (Wenger, 1998, p. 4). The sociocultural view refers to participation as more than just interacting in a context with the same participants; it is part of a more extensive, broader process that involves practice and the development of identity. Wenger includes four interconnected components in his community of practice theory: meaning, practice, community, and identity. He identifies the context as a "point of entry" into a broader conceptual framework (Wenger, 1998, pg. 6). The community of practice framework uses the theory of social structure, the theory of situated experience, the theory of social practice, and identity to describe how learning occurs. Theories of social structure set institutions, standards, and procedures at the forefront of learning. They create a culture built on history and discourse and view agency as a result of this structure. Theories of situated learning focus on the interactions of people in "interactional choreography" in their environment and "emphasize agency and intentions" (Wenger, 1998, pg. 13). Wenger 
believes that learning exists in the middle of these two concepts, involving agency but through cultural procedures and rules. He adds that theories of social practice and identity are not as extreme as the two views presented but include ideas from both. According to Wenger, theories of social practice relate to the way people engage with the world through "every-day activities and real-life settings" in shared social systems (Wenger, 1998, pg. 13). He adds that theories of identity are related to the formation of the self in a social setting and involves categories such as gender, class, and ethnicity.

According to Coburn and Stein (2006), in contrast to most learning research, a more sociocultural approach is being studied using the communities of practice framework to analyze teacher, professional social learning. They define communities of practice as "a group of individuals who, through pursuit of a joint enterprise, have developed shared practices, historical resources, and common perspectives" (Coburn \& Stein, 2006, p. 28). They discuss how a community is "any place individuals opt into relationships with one another" (Coburn \& Stein, 2006, p. 28). Wenger (1998) believes that learning happens in any context and is inevitable; he suggests that if learning does not happen as planned, some learning did occur, even if unplanned. He believes that learning happens for individuals through engagement to their learning community through practice, for communities though growth and progress, and the organization through maintaining multiple communities of practice, giving it more value and effectiveness (Wenger, 1998).

After reviewing the literature, the role of the teachers in communities of practice seems undefined. In constructivist views, the teacher is seen as the facilitator of learning by providing structure and standards. The teacher in a community of practice seems to be 
the context or environment itself. Students learn from each other, whether they are more knowledgeable or not. According to Hartnell-Young (2006), in the community of practice model, teachers and students teach and learn interdependently. In communities of practice, the environment or context seems to be a factor that exists and changes with the learning and progress of the participants, whereas in constructivist learning, the environment is structured and maintained by the teacher. According to Wenger (1998), the learning environment "cannot be designed: it can only be designed for" (p. 229). He describes designing a learning environment as "systematic, planned and reflexive colonization of time and space" (Wenger, 1998, p. 228). The time and space of the learning environment are also affected by the social learning that takes place, developing instruction, using the curriculum, and influencing the organization towards progress. Wenger's view promotes a "living experience of negotiated meaning" and does not focus on the structure of the design (Wenger, 1998, p. 229). Because each community of practice is dependent on the learning and practice of its members, the design can be encouraged and nurtured but cannot be decreed. According to Wenger, components such as practice, roles, and values can be presented in the learning environment, but the meaning taken from these experiences cannot be. For the present study, the community of practice framework was used to help describe the social learning environment in the CTE teacher preparation program at SCHOOL A ECE 1. Wenger recommends looking at context/community as a "point of entry" into the complex social learning theory (p. 6). The present study uses that theoretical thinking as a lens into the practice, meaning, and identity components of the social learning occurring in the CTE courses in the current study and the effects the environment might has on these components. 
A community of practice lens was used to analyze the major components of the Early Childhood program at SCHOOL A ECE 1 . The learning environment consists of high school students who chose to begin or continue in the program for a multitude of reasons. The environment is set up to facilitate socially constructed learning. Students work in small, mixed level (levels 2-4) groups. Beginning students in level 1 (mostly $9^{\text {th }}$ graders) spend a limited time in the on-campus preschool with the children; level 2-4 (mostly $10^{\text {th }}$ thru $12^{\text {th }}$ graders) remain in the preschool room every day. The students work in a group rotation to accomplish specific daily jobs which share the same goal, to operate a successful preschool where everyone is learning. Working towards a shared goal adds to the community of practice framework, highlighting one of Wenger's four components, community. The remaining components, meaning, practice and identity, can also be identified through the roles, jobs and responsibilities of the program's framework. Chapter 2 in this dissertation will further discuss these elements in more detail. To facilitate a culture of agency and learning, these class procedures create a necessary structure derived from community successes and failures throughout the years. As a community, the students work together with the teacher-researcher, through professional discourse and reflection, to create a progressive learning environment. The social learning environment at SCHOOL A ECE 1 fosters identity formation through constant engagement in opportunities for daily teaching practice. Although the state provides curricular standards for programs that have an on-campus preschool, it is unknown if other Early Childhood programs follow a community of practice framework. 


\section{Purpose}

The goal of the present research is to identify the motivating factors for teacher identity, through a social learning lens, that empowers high school students to enter the field of education. The goal is to create learners with high motivation to increase teacher identity through early clinical teaching experiences. The study is a stepping stone towards understanding the importance of time spent in an early clinical practicum in the CTE Education and Training cluster courses. Also, the results of the study may increase the number of high school students who enter teacher preparation programs by providing them with an opportunity to begin to develop a teacher identity before they enter postsecondary education. Currently, there is limited research on the Education and Training cluster in CTE that determines the effectiveness of time spent in an early clinical practicum that would motivate students and develop a teacher identity (Advance CTE, 2019; DeFeo, 2015; Loera et al., 2013).

\section{Problem}

States need a pipeline through which quality educators are prepared and available for hard-to-fill teaching positions such as those in low-income communities. Currently, states are realizing the resource they have in creating an educational academy through high school, CTE, Early Childhood Education programs. These programs are associated and created with the criteria and standards of the National Child Development Associate (CDA) program and the Florida Department of Children and Families. Unfortunately, there is limited research specifically in the Education and Training cluster of CTE programs (Advance CTE, 2019; DeFeo, 2015; Loera et al., 2013). It is unknown if these programs are effective in creating and developing teachers who have a teacher identity 
and carry the self-efficacy needed to go into the field of education and overcome the factors that turn many people away from the field. By adopting and implementing an early clinical practicum that increases teacher identity and motivation, states may be able to address the thinning talent pool by beginning professional development at the high school level.

\section{Research Questions}

The purpose of the present study was to address students' motivation, teacher identity and overall achievement after participating in a CTE, Education and Training cluster to address the gap in research. The following were the research questions:

1. What is the impact of a Career and Technical Education program, including time spent in early clinical teaching practice, on student motivation as measured by the Motivated Strategies for Learning Questionnaire (MSLQ), in three programs and across four levels?

2. What is the effect of a Career and Technical Education program, including time spent in early clinical teaching practice, on teacher identity as measured by the Teacher Identity Survey (Thamotharan \& Hazari, 2018) in three programs and across four levels?

3. What is the effect of a Career and Technical Education program, including time spent in early clinical teaching practice, on program completers'year, twelfth-grade average GPA as compared to their mid-year ninthgrade average GPA? 
4. What is the impact of a Career and Technical Education program, including time spent in early clinical teaching practice, on program completers', mid-year, twelfth-grade average attendance record as compared to their mid-year ninth-grade average attendance record?

\section{Definition of Relevant Terms}

The following are terms used throughout the current study.

Academy: A plan of study which includes more than one course, providing students with a broader scope of knowledge. An academy also provides opportunities for dual enrollment, college credit through articulation agreements, and paid internships through NAF (National Academy Foundation). ECE 1 is an example of an academy in the current study.

Agency: Emirbayer and Mische (1998) define agency as an individual's "will to act, to experience, and to exist." In the present study, agency refers to the preservice teachers' intentional behavior or action because of a personal choice.

Career Pathway: A plan of study towards a specific predetermined career.

Community of Practice: "A group of individuals who, through pursuit of a joint enterprise, have developed shared practices, historical resources, and common perspectives" (Coburn and Stein, 2006, p. 28).

CTE Program: "A Career and Technical Education (CTE) program of study is defined as a multi-year sequence of courses that integrate core academic knowledge with technical and occupational knowledge leading to higher levels of skill attainment over time with a 
unifying career theme around which to organize the curriculum. A program of study by design provides students with a pathway to postsecondary education and career by detailing academic and occupational competencies needed for advancement and providing a series of related courses" (American Youth Policy Forum, 2003, p. 6).

Level: Refers to the level the student is in, depending on their plan of study. All three programs have four levels, which begins in the $9^{\text {th }}$ grade and ends in the $12^{\text {th }}$ grade.

Program: A plan of study which includes one course and no other opportunity beyond the scope of the curriculum of that course. ECE 2 is an example of a program.

\section{Summary}

This chapter provided an introduction to the problem of teacher shortage and retention and will be further discussed in Chapter 2. It outlined the purpose of the study to explore student motivations, dimensions of teacher identity and student achievement when participating in early clinical teaching practice. It explained the theoretical perspective, gave hypotheses and the delimitations. This chapter also exposed the need for more research in the CTE Education and Training cluster and the need for further exploration of early clinical practice. Lastly, it gave definitions for operational terms. 


\section{CHAPTER 2}

\section{REVIEW OF THE LITERATURE}

The present study explores the development of teacher identity, motivation, and student achievement in high school, teacher preparation CTE programs. The purpose of the literature review is to explore previous research on these subjects: teacher attrition, the causes, the costs and the efforts to keep teachers in the classroom; determine historical roots and relevant research on CTE; what teacher identity is, and its role in teacher education; motivation in CTE courses; and how the present study can add to the limited but developing research in early clinical teaching practice and teacher development through already existing CTE courses. The literature review uses a social learning lens to explore the conceptual frameworks that intersect in the study. The literature review has four sections. First, current issues in teacher attrition will be discussed. Then, CTE will be defined, and information about the history of CTE will be discussed to understand its fundamental structure, purpose, and goals. Next, student motivation and achievement in CTE programs will be explored. An inconsistency in the research will be identified, and an attitudinal study that includes high school students in vocational programs will be discussed. In the third section, the conceptual framework for the study will consist of the literature investigating motivation and learning, teacher preparation and practice, and teacher identity. The perception of teacher identity will be defined, and the literature will be reviewed. Four constructs for teacher identity will highlight the main concepts studied in this research, to include: (a) interest, (b) recognition, (c) competence, and (d) performance. Finally, the researcher will summarize the literature review and make appropriate connections to the current study. 


\section{Teacher Attrition}

According to DenBrok, Wubbels, and Tartwijk (2017), the definition of attrition can vary. Some definitions in the research include teacher turnover, where teachers leave one school but begin at another, yet others in research do not include teacher turnover as attrition because teachers have not left the classroom. Some research includes temporary personal leave as attrition, including maternity leave and illness or self-motivations, while other research does not (Carlsson, Lindqvist \& Nordanger, 2019). Surprisingly, some of the data reviewed also include promotions into administration as attrition because they are no longer teachers in the classroom. Carlsson et al. (2019) argue that the best way to determine attrition rates is to calculate the total time spent working in the field of education, not only the time spent in the classroom. The authors argue that calculating the total time in the field gives a clearer picture of the attrition problem. In their longitudinal study, the authors found that in 23 years, some teachers spent $76.3 \%$ teaching in the classroom, but if they included temporary leave and promotions to administrative jobs the number went up to $84 \%$, this might make a difference in the calculation of attrition rates (Carlsson et al., 2019). Because of the difference in views and definitions of attrition, the reader must pay special attention to the definition used in a review of the literature.

\section{Causes for Attrition}

A review of the literature concludes that there are several causes for teacher attrition. Some list the cause as political inconsistency; others list causes more specific to teachers' needs as well as policy demands. DenBrok et al. (2017) cite a theoretical model to explain what they believe to be the root cause for teacher attrition. The Job-Demand 
Resources theory (JDR) suggests that there must be a balance between job demand and teacher preparedness to meet those demands. The authors claim that a balance between demand and preparation will result in job satisfaction and less attrition. The authors identify dissatisfaction to be caused by factors such as negative experiences with mentors and administrators, a lack of teacher identity and feeling a lack of overall support (DenBrok et al., 2017). The JDR theory is relevant and should be noted across attrition research and in pre-service teacher education.

According to Guha, Hylerleve and Darling-Hammond (2017), one of the smaller factors contributing to teacher attrition rates is the retirement of veteran teachers. The data support that a significant reason for attrition is not the retirement of teachers, as previously believed, but more often the short supply of new teachers entering the field (Ingersoll \& Smith, 2003; Glazer, 2018). Guha, et al. cite that about 30\% of new teachers leave the classroom in the first five years of teaching. Their research shows that attrition rates are even higher in urban and high-poverty schools, where attrition rates soar above $50 \%$. The authors claim a major cause of new teacher attrition in urban schools is the lack of support given by districts and schools and a lack of quality teacher preparation, ultimately leading to job dissatisfaction (Guha et al., 2017; Ingersoll \& Smith, 2003; Lee, 2018). In a survey given by Ingersoll and Smith (2003) to $29 \%$ of new teachers who listed dissatisfaction as the primary reason they left the classroom, factors such as low salaries, poor working conditions, lack of support, low student motivation and lack of autonomy led to their decision to leave. The lack of teacher autonomy is a reoccurring theme throughout attrition research, especially in urban schools. Sutcher et al. (2019) reported less than $60 \%$ of teachers in Florida felt they had "decision-making autonomy" 
in their classrooms (p. 23). Some teachers in urban schools are forced to teach a set curriculum, inhibiting their decision-making and professional judgment (Berry $\&$ Shields, 2017). Glazer (2018) adds that a lack of administrative support and opportunity for teacher autonomy increases teacher attrition and turnover.

As mentioned previously, some of the research includes teacher turnover in attrition data. Teacher turnover can be as troublesome as attrition, both causing staffing issues as well as impairment of the school environment and result in a decline of student achievement (Ingersoll \& Smith, 2003). According to Redding and Henry (2018), there is a significant occurrence of teacher turnover in urban schools during the school year, leading to a decline in student achievement, staffing issues, and other school-wide problems. Lastly, Carlsson et al. (2019) introduce a different viewpoint. The authors suggest that attrition is not always a depraved occurrence. They recognize that teachers also leave the classroom for other professional reasons such as a promotion to administrative jobs, higher education, or other opportunities in the education field. The authors argue that teacher who leave the classroom because of job promotion should not be counted into the attrition data because they are still working in the field, just on different paths (Carlsson et al., 2019).

\section{The Cost of Attrition}

Teacher attrition is an issue in schools around the world. According to Berry and Shields (2017), the United States loses $8 \%$ of teachers each year, which is double the number of losses in Singapore or Finland. The enrollment rates of college students entering teacher preparation programs have dropped 35\% from 2009 to 2014 . In the next decade, student enrollment is expected to increase by three million (Berry \& Shields, 
2017). According to Vagi, Pivoyarova, and Barnard (2019), nonminority, female teachers, teachers in the STEM (Science, Technology, Engineering, Math) fields, beginning teachers and teachers working in urban schools are more likely to add to the attrition rates. The peak attrition rates come from teachers teaching less than two years (Glazer, 2018). Attrition affects the country, states, districts, and schools, but worst of all, attrition harms student achievement levels. Guha et al. (2017) mention that states are struggling to recruit qualified teachers into their schools, especially in urban and highpoverty communities. These vacancies are often filled with uncertified teachers or substitutes that are often temporary. According to Sutcher et al. (2019), in the 2016-2017 school year, thirty-six states reported over 87,000 teaching positions left unfilled by certified teachers. The authors mention that Florida does not disclose data on uncertified teachers in teaching positions but did report 6,628 teacher vacancies in the 2017-2018 school year (Sutcher et al., 2019). Vagi et al. (2019) mention that recruiting and retaining qualified teachers is essential for student learning and maintaining a stable learning environment. The authors also add that replacing a teacher is costly because of the training requirements and time spent in preparation. According to Vagi et al. (2019), the total cost of attrition can range from $\$ 4,000$ per teacher in small rural areas to $\$ 18,000$ in sizable urban communities. The authors also argue that it is becoming more and more challenging to find qualified teachers to replace teachers who have left, especially in high poverty districts.

\section{Efforts to Reduce Attrition}

Among others, two major themes have been noted in the review of the literature as it relates to efforts to reduce attrition: strengthening teacher preparation and changing 
the focus from recruitment to the retainment of teachers. Lee (2018) cites The National Council for the Accreditation of Teacher Education's Blue Ribbon Report (2010) which called for a complete restructuring of teacher education to include more clinical experiences and efforts towards the creation of a pipeline that encourages students to remain in their communities through their education and into their teaching careers, especially if they are from urban, high-poverty districts. The pipeline would include schools, teachers, and local universities. The restructuring or teacher preparation has led to alternate teacher preparation programs that are significantly different from the university-based programs. The Summer Teacher Education Partnership for Urban Preparation (STEP-UP) seeks to prepare students to work in urban communities by immersing them into the culture during a four-week internship. According to Lee, students who complete this fellowship have shown a secure connection to the community and an increased desire to work there after they graduate. Teachers without adequate preparation to work in an urban community have a three times higher attrition rate than teachers who are prepared and understand the culture (Guha et al., 2017). Other teacher preparation programs are known as teacher residencies. Modeled by the medical residency program, preservice teachers receive clinical training under the supervision of a teacher mentor. The cohort apprenticeship is over a yearlong and is usually in a highpoverty school. Students use the content learned in their university courses in their clinical teaching practices as they work towards a master's degree. The norm of most teacher preparation programs mandates about 400 to 600 hours of clinical teaching practice; the teacher residency programs require at least 900 hours (Guha et al., 2017). Lastly, to remedy the teacher shortage through teacher preparation, some states created a 
Teacher Cadet Program, which allowed high school students to learn about the teaching profession and earn college credit (Berry \& Shields, 2017). Lee (2018) argues that these programs bridge the gap between content and practice and raises self-efficacy and agency, creating more resilient teachers for schools in high-need urban communities. The author adds that resilient teachers have high rates of retention and job satisfaction (Lee, 2018). Teacher retention is especially problematic in hard-to-staff schools. According to Holmes, Parker, and Gibson's study (2019), many teachers that leave urban schools do so as a result of weak administrations and mandated district policies. In comparison, schools which have strong administrative support, have less attrition and teacher turnover. In addition, these schools also have fewer disciplinary problems, better class sizes, higher self-efficacy among teachers, and a better overall work environment than the schools with weak administrative support (Holmes, Parker \& Gibson, 2019). The study also revealed that primary intrinsic motivation was a key factor as to why teachers remain in the profession, but the other negative factors discussed here can be of more significant influence when deciding to leave. Intrinsic motivation may be increased if principals and administrators are focused on student success, teacher growth, and promoting a positive work environment, teachers are more likely to remain at the school (Holmes et al., 2019).

To build a more diverse and resilient population of future teachers, Washington began a high school teacher academy program called Recruiting Washington Teachers (RWT), which includes opportunities for clinical teaching practice and college preparation (Rosenberg \& Sowders, 2019). The state legislature created the academy to encourage underserved high school students to enter the field of education and to build a diverse workforce. Using the "grow your own" framework, Washington seeks to support 
and prepare future teachers in a holistic program that includes identity, professional, academic and social development through clinical teaching practice and over 80 hours per year of field experience (Rosenberg \& Sowders, 2019). The goals of the RWT program includes diversifying the teaching profession, provide more opportunity for underserved students, and eliminate the teacher shortage in their state. During the 20182019 school year, the annual status report states that 96 students were attending four "learning laboratories" in the program (Rosenberg \& Sowders, 2019, p. 3). According to Rosenberg and Sowders (2019), 87\% of the students identified as a person of color, and $73 \%$ said English was their second language; $70 \%$ of students would be the first in their family to attend college.

Regarding support offered to the students during the teacher preparation program, 93\% of the students reported that the "classroom field experience/practicum" was the component that helped them in achieving their goals (Rosenberg \& Sowders, 2019, p. 9). Rosenberg and Sowders (2019) also reported that $88 \%$ of students said the course content helped them to achieve their goals. Ninety-five percent of RWT students reported that their academy teacher was the most influential support person; this result exceeded classmates as most influential by only a small margin. The report showed that $93 \%$ of students felt the academy had helped them learn how to teach children, and 95\% said they felt they could be a role model for children (Rosenberg \& Sowders, 2019). Also, 92\% stated that they learned about the teaching profession, and 95\% felt they had acquired leadership skills. To measure college readiness, their report showed that $98 \%$ of students in the RWT were accepted into a college program. The survey data also showed that 
although $70 \%$ of the students felt more interested in the teaching career, the survey saw a $20 \%$ drop in teaching as a career choice (Rosenberg and Sowders, 2019).

\section{Historical Foundation of Career and Technical Education (CTE)}

The use of CTE courses lead students into different vocations through workrelated experiences and opportunities. The Smith-Hughes Act of 1917 was the first federally funded legislation that supported vocational education after a diverse collection of interest groups came together to educate the working class of America. The authors of the act advocated for a separation of educational settings, separating vocational education from regular schooling. Wirth (1980) noted that "vocational education was designed to make an efficient producer and liberal education was intended to train the efficient consumer" (p. 158). The National Research Center for Career and Technical Education, also known as NRCCTE (2010), noted that John Dewey believed students "could be educated through the occupations rather than for the occupations" (p. 2). Dewey suggested that these vocational classes could act as a vehicle to connect occupational skills with critical fundamental concepts, and he argued that vocational education should integrate into the existing curriculum. According to Stipanovic, Lewis, and Stringfield (2012), several reports over the years have advocated for a balance between both sides of the debate over the unity of vocational and academic education (p. 81). In 1988, The Forgotten Half, published by the W.T. Grant Foundation, reminded Americans that less than half of students go to college; less than two-thirds complete college degrees. The report supported the idea that without degrees and technical skills, Americans could not have a "healthy society" (Stipanovic et al., 2012, p. 81). As a result, in 1988, the American Youth Policy Forum released a publication explaining the extent of the 
continuing problem and called for action. The final report called for a pathway that included a high school career training focus. It also called for a connection between high school and college-level training. They concluded that this would successfully increase the number of students who complete a career track (Stipanovic et al., 2012, p. 81, pp. $81-82)$.

According to the American Youth Policy Forum (2003), "A Career and Technical Education (CTE) program of study is defined as a multi-year sequence of courses that integrate core academic knowledge with technical and occupational knowledge leading to higher levels of skill attainment over time with a unifying career theme around which to organize the curriculum. A program of study by design provides students with a pathway to postsecondary education and career by detailing academic and occupational competencies needed for advancement and providing a series of related courses" (p. 6). Schools arrange CTE programs depending on their demographics, school design, and needs. These arrangements include career clusters, career academies, technical preparation programs, small learning communities, and small schools within a school.

\section{CTE Vocational Programs: Student Motivation and Achievement}

Herein, vocational education in high schools will be discussed, specifically in CTE programs that follow a plan of study framework. The courses in the current study are CTE vocational programs. The literature regarding the achievement of students as well as their motivations in these programs is significant. The current dissertation seeks to provide preliminary data for CTE programs, specifically in the Education and Training cluster in a large community that serves underrepresented students. The literature review will show the disparity in the research data within vocational education research and the 
importance of the attention given to the population of students, the structure of programs, as well as what CTE provides and what it does not.

According to DeFeo (2015), there has not been a significant amount of research in CTE since the initiation of these high school programs. Five areas of research have been found lacking and with conflicting data: foundation for teaching and learning content, curriculum and program structure, teaching pedagogy, assessment, and overall program evaluation (Defeo, 2015). Although the author mentions that student achievement is not part of the list, they contend that these are all factors that contribute to the success of the students in vocational programs. Loera, Nakamoto, Oh, and Rueda (2013) add that there is also limited research connected to student goals within the context of the vocational course and "little attention" is given to student achievement in connection to the operation of the CTE program within a large school (Loera et al., 2013, pg. 174). Defeo argues that although there has been development in structure and curriculum in the last two decades, there "are few empirical or longitudinal studies to document the effectiveness of CTE initiatives" (Defeo, 2015, pg. 83). Defeo mentions that the expected results for CTE vocational high school courses include improved high school performance, college readiness, graduation rates, and overall economic advances. The goal is to connect academic content with vocational content in order to intrinsically motivate students, make education more meaningful, and help them transition into the workforce (DeFeo, 2015; Loera et al., 2013). Loera et al. add that providing students with experiences that are both in and out of school, through a vocational program of study, will motivate career and college interests and goals. Lastly, the authors mention that adult mentors are an essential motivating factor in vocational CTE programs. Loera et al. cite 
research that shows that students who have a secure connection with a vocational teacher are more motivated and engaged.

DeFeo (2015) cites multiple studies to show that little to no gains in student performance has been achieved for students in CTE programs; although, the author notes, that CTE courses do not hinder performance either. DeFeo's research does show an effect on student enrollment, showing that students in CTE programs take less math and science courses than students in general academic programs. Research on student graduation rates is conflicting. DeFeo notes that some studies have found that enrollment in a CTE program can help students follow that path to graduation, with these students having a higher graduation rate than general education students; other studies have found that CTE program participation has no direct impact on graduation rates (DeFeo, 2015). Also, DeFeo noted that studies show only "modest improvements in college readiness" and found no direct link between CTE program participation and increased college readiness (p. 84). Subsequently, DeFeo mentions that only 30\% of students in CTE programs complete the plan of study, but also notes that these students are more likely to enroll in college as full-time students. When compared to students in general education courses, students who complete CTE programs are more likely to attend two-year college programs and are less likely to attend four-year programs. Overall, DeFeo notes studies that show that CTE participation does not show an advantage for students when transitioning from high school to college. The author argues that the literature has not changed since the 1980s, showing marginal alignments between high school CTE curriculum and career choice. DeFeo summarized studies and notes that students who do not complete CTE programs of studies have a change of interest, are provided limited 
guidance in the career field, or the program focused on developing skills and did not develop knowledge about the career overall. The outcomes discussed above are especially true of students in underrepresented populations. DeFeo notes that these students are already at a disadvantage, and increasing graduation rates and college readiness is steep, even for CTE programs.

The literature shares a consensus that career exploration should begin in the early grades, beginning in middle school and even in elementary school (DeFeo, 2015). As students enter high school, they should "narrow their focus, identify clusters of interest, and ultimately select a high school [plan of study] that will position then to begin a postsecondary program aligned with their career goals" (DeFeo, 2015, pg. 86). The author cites studies that show an early intervention in career development can lead to better transitions into college and the workforce (e.g., Arrington, 2000; Hughes \& Karp, 2004; Super, 1980; Ting, Leung, Stewart, Smith, Roberts, \& Dees, 2012). Defeo agrees that with these researchers that with proper guidance, students will choose appropriate courses and stay on track to complete their vocational program of study. According to Loera et al. (2013), research shows that students who accomplish the necessary skills from their enrollment in CTE courses are more successful in their transition into the workforce and make better choices than students who do not acquire necessary skills. The authors use the term career academies to describe a CTE program with a sequence of courses under a determined vocation. Studies show that students who participate in these career academies are exposed to an academic curriculum that is integrated into vocational education. These students ultimately are more connected to their peers and teachers, find 
more meaning and value in their education, receive a college degree, and earn more money than students who do not complete a career academy program (Loera et al., 2013).

In a study by DeFeo (2015), including eight general education high schools and one technical high school, students from a large school district with several CTE vocation program offerings answered several questions about their career explorations. The findings showed that there was a marginal increase in the number of students from the CTE programs that named their career choice. When asked why they chose to take the CTE vocational courses, students from the technical high school showed a higher level of interest in their respected fields than the students in the general education high school. A large number of technical students also responded with a profound connection of meaning and value concerning what they were learning in their technical course programs (DeFeo, 2015). These students were more likely to respond with a vocational or academic response to why they were in the program than students from the general education high school. The data from DeFeo's study support that students in vocational programs have an interest in the subject area and that because they choose to be in these programs, they may see the value and meaning of the education they are receiving through their participation in these programs. DeFeo's study also brought to light the need for better guidance during the career exploration phase in adolescents. DeFeo discusses a lack of career knowledge even in the technical high school; the author argues that there should be a significant disparity between the student responses in the study.

\section{Conceptual Framework}

States need to create and foster a career pipeline between high schools, universities, and the teaching workforce using an instructional framework that 
emphasizes high motivation and teacher identity through the CTE framework. The present study sought to find an interaction between teacher identity, motivation, and overall student achievement using a quasi-experimental design. The Motivated Strategies for Learning Questionnaire (MSLQ) provided valuable information regarding student motivation, task value, self-efficacy, as well as intrinsic and extrinsic motivators in the program (Pintrich et al., 1991). The data collected from the teacher identity survey provided information that identifies students as having a teacher identity as well as the dimensions of teacher identity that are most prominent. The collection of student achievement data evaluated student progress and found relationships with student motivation, agentic profiles, and teacher identity. Overall, the current study evaluated the effects of the current instructional frameworks used in the high schools' CTE teacher preparation programs in producing teacher identity and motivation. The information presented in the current study can lead to modifications to existing frameworks, evaluations, and assessments used in high school CTE teacher preparation programs.

After discovering the political tug that affects teacher attrition and teacher retention, future educators must be prepared to advocate for themselves and their students, through agency and self-efficacy, to reduce teacher attrition and retain teachers in the profession. Future teachers should be prepared to: accept and understand students of different cultures and learning abilities; know how to access resources that will help them succeed when they begin teaching, such as resources for pedagogical and content assistance as well as resources for classroom management. It is also vital for future teachers to consider other jobs in the profession, besides teaching and advocate for their students, in the community by understanding their culture, in school by providing all 
opportunities for advancement and knowledge, and at home by involving parents in their child's education. By adequately equipping and preparing future teachers for work in urban communities, attrition rates will decrease, and teachers will remain in the profession.

In the present study, the target program's vision, goals, and framework mimic those of teacher residencies and fellowships across the country. These programs are currently offered to college students, leaving most high school students out. Although the CTE cluster in the state does host Early Childhood Education programs, there is little to no research on the ability of this cluster to promote the teaching profession to high school students. Although the state provides a rigorous set of standards for this program, including 480 required contact hours with children three to five years old, it is contentbased and does not reach past that. Teachers and program organizers must create their instructional framework and hope to meet set goals. Future research on these programs may include the current professional status of the students who have graduated from a high school teacher preparation program and their effect on the teacher shortage and attrition rate. The present study will add to the limited research on high school teacher preparation programs in the country. The results of the present study can begin to build a model instructional framework from the foundation of this program and can be replicated if successful for other CTE teacher preparation programs.

\section{Motivation and Learning}

In this section, motivation will be defined; the social cognitive view and the sociocultural approach to motivation will also be compared. Similarities and differences 
will be identified, and an interrelationship between the two approaches will be discussed. Next, motivation will be examined in connection to identity and student achievement. Lastly, student motivation research will be discussed concerning vocational education and teacher education.

Much of the literature on student motivation maintains a social cognitive view (Dweck \& Leggett, 1988; Miltiadou \& Savenye, 2003; Schunk, 1989; Zimmerman, 1989) but more recent literature calls for a sociocultural approach (Hickey \& Zulker, 2005; Jarvela \& Salovaara, 2004; Nolen, 2007;). Some researchers see the similarities under the social learning theory and recognize a thin line between the two (Jarvala, 2001; Linnenbrink \& Pintrich, 2001; Volet, 2001). To begin, the current literature review on motivation will attempt to find the similarities and differences between the two viewpoints and use both to analyze the results of the current study.

Schunk, Pintrich, and Meece (2012) define motivation as the desire to take part and continue in a task and are activated to participate in learning. Schunk and Meece (2012) discuss the early theories of motivation beginning in the 1930s when stimuli explained motivation in classical and operant conditioning. Motivators resulted from and by environmental reinforcements and cues. The authors cite Hull (1943) when discussing that motivation is "the initiation of learned, or habitual, patterns of movement or behavior" (Schunk \& Meece, 2012, pg. 8). Schunk and Meece mention Bandura’s (1986) work and discuss that, more than just a history of reinforcement, the beliefs behind the reinforcers had a greater influence on learning. To follow, the authors mention the inclusion of several theories that developed an early cognitive view of motivation, such as the expectancy-value theory which explained concepts such as "fear of failure" and 
"hope for success," and models of control which explained internal and external control factors of learning, learned helplessness and perceived control beliefs (Schnuck \& Meece, 2012, pg. 9). As theories developed, motivation was described as a behavior that was centered around goals, expectations, outcomes, and actions. Bandura's (1991) social cognitive theory explained motivation as a result of progress monitoring towards a learning goal. Success in achieving these goals leads to self-efficacy and encourages the setting of more challenging goals (Schnuck \& Meece, 2012).

Motivation has been studied using many different theories and viewpoints. Many theories on motivation have been analyzed using a social cognitive lens. The social cognitive theory has been seen as the dominant approach for motivational studies (Turner, 2001). The social-cognitive approach concentrates on the student's own beliefs and the environmental factors that influence motivational constructs. More recent decades have seen a call for a more sociocultural view when studying motivation, calling for a more substantial focus on the context of learning as a primary focus in the research of motivational studies (Jarvela, 2001; Walker, Pressick-Kilborn, Arnold, \& Sainsbury, 2004). According to Rueda and Dembo (1995), research in sociocultural motivation studies has worked to explain beyond traditional cognitive views to include cultural, historical, and contextual impacts on learning. The authors emphasize that, although these two views have conflicting differences, they have important similarities as well.

\section{Social Cognitive Approach}

Social cognitive views on motivation take into account how students think about their goals, value tasks, and achievement. Rueda and Dembo (1995) suggest that a social cognitive perspective investigates why students are motivated and not what they are 
doing to be motivated. A social cognitive point of view also proposes that students must change the way they think about themselves to experience motivation (Rueda \& Dembo, 1995). According to Turner (2001), in the social cognitive viewpoint, cognition is the basic unit of learning. Many theories used to explain social cognition focus on the self and the interactions in different contexts. For example, Turner mentions selfdetermination theory as a theory used to explain how individual interests are precise determinants of internal motivators. The social cognitive theory highlights constructs, such as control and competence (Turner, 2001).

Pintrich and Schrauben (1992) identified three motivational components of motivation: a value component (including the students' goals and interest in the task); an expectancy component (including a student's belief in their performance); and an affective component (including a student's emotional reaction). Rueda and Dembo (1995) explain that the value component is approached using the goal theory. By setting goals, students are motivated by their success or failure in the attainment of these goals. When studying goal theory and motivation, the authors mention that three concepts are essential in the effects of goals on learning: difficulty, specificity, and proximity. They argue that if a task is too difficult, students may not put in the required effort to accomplish the task. Students will try if the goal seems attainable. Also, Rueda and Dembo recommend using specific goals for performance standards. The authors contend that if the learner understands precisely what they are supposed to do to realize their goal, they will be more motivated. Lastly, the authors suggest setting proximal goals that can be attained in a set amount of time. It is difficult to maintain motivation if the goal seems distant (Rueda \& Dembo, 1995). Pintrich and Schrauben believe that task value differs from goal 
orientation. They mention that goals will motivate a student's behavior throughout the learning process, but the value a student places on a given task will determine the amount of effort given in the task. Wigfield and Eccles (1992) believe that students will be more involved in a task if they value the work positively. Although, these authors add that task value falls as students become older and note that achievement was correlated to expectancy for achievement. Rueda and Dembo believe this may be caused by a change in view between effort and ability, adding that older students tend to see ability as a more significant influence on achievement than effort.

Under the expectancy component, Pintrich and Schrauben (1992) include selfefficacy beliefs. The social cognitive theory explains a reciprocal interaction between personal, behavioral, and environmental influences (Schunk, 2012). Schunk also mentions that self-efficacy is a critical part of this reciprocal process. He explains that self-efficacy is the belief that one can carry out behavior and it can influence actions such as choosing appropriate tasks and encouraging effort. The reciprocal process between the variables may be affected if the student does not have self-efficacy for learning in that content area. Bandura (1991) also believes that these transactions in everyday life echo the transactions seen in experimentations regarding self-efficacy. He discusses the correlation between self-efficacy and the ability of the learner to control their environment. In his writing, Bandura (1991) stresses the importance of providing students with a setting where they can control at least some of their environment. $\mathrm{He}$ mentions that this level of control allows learners to make changes leading to higher effort, self-efficacy, and motivation. Bandura (1991) explains that students become persistent learners after repeated validation of self-efficacy under harsh conditions. If the 
environment always seems uncontrollable, students will approach the setting with low self-efficacy for learning, unmotivated, and have a high chance for failure and a lower chance for developing self-regulatory behaviors (Bandura, 1991; Wilson \& Narayan, 2016; Zimmerman, 2002). Bandura (2000) contends that self-efficacy is the foundation of human agency because unless people have self-efficacy for their actions, they may not get the desired effects, leaving them with little desire to act again. A focus on selfefficacy, in turn, affects their motivation and how people self-regulate their behavior (Bandura, 2000).

As cited in Emirbayer and Mische (1998), Vygotsky (1978) argues that agency is the central concept in the sociocultural learning theory. Emirbayer and Mische define agency as an individual's "will to act, to experience, and to exist." It also refers to a group's feeling of making a difference that will affect their world. It is essential to evaluate the concept of agency in motivation research, not only as individuals but in a social learning environment (Rainio, 2010). Bandura (2001) referred to agentic behavior as an intentional, proactive result of actions. According to Reeve (2013), agentic students who understand their role in the class are agentically engaged and motivated by the teacher and the learning process. Students and teachers share the role of facilitators of learning. Agency builds a sense of choice and control, giving students autonomy in the development of their knowledge (Reeve, 2013).

A study from the Spanish National University of Distance learning investigated academic motivation and motivational self-regulatory strategies. Fernandez, Anaya, and Suarez (2012) share the social cognitive belief that motivation is the process that drives students towards a goal and that these motivational variables will lead to learning. The 
authors mentioned that performance-oriented students sought more approval and feedback versus more goal-driven students. Goal-oriented students showed more motivation in learning. These students are reinforced by gained knowledge and not an external motivator. They theorized that self-regulating students use motivational strategies in their learning reward (Fernandez et al., 2012).

The results of the Fernandez et al. study (2012) showed that students' use of motivational, self-regulatory strategies depended on who they were in their peer group and how they perceived others in the group viewed them. They found that, in a social setting, the students' motivation, self-efficacy, and choices of self-regulatory strategy use was influenced by their peers (Fernandez et al., 2012). According to Bandura (1991), learners compare themselves to their peers, resulting in a positive or negative effect on their learning. He believes that the consequences are difficult to avoid in a socially competitive situation. A strong self-efficacy and the amount of environmental control has a considerable influence on the ability to overcome adverse effects from social competitiveness. Interestingly, Bandura (1991) argues that high achieving students put forth less effort and use less self-regulation in a group where they feel they dominate or have more knowledge.

Pintrich and Schrauben (1992) also include control beliefs in their expectancy component in the development of motivation. Rueda and Dembo (1995) discuss the student's perception of control in outcome expectations. The authors emphasize that students who believe they have no control over their achievement fail to see that their actions have consequences; these students often blame other people for their failures and shortcomings. Refusing to take responsibility for their behavior may lead to learned 
helplessness, where students see no connection between their motivation and their achievement (Rueda \& Dembo, 1992).

The last motivational component of Pintrich and Schrauben's (1992) model is the affective component. The affective component involves how students feel about a task. Rueda and Dembo (1995) mention that young children believe that effort is the most critical attribute of learning. As students begin to compare themselves to others, they begin to believe that ability is more important than effort. Rueda and Dembo believe this is the result of the self-worth theory of achievement and motivation. The self-worth theory by Covington (1992) combines ideas of motivation with ideas of failure and success determined by social interaction. Convinton (1992) argues that a student's selfworth is more important than grades and other external motivators.

\section{Sociocultural Approach}

Throughout the literature, a sociocultural approach to understanding student motivation is an unconventional perspective (Jarvela, 2001; Rueda \& Dembo, 1995; Volet, 2001). According to Rueda and Dembo, the sociocultural theory emphasizes the work of Vygotsky (1978) and brings to light ideas such as thinking and learning in a social context, social negotiation, and collaborative work. The sociocultural theory argues for the rethinking of cognitive concepts regarding motivation and the recognition of the connection and interrelationship between cognition and sociocultural influences. Rueda and Dembo contend that this view describes motivation as occurring in a social and cultural context where individual behaviors occur. In this aspect, the authors emphasize, sociocultural views are similar to cognitive views; both believe that the context where learning occurs is essential, they argue that sociocultural theory measures beyond the 
context and includes the idea that culture is formulated from the context. Collins and Green (1992) discuss that a classroom can be seen as having its own culture, following a determined set of norms. The authors provide a framework that includes three overlapping dimensions that help to conceptualize a classroom learning environment into a culture: dimension 1: classroom as a social group; dimension 2: holistic classroom life; dimension 3: continuous experience (Collins \& Green, 1992). Rueda and Dembo argue that motivation does not belong to the individual but the individual within the culture. The authors claim that motivation cannot exist if it is not exhibited in a social context. When comparing the two frameworks, Rueda and Dembo (1995) believe there is a clear interrelationship between motivational and cognitive activity when learning; if students are cognitively involved, they are motivated. If the context provides for positive learning, promotes intrinsic motives, and engage critical thinking using self-regulatory behaviors, students will be more motivated to learn. The authors argue that the two viewpoints are similar in constructs, such as reward systems, student grouping methods, and performance goals. They add that both approaches emphasize a focus on rigorous cognition, self-regulation, the impact of the environment on learning, and a constructivist view on learning (Rueda \& Dembo, 1995). The authors argue that the sociocultural view seeks a broader view of learning within the context and not the individual. They suggest that by broadening the scope, researchers can build a better understanding of motivation. Context is referred to as an independent variable in cognitive research. In sociocultural research, context is studied as the critical focus of the study. The sociocultural theory does not separate behavior from the context, and the culture of the context is said to be socially structured (Jarvela, 2001; Rueda \& Dembo, 1995). Also, the cognitive 
framework sees social interaction as part of the learning process but studies the effect on the individual student, whereas the sociocultural framework sees social interaction as the foundation where learning takes place. Jarvala argues that traditional ways of studying motivation may not be appropriate for current, more socially based constructivist instructional practices.

According to Rueda and Dembo (1995), both frameworks share a constructivist viewpoint, agreeing that the learner plays an active role in their learning. The authors argue that although these ideas link the frameworks, cognitivists ideas on metacognition and self-regulatory behavior do not allow room for culture and social differences in the context where students are learning. Ultimately, the authors recommend analyzing the learning processes through a cognitive framework but, also, using the sociocultural perspective when analyzing social and cultural foundations in dimensions such as motivation. They believe that combining the two frameworks will give a deeper understanding of student learning and motivation in a situated context (Rueda \& Dembo, 1995).

In the present dissertation, the Motivated Strategies for Learning Questionnaire (MSLQ) was used to determine the motivational constructs found in three individual groups of high school students in vocational contexts, to compare the type of motivation dimensions exhibited in the students and how they correlate with teacher identity and student achievement. The MSLQ was created using the social cognitive lens, looking for factors of the individual student's interests and values. For the dissertation, a social learning lens was used in the analysis of the results to determine the effects of a community of practice on these motivational constructs. 


\section{Teacher Preparation and Practice}

Researchers agree that a redefining and restructuring of teacher education needs to take place in order to alleviate the teacher shortage and reduce teacher attrition rates (Darling-Hammond, 2006; NCATE, 2010). Although there is extensive research on the many factors affecting teacher education, for the present dissertation, a focus on teaching clinical teaching practice will be reviewed, including clinical teaching practice in nontraditional university models. It is important to note that the review of the literature will not include information on practicums for alternative certification methods for becoming a teacher. These methods may not require a formal practicum or teaching experience with students to achieve a teaching certificate. The term alternative will be used to point out a different clinical teaching practice model than the traditional university-based model.

For the past two decades, researchers have identified a need for preservice teacher practicum research to reach the forefront (Cochran-Smith et al., 2016). Although a report by the National Council for Accreditation of Teacher Education called for additional research in 2010, Cochran-Smith et al. found very little research beyond the traditional university field experience model in their review of the literature. The authors found that, although preservice teachers reported that their field experience was an essential learning experience during their teacher preparation, they did not feel adequately prepared for the challenges that they realized after beginning to teach. Levin (2006) argues that a discrepancy is caused by the university programs' focus on the preservice teacher's learning the skills to teach rather than focusing on whether their students are learning. He discusses a mislead priority on teaching content rather than clinical teaching practice; he adds that clinical teaching practice in the university teacher preparation model "is too 
short and involvement of university professors in the schools is insufficient" (Levine, 2006, p. 28). Cochran-Smith et al. discuss "building bridges" between schools and universities, where preservice teachers learn how to teach (p. 481). The authors explain that other countries are creating policies to increase the amount of clinical teaching practice required by preservice teachers, citing Rajuan, Beijaard, and Verloop (2008) suggestions of "beginning those school-based experiences early in the preparation program" (p. 481). Much of the research cited by Cochran-Smith et al. was critical of the traditional university model of student teaching, calling for a more social learning approach to clinical teaching practice. The social learning perspective would allow preservice teachers to work with, talk to, and interact with more knowledgeable colleagues. The research cited called for a learning environment where preservice teachers saw teaching as a community that "involves learning with and from others" (p. 481). To socialize the experience and attempt an alternative model for clinical teaching practice, Baker and Milner (2006) used the work of Vygotsky to create a model where two preservice teachers worked together with the same cooperating teacher to access their zones of development. They compared the development of two paired preservice teachers with four single preservice teacher placements throughout a fifteen-week practicum. They found that the paired preservice teachers had a more developed pedagogical dialogue with their mentors and had created stronger relationships. Their research found that paired placements were more effective in preparing teachers for teaching (Bajer \& Milner, 2006). Bullough et al. (2002) also studied paired student teaching and reported that preservice teachers had a different experience than those who were not paired. Paired preservice teachers, although they taught for less time, received a fuller experience. In the 
Bullough et al. study, participants felt they could take risks, allotted more time to lesson plan, had better classroom management, and developed a greater sense of self-efficacy. The authors argue that the results come from a social and collaborative relationship built in the classroom. They report that the preservice teachers felt a sense of responsibility not only to the students but to each other. Also, the study found that the children in the class benefitted from the experience (Bullough et al., 2002).

Clinical teaching practice has not been disputed among educators (Retallick \& Miller, 2010). The questions lie in the differences in the degree of field experience and the impact these differences have on the effectiveness of clinical practicum. Zeichner (2010) found that clinical practicums with a narrow focus and an inattention to school and community contexts, fail to prepare students for the reality of teaching. The author calls for broadening of the expertise that is brought into clinical teaching practice and an epistemological shift from a knowledge-based focus to an educational culture where the school and community are involved in the academic knowledge. The author also mentions that exceptional teacher preparation programs, with clinical teaching practice experiences that are directly connected with coursework and have strong mentorship opportunities, prepare teachers for the reality of the classroom (Zeichner, 2010).

Retallick and Miller (2010) heard the call for a CTE framework for executing early field experiences. Their study resulted in a framework for early field experience through CTE with four primary components: "foundation, organization, implementation and evaluation" (Retallick \& Miller, 2010, p. 62). Their framework is derived from the theory of experiential learning, which they mention is a significant basis for learning in CTE programs. Career and Technical Education educators create authentic settings that 
allow students to integrate content knowledge with practice. Experiential learning is exemplified in CTE teacher education programs and creates students who are actively involved in their learning, turning academic knowledge into the experience (Retallick \& Miller, 2010). According to the authors, early field experience has been recognized as an essential opportunity in teacher preparation and has been noted in accreditation standards and curriculum. Retallick and Miller acknowledge that the National Council for Accreditation of Teacher Education and the Teacher Education Accreditation Council have included early field experience in their evaluation and standards of teacher education. States have included early field experience as a requirement within their curricular frameworks for vocational courses within the CTE Education and Training cluster. Retallick and Miller believe that these standards serve as a basis for the foundation of their framework.

The second component of Retallick and Miller's (2010) CTE framework is organization. Organization includes the placement and experiences available to preservice teachers for early field experiences. The placement of students-teachers when completing their early field experience is critical to successful teacher preparation. Retallick and Miller cite research that supports the importance of an experienced cooperating teacher at a site that will foster effective pedagogy, use content knowledge and expose the preservice teacher to a diverse population, demonstrating several teaching models and experiences. The authors mention that placement is essential because preservice teachers will model the teaching pedagogy of their cooperating teacher, even if it contradicts what they learned in school (Retallick \& Miller, 2010). 
Retallick and Miller's (2010) third component includes the implementation of opportunities for interaction and positive outcomes using a variety of learning strategies. The authors claim the third component is the essential stage of the framework because its student goals and learning strategies are developed, and defining roles are determined in the field experience classroom. The third stage of the framework requires the interaction between theory, practice, and reflection through a "dialogic process" between the university and the school and everyone involved. The authors divide this stage into two orientations, exploratory and teacher development (Retallick and Miller, 2010). They believe that the initial goal of early field experience is to explore the teaching career: research-based activities and learning strategies such as guided observations, journaling, and identifying characteristics of a good teacher. The early field experience can then continue with skill development and the application of content knowledge. At an early level, they can take attendance, distribute papers, teach mini-lessons, analyze case studies, and begin to grade student work (Retallick and Miller, 2010). Next, the preservice teacher can begin to teach lessons and participate in professional development with their cooperating teacher in theory into the practice stage of the framework. Then, the last stage of the framework includes transitioning from student to teacher. One of the goals for the final stage is that the preservice teacher can communicate an understanding of teaching philosophy (Retallick and Miller, 2010). The last stage of Retallick and Miller's framework includes the assessment of the preservice teacher and the program itself. On the basis of their research, they recommend a portfolio assessment that includes self-evaluation and reflective practices. The authors do not give a detailed recommendation for the program assessment but do suggest ongoing progress monitoring 
of outcomes and learning strategies used. The authors claim that this framework can be a start in the development of a comprehensive early field experience CTE teacher preparation program.

Researchers agree there is a need for more research on a structure that would develop the context of the experience in early teaching clinical practicums (Clift \& Brady, 2005; Darling-Hammond, 2006; Ducharme \& Ducharme, 1996). Retallick and Miller (2010) agree that research for a comprehensive model in CTE teacher preparation programs is a critical element missing from the literature. Although research is needed, McIntyre, Byrd, and Foxx (1996) found that what happens during a clinical practicum is more influential than the length of the practicum, but Knowles and Cole (1996) believe that practicums that are too short do not allow for a variance of experiences and may lead to a lack of teacher identity. Carter and Anders (1996) add that high-quality field experiences help students transition from an academic identity to teacher identity. Friesen and Besley (2013) found that early teacher identity is developed through opportunities for teaching practice, leading to the merging of personal, social, and professional identities. Ivanova and Skara-Mincane (2016) found that participants recognized, for the first time, their teacher identity during clinical teaching practice. Researchers also found that the participants had personal as well as professional growth during teaching experiences.

Chong, Low, and Goh (2011) examined emerging teacher identity in pre-service teachers at the end of their teacher preparation program, which included early clinical teaching practice experience. The authors claim that the pre-service teacher's sense of teacher identity stems from how they view themselves "as teachers before they begin teaching" and how their identity is developed through teaching practice (Chong et al., 
2011, p. 50). The authors add that the teacher's identity is fluid and developed through different levels of practice as their beliefs, views, and roles change. Chong et al. support identity development through a community of practice where preservice teachers can use reflection to embrace appropriate identity viewpoints as a result of their experiences in different teacher preparation contexts. The authors consider that the emerging of a teacher identity during early clinical teaching practice would reveal to the preservice teacher if they are capable of being a teacher (Chong et al., 2011). Their study revealed that one-third of their participants reported continued altruistic views about teaching, even at the end of their program. The researchers cite evidence that supports their findings and state that preservice teachers who are motivated by caring and noble reasons, stay in the profession longer. Thirty-nine percent of the participants reported the realization of the realities of teaching after clinical teaching practice experience. The authors emphasize that preservice teachers enter the program with a set of expectations and subsequently realize that teaching is more complicated than they initially thought. The authors add that how the preservice teachers react to the realizations of teaching will determine their resiliency in the profession (Chong et al., (2011). The Chong et al. study also found that $14 \%$ of participants were disenchanted after having the clinical teaching practice experience. Participants reported oversimplified beliefs and conceptions about the profession. Chong et al. cite research by Alsup (2006), which found that through reflection and discourse, preservice teachers stay engaged and continue to expand their identity as they progress through the program, helping them self-regulate in the context, using language (Chong et al., 2011). The researchers also found that preservice teachers reported the "role of teaching and learning" as their biggest concern when teaching, 
evidence of a typical beginning teacher (Chong et al., 2011, p. 60). The researchers attributed one of their lowest factors, "sense of professional identity," to the aspects of the experience that create disillusionment. The study also showed that preservice teachers demonstrated an emerging teacher identity, identifying themselves as "self as a role model" and "professional growth as a teacher" (Chong et al., 2011, pg. 60). As a result of Chong's study, the authors agree that there is a gap in clinical teaching practice research. They believe that university methods courses are not enough and do not provide enough practice in the field. In order to motivate and develop an emerging teacher identity, preservice teachers must be faced with the realities of the professions and mentored through the disillusionment through reflection and discourse (Chong et al., 2011).

\section{Teacher Identity/Professional Identity}

A sociocultural lens will be used to explore teacher identity and its development in the present study. Using a sociocultural lens will allow for the perspective of a social context in the development during early clinical teaching practice, which differs from the viewpoint that identity is formulated as an individual construct in preservice teachers (Mead, 1934). The current section of the literature review highlights the important topics in teacher identity. Topics such as defining teacher identity, the self in relation to identity, the connection between teacher identity and agency, and teacher preparation will be discussed. Other important theoretical and conceptual constructs will also be discussed.

The research shows that the continuous development of teacher identity is necessary to develop teachers who are competent and resilient educators. By fostering a teacher identity through early clinical teaching practice, high school teacher preparation 
programs can create a foundation in which a professional identity can grow. According to Nguyen and Yang (2017), professional practice is vital for the development of teacher identity and the influences it has on teacher motivation, commitment, and overall purpose. Beauchamp and Thomas (2009) believe that developing research on teacher identity has brought an awareness of the different aspects of teaching. Although research on defining, evaluating, and theorizing teacher identity is vast and complex, a framework has yet to be defined (Nguyen, 2016). Researchers agree on the importance of teacher identity in the production of good teachers but also recognize the challenge in understanding the issues in its development (Freese 2006; Olsen, 2008; Nguyen \& Yang 2017). According to Beauchamp and Thomas, to begin to understand or create a definition for identity, one must recognize the complicated relationship between the self and identity, the understanding of identity through discourse (Gee, 1992), the emotional role in identity formation, the influence of reflective practice and identity, the connection between agentic behavior and identity, environmental factors that contribute to one's identity, and finally, the responsibility of the teacher preparation program to develop and explore professional identity (Beauchamp \& Thomas, 2009). Collectively, these factors contribute to the development of identity in the context of a teacher preparation program.

Beauchamp and Thomas (2009) believe that a definition for teacher identity can be understood through a sociocultural lens; as opposed to other "traditional approach[es] to teacher learning" which focuses more on the individual teacher's learning and not through social teaching practice (Yazan, 2018, p. 30). By viewing teacher identity as a product and a process of emotions, values, and experiences, researchers can begin to understand the phenomenon that occurs. Olsen (2008) believes that the constructs that 
make up teacher identities, such as meaning systems, social positioning and prior selfconstructs, act together as a teacher reacts to their environment and professional community (p. 139). The review of the research suggests that identity is an ongoing, unstable phenomenon that is always shifting because of internal and external factors, involving both the person and the context (Gee, 2001). Gee recognizes the idea of multiple identities and that these identities are dependent on the interaction within the context. In his research, he identifies four approaches to identity perception. These approaches emphasize the different dimensions of identity because of external influences such as one's natural state, the perception of authority figures to oneself, social perception about oneself, and one's perception about oneself within a social group (Gee, 2001). Teachers develop multiple identities within their professional identity as a result of the unique characteristics they have attained while working within a context. An "active pursuit of professional development" stems from agentic behaviors set forth by their teaching goals (Beauchamp \& Thomas, 2009, p. 177). Day, Kington, Stobart, and Sammons (2006) explain that understanding both the cognitive and emotional identities of teachers is essential to comprehending the tension between external influences and internal agentic decisions derived from valued goals. Analysis using a sociocultural lens helps to evaluate these dynamic characteristics in teacher identity but makes defining the concept exceedingly difficult.

The authors discuss different terms used in the research of teacher identity, terms such as the development of, construction of, the formation of, and creation of. These terms are used interchangeably in teacher identity research as critical aspects to evaluate. In their review of the literature, Beauchamp and Thomas (2009) cite Sachs' (2005) 
statement to provide an overall perception of identity: "Teacher professional identity then stands at the core of the teaching profession. It provides a framework for teachers to construct their ideas of how to be, how to act, and how to understand their work and their place in society. Importantly, teacher identity is not something that is fixed, nor is it imposed; rather, it is negotiated through experience and the sense that is made of that experience" (p. 178). They argue that Sachs' description of what identity can be used to begin to define teacher identity, but a sociocultural lens will bring to light more dynamic constructs, such as emotion, values, and beliefs (Beauchamp \& Thomas, 2009).

Despite the difference in terminology across the literature, researchers agree that understanding of the self is a crucial component in the shaping of a teacher identity (Beauchamp \& Thomas, 2009). According to Day et al. (2006), Mead (1934) discussed the self as a stable concept linked to sociocultural experiences. A stable self perspective is contradictory to some of the research that says that the self is unstable and always changing. Mead provides the perspective that a stable identity could take on different attitudes to different social experiences derived from their role in the social environment. According to Stets and Burke (2014), Mead understood through a sociological perspective that the self emerges from cognition and interacts with social structures through language. A stable self is a collection of values, roles, and attitudes that reflect the self's attitude about themselves. Their research emphasizes the importance of the understanding of the self in teacher education in order to understand how teachers construct an identity on the basis of beliefs, actions, and attitudes and how this is connected to the experiences in their personal lives and professional roles (Day et al., 2006). Day et al. reference research that mentions that teacher identities are fostered 
through more than emotional and technical attributes of teaching, but "as a result of an interaction between the personal experiences of teachers and the social, cultural and institutional environment in which they function on a daily basis" (p. 603).

According to Beijaard et al. (2009), important factors to understand about teacher identity include the relationships with their students, how they perceive their subject area, the context in which they teach, and the relationship between these factors and a stable and unstable identity. He also found that teachers of similar age and sex had similar experiences, attitudes, and frustrations. He believed they also shared similar motivations, creating predictable patterns as they aged (Beijaard et al., 2009).

Korthagen (2004) believes that teacher identity can be influenced, but critical changes cannot be made quickly. The author asserts that changing a teacher's identity can be a slow process and may not happen at all. Specifically, with preservice teachers, Cooper and Olson (1996) believe that the self is not applicable yet in the teaching context until identity can be constructed through a progressive process of daily teaching practice. They also found that meaning in teacher preparation is created through interactions between the self and the experience lived through. The authors suggest that a more indepth focus on these transactions may help to understand the multiple identities formed/created in a teaching context for preservice teachers (Cooper \& Olsen, 1996). Lauriala and Kukkonen (2005) discuss these different selves in three dimensions, "the actual self," "the ought self," and "the ideal self" (p. 207). They argue that these different selves act as identities that stem from an inner teacher's self and interact to form a selfconcept. 
Much of the research on teacher identity leads back to professional identity. Ivanova and Skara-Mincane (2016) list three components that are fundamental components of professional identity, including connecting personality to the profession, the search for meaning within the profession, and having professional ambitions. Their perspective lies on the premise that the goal for any teacher education program is to develop a professional identity. Beijaard, Meijer, and Verloop (2004) define teacher professional identity as "professional identity as an ongoing process of integration of the 'personal' and the 'professional' sides of becoming and being a teacher" (p. 113). Researchers agree that personal history, characteristics, and experiences, as well as teaching context, greatly influence professional identity (Beauchamp \& Thomas, 2009; Beijaard et al., 2009; Cooper \& Olsen, 1996; Olsen, 2010). Dillabough (1999) adds that professional identity is ongoing and forms through interpretations, meaning, and practice. According to Ivanova and Skara-Mincane, preservice teachers begin to see themselves as teachers through the learning process and teaching practice. Many researchers also agree that the interaction between the personal and professional aspects of a teacher in a particular teaching environment builds their teacher identity (Beijaard et al., 2004). On the other hand, some researchers caution that conflicts between a teacher's personal beliefs and values and their professional demands, may cause issues within their identity, causing tension, leading to them leaving the profession; and is especially true for preservice teachers (Pillen, Beijaard \& den Brok, 2013). According to Ivanova and Skara-Mincane, preservice teachers begin to see themselves as teachers through the learning process and teaching practice. 
Researchers agree that both personal and professional identities influence identity formation (Beauchamp \& Thomas, 2009; Day et al., 2006). Beauchamp and Thomas suggest analyzing identity in teacher preparation through the self as well as the profession. Researchers agree that the interrelationship between personal and professional aspects of teaching is an essential construct in teacher identity. The authors emphasize that emotion, discourse, reflection, and agency and critical factors in understanding the link between the personal and professional selves of a teacher. They found that reflection is a critical component of a teacher's sense of self, therefore an essential part of the shaping of the teacher identity and how the identity fits into the social teaching context (Beauchamp \& Thomas, 2009). The authors conclude that reflection is an indispensable part of a teacher preparation program and the development of teacher identity.

As preservice teachers have experiences in a teacher preparation program, they undergo several shifts in identity. Researchers believe that these shifts in identity do not only happen at the beginning of a teaching career but happen throughout (Beauchamp \& Thomas, 2009). Beauchamp and Thomas not only draw on Mead and Borich's ideas on the importance of knowledge of the teacher self, from early in their career, but also believe that knowing the teacher self has an essential impact on teacher effective practice. They believe that when a teacher understands and works to realize their ever-changing identity, they create a sense of agency. A feeling of agency may lead to "empowerment to move ideas forward, to reach goals or even to transform the context" (Beauchamp \& Thomas, 2009, pg. 183). The authors state that a sense of agency "can be a powerful force for good," helping to maintain or shape the multiple facets of a teacher's identity (Beauchamp \& Thomas, 2009, pg. 184). Preservice teachers are challenged with 
negotiating between these shifts in identity and must learn how to be "agents of their identity development" (Beauchamp \& Thomas, 2009, pg. 185). The authors claim that the reshaping and shifts of identity also make teacher identity a complex notion to define across the literature. Researchers agree that attention to the shifts in teacher identity has not received the necessary attention in teacher preparation programs. The authors argue that although the importance of teacher identity in teacher preparation is not disputed, a call to action has not been defined (Beauchamp \& Thomas, 2009).

According to Olsen (2008), teacher preparation is a continuum that links teacher recruitment, preservice training, professional development, and teacher preservation. The author describes the continuum as an interrelationship of experiences that influence each other resulting in a teacher's professional goals, values, beliefs in teaching practice. Wenger (1998) connects identity to teaching practice. He identifies five attributes that pertain to both: "identity is the negotiated experience of self, involves community membership, has a learning trajectory, combines different forms of membership within identity, and presumes involvement in local and global contexts" (p. 149). Preservice teachers working in a community of practice are influenced by their peers, especially beginning teachers who are building an uncertain identity. Preservice teachers need to be aware of the shaping and reshaping of their own identities throughout their preservice education and practice (Wenger, 1998). Researchers emphasize that teacher preparation programs should take into consideration the external factors, such as the school environment, colleagues, and administrators; they have a strong influence on the shaping of a preservice teacher's identity, and the program must have positive ways to help preservice teachers develop (Hammerness, Darling-Hammond, \& Brandsford, 2005). 
Hammerness et al. emphasize that the development of early teacher identity is crucial to the development of their professional behaviors. The authors claim that the identities developed through early practice will determine their desire to grow professionally as educators, will help to develop a teaching nature, and will determine what commitments and responsibilities they will intrinsically seek out as a role. Riopel (2006) agrees and calls for the strengthening of the connection between early practice and the development of teacher identity in teacher preparation programs.

Beauchamp and Thomas (2009) claim that the effect of a context in which a preservice teacher's identity will be shaped must be taken into consideration in a teacher preparation program. The authors add the importance of constructive environments that challenge their identity as a teacher. It is through these challenging situations that preservice teachers will confront and discover their teacher identities (Beauchamp \& Thomas, 2009; Olsen, 2010). Freese (2006) encourages self-discovery through challenges in practice, encouraging self-questioning and reflection. Beauchamp and Thomas add that different forms of collaboration, within educational contexts, should be developed and included in school-based teacher preparation programs. They state that these programs "provide an opportunity for close examination of the self and interaction with the context: an ongoing reassessment of a teacher's participation in the discourse of the context and the additional contextual factors that may affect the shaping of identity" (Beauchamp \& Thomas, 2009, p. 186).

For the present study, a social learning lens was used to analyze the significant features of high school level preservice teachers participating in a community of practice. As a definition, the study uses the findings of Beijaard et al. (2004) when researching 
teachers' professional identities. On the basis of their research, the authors found the following essential features for teacher professional identity: (1) "professional identity is an ongoing process of interpretation and reinterpretation," meaning it is a dynamic construct, not fixed or stable, (2) "professional identity implies both person and context," meaning the teacher sees themselves as a teacher in a community of practice, (3) "professional identity consists of sub-identities that more or less harmonize," meaning that, although the sub-identities of new teachers experience conflict, the goal is to have balance, (4) "agency is an important element of professional identity," meaning that teachers must be active participants in their identity and professional development (pgs. 122-123).

The present dissertation utilized the social learning theory to explore the different aspects of identity in high school students participating in a teacher preparation community of practice. The identity framework used for the current study originated as part of a study by Carlone and Johnson (2007) looking to understand the science identity of women of color. Gee's theory informed their model of identity, which defines identity as something that cannot be claimed by a person; it requires the corroboration of others (Carlone \& Johnson, 2007). The authors explain that one cannot claim an identity if they are not recognized by others to have the competence to perform under that identity. Finally, Carlone and Johnson's model includes these three characteristics, which include: competence, performance, and recognition. These dimensions overlap and work together, depending on the context. The authors claim that identity is developed in an environment that is challenging and resourceful. Contrary to other holistic views (Nguyen, 2016; Olsen, 2008), the model does not include feelings or the idea that identity 
is innate (Carlone \& Johnson, 2007). Adding to Carlone and Johnson's model, researchers Hazari, Sonner, Sadler, and Shanahan (2010), included a fourth dimension to the framework. To meet the needs of their study on high school student's science identity, they included interest as the fourth dimension to their framework, on the basis of the social-cognitive career model. Hazari et al. (2010) argue that an identity framework has been proven to be a useful lens for studying these constructs. Evidence in the field of the Hazari et al. study, connecting identity constructs in teacher education, have also been recognized (Beauchamp \& Thomas, 2011; Nguyen, 2016; Sutherland, Howard \& Markauskaite, 2010). Hazari et al. also mention the work of Burke (2003) and recognize other aspects of identity which include personal identity factors, such as self-defining characteristics, social identity factors which come about from shared experiences, and context-specific identity, which is the component the current study focuses on (teacher identity). In the Hazari et al. model, the four dimensions which exemplify the contextspecific identity include interest, competency, recognition, and performance.

\section{Teacher Identity, Interest, and Recognition}

According to Renninger (2009), identity and interest have appeared in psychological literature throughout history. The author suggests that each develops with age and is both a product and a process. Interest is defined as a psychological factor that is reengaged, in a particular context, over a period of time, a preference, or an attraction (Renninger, 2009). Renninger suggests that the development of interest is measured in phases; if students are not supported or challenged, these phases may revert. Teachermentors must provide feedback, set goals, and provide adequate content instruction in order for the student to have enough content knowledge to ask questions and grow 
interest (Renninger, 2009). Olsen (2008) believes that gender affects an interest in teaching. He suggests that girls, more often than boys, will pretend they are teachers, setting up pretend classroom scenarios with all the major players. He explains that pretend play is a result of observations of positive, often female teachers, made in reallife school settings and that play was encouraged by influential adults in their lives (Olsen, 2008). Olsen also suggests that pretending to be a teacher creates an interest on the basis of power, (directing the class, giving quizzes, grading papers) and that interest to be a teacher may be distorted when they realize that newer classroom pedagogy is student-centered (group work, authentic evaluations of work.). Olsen contends that these conflicts between policy and identity create a conflict of interest.

Olsen (2008) also discusses recognition from family and friends as reasons for their interest in teaching. In his research, he found that some participants had influential people in their family that were teachers themselves. Some of his participants felt that they were competent in helping others, explaining difficult concepts, and even felt a "mothering" connection to children; others recognized those qualities and reinforced them with feedback and praise (Olsen, 2008, p. 30).

Also, Olsen (2008) found that all his participants felt that they were strong readers and writers. Their interest in language arts led them to want to teach the subject matter to young populations. Olsen suggests that these participants may have liked language art because they felt competent and were recognized as being good in that subject area; therefore, they had a higher personal interest in it. Finally, Olsen's research found that all of his participants felt the desire to work with children or young adults. He suggests that some may be projecting their memories about themselves as a student "onto their 
conceptions of students" (p. 33). He also reports an interest in social justice or "making a difference in the world" as reasons for their interest in teaching (p. 33). Olsen mentions that regardless of the reason for their interest in teaching, teacher preparation programs must find ways to include the development of teacher identity early in a teacher's education. An early intervention may reduce or help with conflict in identity formation during a difficult first year teaching.

\section{Teacher Identity, Competence, and Performance}

According to Hakim (2015), the success of a student in a classroom is related to the competency and performance of their teacher. The author cites Spencer and Spencer (1993) when defining competency and infer that competency is a characteristic of a person related to performance in a particular context. Although the terms competence and performance are often used in conjunction, the authors recognize the causal relationship between them; suggesting that competency in "job duties" can be a "decisive tool" for overall performance (Hakim, 2015, p. 1). Hakim mentions four types of competence required for teaching students: pedagogical competence, personal competence, professional competence, and social competence. He explains that pedagogical competence is the ability to understand learners, use appropriate instructional strategy and implementation, give valid assessments of learning, and the ability to move students forward in their learning. Hakim describes personal competence is the ability to connect with an identity. He explains that to have personal competency, a teacher must have "self-acceptance" and "self-realization" (p. 2). He also suggests that personal competence is related to becoming a role model for students and teaching them to be the best versions of themselves. Next, Hakim describes professional competence as a teacher's 
understanding of teaching philosophy and as having the ability to step out of the classroom and participate in different educational contexts. He mentions a professional's competence includes the involvement with the influence of other contextual factors such as understanding the organization of school administration and processes, managing appropriate school-wide programs, understanding the foundations of teaching, learning and education as a whole and finally, being able to interpret and use educational research (Hakim, 2015). Finally, Hakim describes social competence as being able to work with others, including the ability to communicate ideas and thoughts with students, other teachers, administrators, parents, and the community.

Hakim (2015) explains that performance can be used to determine competence as well as motivation. He clarifies that performance involves the results of the execution of a task on the basis of predetermined goals. Hakim (2015) goes on to say that "performance is the result of interaction between the ability, motivation, and opportunity [of] a person completing a task" (p. 3). Regarding teaching, he believes that a teacher's performance should be measured by the learners' success in learning, in a given time, by a specific criterion (Hakim, 2015).

Moreover, the competence and performance of a teacher are currently measured using university and state assessments and district evaluations derived from standards and specific criteria. For individual states, preservice teachers must graduate from a stateapproved teacher education program and pass all the state certification examinations. The program must use The Educator Accomplished Practices (FEAPS) as a criterion for preparing their teachers. These practices are displayed as a rubric, giving an accomplished, professional, and preprofessional level. They include practices such as 
using appropriate assessment strategies, employing effective communication techniques, using strategies that encourage rigor and critical thinking in students. Teachers are evaluated with similar standards but using a state model for the evaluation system. Each district determines which model they want to implement with their teachers. Many of them include factors such as instructional practice, the performance of students, and other indicators of performance.

According to Hazari et al. (2009), the four components in their model (interest, recognition, competence, and performance) influence each other as well as the learning environment and experiences in that environment. The authors discuss that the social cognitive career choice model link student interest to their learning experiences. They believe that the four components of their identity model are influenced by specific pedagogy, the structural characteristics of their classroom and school environment, the unique traits of the teacher, the unique traits of the student, significant relationships with family and friends, and other experiences outside of school (Hazari et al., 2009). Using the Hazari et al. model, the four components mentioned were quantitatively studied in the present dissertation in teacher preparation, a community of practice environment using a sociocultural lens. The present research investigated which components, if any, are fostered in learning environment of SCHOOL A ECE 1.

\section{Summary}

As states struggle to encourage students to enter the field of education, they also struggle to keep teachers in the classrooms (Glazer, 2018; Guha, Hyler, \& DarlingHammond, 2017; Ingersoll \& Smith, 2003). To create a pipeline for high school students that inspires them to enter the field, a CTE framework that fosters motivation, student 
achievement, and teacher identity should be implemented. A review of the literature shows that deficiency in these factors contributes to teacher attrition rates, especially in high poverty schools. The research on attrition shows that a lack of teacher identity is one reason teachers leave because they feel an overall lack of support, effecting their selfefficacy (DenBrok, Wubbels \& Tartwijk, 2017). Teacher preparation programs that bridge the gap between content and practice raise motivation, self-efficacy, increase teacher agency, and creates more resilient teachers (Lee, 2018).

A review of the development of CTE revealed that unity between academics and vocational skills could benefit students tremendously (Stipanovis, Lewis, \& Strinfield, 2012). The growth of CTE has resulted in a connection between high school and college students. DeFeo (2015) and Loera et al. (2013) agree that a pipeline between the college and the high school leads to higher motivation to transition into the workforce. The literature shows that the earlier students explore career options, the more likely they will complete a vocational track. Finally, although there has been significant development in curriculum development and program structure, there is a significant lack of research on student achievement in CTE programs.

In the current literature review, two views on studying motivation were analyzed. Both the sociocultural and social cognitive views share a constructivist approach that places the learner at the forefront of active learning. Some researchers believe that combining the two views will give a deeper understanding of motivation and learning in a social, situated context (Rueda \& Dembo, 1995). Given that when students are cognitively engaged, they are motivated, a social cognitive approach is appropriate for analyzing student learning motivation. Also, the sociocultural approach gives a broader 
view of the culture of the classroom environment and analyzes student learning in connection to the context.

Clinical teaching practice is not disputed as being an essential component of teacher preparation, but the present review has found that there is little research beyond the traditional university field experience model. Some researchers believe that the university model focuses more on the content skills learned and not enough on the learning that occurs organically in practice. Studies show that preservice teachers should practice in an environment where they feel free to take risks and learn to view teaching as a community where relationships create a classroom culture. Researchers agree that the discrepancy lies in the degree of how much clinical teaching practice is enough. Some researchers believe that it is quality and not quantity that creates an effective teacher preparation program. Zeichner (2010) describes an exceptional teacher preparation program to be one where content and practice are interconnected, and strong mentorship is available. Early clinical teaching practice has shown to be a promising inclusion in teacher preparation. A connection between clinical practice and content will give students an earlier opportunity to explore the career field, and early clinical teaching practice will begin to develop a teacher identity.

Finally, a review of the literature shows that researchers agree that there needs to be more attention paid to the development of teacher identity. Beauchamp and Thomas (2009) point out that the literature on teacher identity has identified many uses for an investigation: as an analytic lens, as a framework in teacher preparation, as an avenue for discourse and reflection and finally as a source to help the teacher explain their changing selves. Most importantly, for the current study, the research shows that teacher identity 
should be used to create teacher education programs that address the development of teacher identity early in a teacher's education.

A gap in the literature is evident regarding the development of teacher identity in learning environments specifically created for high school students in vocational, teacher preparation programs. Most of the research found include studies done at the college and student-teaching levels or the veteran teacher level. Research conducted from the perspective of a high school student, which encompassed their sense of identity, was rare, although some research was found that included studies done in high school teacher preparation programs, research in the Education and Training cluster (teacher preparation) of CTE was not found. 


\section{CHAPTER 3}

\section{METHODOLOGY}

In this chapter, the methodology used to analyze the research questions in the current study is presented. A quantitative design was used to collect and analyze attitudinal data to examine the dimensions of teacher identity as well as the constructs of motivation that are exhibited by students in three CTE programs. Quantitative hard data were collected from students enrolled in early childhood to analyze the role of GPA and attendance in overall student achievement and connections with motivation and teacher identity after participating in early clinical teaching practice.

\section{Research Questions}

The current study addressed students' motivational constructs, dimensions of teacher identity, and overall achievement as they participated in a CTE program to address the gap in research. The following questions were explored:

1. What is the impact of a Career and Technical Education program, including time spent in early clinical teaching practice, on student motivation as measured by the Motivated Strategies for Learning Questionnaire (MSLQ), in three programs and across four levels?

2. What is the effect of a Career and Technical Education program, including time spent in early clinical teaching practice, on teacher identity as measured by the Teacher Identity Survey, in three programs and across four levels?

3. What is the effect of a Career and Technical Education program, including time spent in early clinical teaching practice, on program completers,' 
mid-year, twelfth-grade average GPA as compared to their mid-year ninthgrade average GPA?

4. What is the impact of a Career and Technical Education program, including time spent in early clinical teaching practice, on program completers', mid-year, twelfth-grade average attendance record as compared to their mid-year ninth-grade average attendance record?

\section{Research Design}

This study used quantitative, descriptive measures to explore constructs of student motivation, teacher identity, overall achievement (including GPA and attendance record), and possible relationships with time spent in an early clinical teaching practicum. The study exemplified an identity theoretical framework to examine student motivation and student achievement in a program that uses early clinical teaching practice in a high school program. Drawing data from the Motivated Strategies for Learning Questionnaire (MSLQ), teacher identity survey, and student GPA and attendance records, the study used descriptive data as well as relevant interactions to examine the responses of the student participants of two CTE Early Childhood Education programs (ECE) and one CTE non-teacher education program (BIO 1) in a large urban community. A two-way MANOVA analysis was performed to analyze the two independent variables (vocational program and program level) and the dependent variables derived from the motivational constructs and dimensions of teacher identity. Finally, independent T-Tests were performed to compare the means of SCHOOL A ECE 1 and SCHOOL B ECE 2 to specifically determine the significant differences between the level of students in these teacher preparation programs. 
A quasi-experimental design was used to seek relationships between student motivation, teacher identity, student achievement, attendance, and the amount of time spent in an early, high school level, teaching clinical practicum. Two control groups, SCHOOL B (ECE 2) and SCHOOL A (BIO 1), were chosen to strengthen the internal validity of the study and enhance generalizations and general trends in CTE high school teaching programs. No changes occurred to the intervention group, SCHOOL A (ECE 1), or the control groups to avoid disruption of the natural classroom setting for the duration of the present study. The early clinical teaching practicum in the ECE 1 program at SCHOOL A was already in place, ECE 2 at SCHOOL B program, and BIO 1 at SCHOOL A continued regular program routines. Time in early clinical teaching practice was measured by the possible time spent in practice in each program: SCHOOL A ECE 1 includes a total of 680 on and off-campus hours, SCHOOL B ECE 2 includes a total of 480 off-campus hours, and SCHOOL A BIO 1 includes 620 on and off-campus clinical teaching practice hours. These hours are completed in four years, beginning in the $9^{\text {th }}$ grade and ending in the $12^{\text {th }}$ grade.

The study utilized the (MSLQ) instrument to answer research question one (See Appendix A for questionnaire items). The MSLQ is comprised of 81 items that are divided into two sections: motivation and learning strategies. For the current dissertation, only the motivation section was administered. The MSLQ uses a seven-point Likert scale to measure the following motivational subscales: intrinsic and extrinsic goal orientations, task value, learning beliefs, self-efficacy, and test anxiety. For the present study, the test anxiety items were not analyzed or reported since tests and exams are rarely given in the courses; therefore, the items were excluded from the data analysis. The descriptive 
statistics from the MSLQ provided a mean and standard deviation for student responses for each dimension. A multivariate analysis of variance (MANOVA) was performed to compare the five motivational subscales that served as multiple dependent variables to the two independent factors (vocational program and program level). Table 3.1 shows the relevant components, scales, and items that were measured in the present study. Finally, an ANOVA was performed as a follow up to the MANOVA results in order to examine each motivational construct in comparison to the independent variables $t$-test analysis was also performed to directly compare the means of the two early childhood programs in isolation.

Table 3.1

Motivational Scales and Item information

\begin{tabular}{|c|c|c|c|c|}
\hline $\begin{array}{l}\text { Motivational } \\
\text { Construct }\end{array}$ & Scale & Items & Example & Alpha \\
\hline $\begin{array}{l}\text { Value } \\
\text { Component }\end{array}$ & $\begin{array}{l}\text { Intrinsic Goal } \\
\text { Orientation }\end{array}$ & $\begin{array}{l}1,16,22 \\
\text { and } 24\end{array}$ & $\begin{array}{l}\text { In a class like this, I prefer } \\
\text { course material that really } \\
\text { challenges me so I can learn new } \\
\text { things. }\end{array}$ & $(a=0.7)$ \\
\hline $\begin{array}{l}\text { Value } \\
\text { Component }\end{array}$ & $\begin{array}{l}\text { Extrinsic Goal } \\
\text { Orientation }\end{array}$ & $\begin{array}{l}7,11,13, \\
\text { and } 30\end{array}$ & $\begin{array}{l}\text { Getting a good grade in this class } \\
\text { is the most satisfying thing for } \\
\text { me right now. }\end{array}$ & $(a=0.6)$ \\
\hline $\begin{array}{l}\text { Value } \\
\text { Component }\end{array}$ & Task Value & $\begin{array}{l}4,10,17 \\
23,26, \\
\text { and } 27\end{array}$ & $\begin{array}{l}\text { It is important for me to learn the } \\
\text { course material in this class. }\end{array}$ & $(a=0.9)$ \\
\hline $\begin{array}{l}\text { Expectancy } \\
\text { Component }\end{array}$ & $\begin{array}{c}\text { Control of } \\
\text { Learning Beliefs }\end{array}$ & $\begin{array}{l}2,9,18 \\
\text { and } 25\end{array}$ & $\begin{array}{l}\text { It is my own fault if I don't learn } \\
\text { the material in this course. }\end{array}$ & $(\mathrm{a}=0.7)$ \\
\hline $\begin{array}{l}\text { Expectancy } \\
\text { Component }\end{array}$ & $\begin{array}{l}\text { Self-Efficacy for } \\
\text { Learning and } \\
\text { Performance }\end{array}$ & $\begin{array}{l}5,6,12 \\
15,20 \\
21,29 \\
\text { and } 31\end{array}$ & $\begin{array}{l}\text { I believe I will receive an } \\
\text { excellent grade in this class. }\end{array}$ & $(\mathrm{a}=0.9)$ \\
\hline
\end{tabular}


According to Pintrich, (1991), intrinsic goal orientation relates to the extent to which a student participates in a task because of curiosity, a personal challenge, or to gain mastery. An extrinsic goal orientation relates to the extent to which a student participates because of grades, performance, and perception of others. Task value relates to how interested a student is in the activity or lesson; also referring to how important or useful the student thinks the task is. Task value relates directly to the interest and importance of course material (Pintrich, 1991). Control of learning beliefs relates to the student's belief that they will learn because of their efforts; referring to a student's control of their learning. Self-efficacy for learning and performance includes two facets of expectancies, expectancy for success and self-efficacy. Expectancy for success suggests task performance expectations; self-efficacy refers to one's judgment about his/her capability to perform and accomplish a task (Pintrich, 1991).

A modified version of a teacher identity survey was used to answer question two. Thamotharan and Hazari (2018) presented an identity framework that measures the following dimensions for teacher identity: recognition, interest, performance, and competence. These dimensions were adapted for their work in math and science teaching identity. With permission, these items were modified, and the math and science components were eliminated, leaving only the teacher components. The teacher identity survey uses a 4-point Likert scale and consists of 13 items (See appendix A for survey items). A multivariate analysis of variance (MANOVA) was performed to compare the four dimensions of teacher identity that served as multiple dependent variables and the independent variable (vocational program and program levels). Finally, an ANOVA was performed to follow up the MANOVA results to examine each motivational construct in 
comparison to the independent variables. The $t$-test analysis was also performed to directly compare the means of the two early childhood programs in isolation. Reliability analysis was run for the items in the present study and reported below.

\section{Table 3.2}

Teacher Identity framework dimensions and survey item information

\begin{tabular}{|c|c|c|c|c|}
\hline $\begin{array}{l}\text { Teacher } \\
\text { Identity } \\
\text { Dimension }\end{array}$ & Description & Items & Example & Alpha \\
\hline Recognition & $\begin{array}{l}\text { Recognition by } \\
\text { others as being } \\
\text { a good teacher }\end{array}$ & 3 items & $\begin{array}{l}\text { My family sees me as good at } \\
\text { teaching. }\end{array}$ & $(a=0.8)$ \\
\hline Interest & $\begin{array}{l}\text { Desire/curiosity } \\
\text { to think about } \\
\text { and understand } \\
\text { the teaching } \\
\text { profession }\end{array}$ & 4 items & I enjoy teaching others. & $(a=0.8)$ \\
\hline Competence & $\begin{array}{l}\text { Belief in ability } \\
\text { to know how to } \\
\text { teach }\end{array}$ & 3 items & $\begin{array}{l}\text { I know the steps necessary to } \\
\text { teach. }\end{array}$ & $(a=0.7)$ \\
\hline Performance & $\begin{array}{l}\text { Confidence in } \\
\text { ability to } \\
\text { perform } \\
\text { required } \\
\text { teaching tasks }\end{array}$ & 2 items & $\begin{array}{l}\text { I understand teaching } \\
\text { concepts well enough to be } \\
\text { effective when teaching a } \\
\text { lesson. }\end{array}$ & $(a=0.8)$ \\
\hline
\end{tabular}

To answer research questions three and four, $12^{\text {th }}$ grade, level 4 , early childhood student's mid-year grade-point average (GPA), and attendance records were collected to determine any changes in average GPA and average attendance records (unexcused absences) from their $9^{\text {th }}$-grade mid-year averages. The study sought to find interactions between overall student achievement and time spent in early clinical teaching practice in grades 9-12. The GPA was measured on a 4-point scale with $4=90-100 \%, 3=80-89 \%, 2$ $=70-79 \%, 1=60-69 \%, 0=0-59 \%$. The biomedical control group was excluded from the 
GPA analysis because the research questions sought to determine the effects on GPA an attendance after early clinical teaching practice. To examine these factors, a dependent sample $t$-test analysis was used to compare GPA and attendance data from their mid-year $9^{\text {th }}$-grade year to their mid-year $12^{\text {th }}$-grade year, for program completers $\left(12^{\text {th }}\right.$ graders in level 4), in the two early childhood programs.

\section{Role of the Researcher}

The teacher-researcher who led the present study is a Hispanic teacher who has been teaching for 19 years. She has a bachelor's degree in Exceptional Student Education, a master's degree in Special Education, and received the National Board Certification for Teachers. She is certified to teach English $9^{\text {th }}-12^{\text {th }}$ grade and taught high school reading and Language Arts for 12 years. The teacher-researcher holds administrative responsibilities at her school, including the lead teacher position for the Academy of Education teacher preparation program. Shortly after starting the Academy of Education, she opened the on-campus preschool after earning the required state certifications for preschool education, including the state's Department of Children and Families certification, passing the Preschool birth-four state subject area exam, earning state director credential, and the Child Development Associate (CDA). The Academy of Education started by the teacher-researcher is also the first NAF (National Academy Foundation) Academy of Education in the U.S. She is also the advisor for the Florida Future Educators of America at her school. Lastly, the teacher-researcher grew up in the community where she teaches and therefore is familiar with the culture and social expectations of the community. 


\section{Settings}

According to the Florida Department of Education, in 2018, 431,730 students enrolled in CTE courses. In the large urban district where these schools are located, 50,616 students were enrolled at the time of the current study. Although the district has the highest CTE enrollment in the state, enrollment for early childhood courses declined significantly. In the 2017-2018 school year, early childhood course's enrollment fell from 19,877 to 18,939 . The reasons are unknown, but it may be as a consequence of students taking more college-level courses in high school as electives (http://www.fldoe.org/core/fileparse.php/9904/urlt/1718secondarycte.pdf). In the district, principals have also closed many on-campus preschools; resulting in a decline in overall student enrollment in the early childhood programs.

The district provides high school students with college credit through an articulation agreement with the local college for early childhood program completers (having completed all four levels of the program between 9th-12th grade). If students enroll in the local college and enter their early childhood program, they receive nine college credits. Students also graduate from the course with state certifications such as the Early Childhood Professional Certificate (ECPC), awarded through the state's Department of Children and Families. They may also complete the course with the Child Development Associate (CDA) Credential, which is the national early childhood certification. These credentials are made available to qualifying students by the district and the state to all high schools which have a CTE early childhood course, regardless if they have an on-campus preschool (http://www.fldoe.org/academics/career-adult-edu/careertech-edu/curriculum-frameworks/2019-20-frameworks/edu-training.stml). The state provides 
interested schools with a curricular framework for the CTE Education and Training cluster which include vocational standards that provide a pacing guide into teacher preparation content. The Education and Training cluster has two strands: early childhood and principles of teaching. The early childhood strand is a four-level course, for $9^{\text {th }}-12^{\text {th }}$ graders, which gives schools the option of an on-campus preschool where students fulfill the required 480 hours of contact with preschool children, ages 3-5 years old, without having to leave the high school campus; or they can complete the hours off-campus at local daycares in the community. Schools that choose the off-campus model have to provide transportation to the students during school, or the hours can be done after school and in the summer. The second strand, principles of teaching, is also a four-level course for $9^{\text {th }}-12^{\text {th }}$ graders for students interested in teaching PK-12 grades. These students must meet a 200-observation hour requirement in PK-12 grades as well as a portfolio assessment. The students in the Principles of Teaching strand were not participants in the current study.

\section{SCHOOL A ECE 1 Academy Program Overview}

The target high school in the present study (SCHOOL A) has 11 CTE programs arranged as career academies. One of those academies is known as the Academy of Education, which prepares students who were considering entering the field of education. The academy's framework consists of both strands previously discussed: Early Childhood Education and Principles of Teaching. Both programs follow state-mandated structures for both academic and vocational standards provided by the state as a set of curricular frameworks. While both CTE elective courses are under the same academy, they have separate academic standards, structures, and plans of study. For the current 
dissertation, the Early Childhood Education (ECE) program is the focus of the current research.

Students in the ECE program assume all the responsibilities of a preschool teacher in a preschool lab located on the high school campus. High school students work with children 3-5 years old daily to teach them the fundamental skills needed to succeed in kindergarten. The high school students are responsible for planning, teaching, and evaluating the preschool children using the state voluntary prekindergarten (VPK) curriculum as well as participating in all other activities required to operate a successful preschool (see appendix B, C and D).

The SCHOOL A ECE 1's Early Childhood program follows a four-year plan of study that includes four program levels starting in ninth grade and completing in twelfth grade. The high school students have four classes per day and spend one hour and fifty minutes in each class. Each program level includes more complex vocational/professional standards increasingly; students are expected to apply the knowledge learned at each level and demonstrate what they have learned during their clinical teaching practice. At the high school (SCHOOL A), the teacher-researcher focuses on an increase of opportunity to develop student agency and responsibility at each level. For example, students in level one, primarily ninth graders, do not instruct the preschool children in the preschool lab. Level one students prepare to work with the children by learning about child development, learning theories, classroom management, and curriculum. In level two, primarily tenth graders, students begin to work with the children each day, beginning to work within the lab's collaborative framework and procedures. Students apply the knowledge learned in level one to interact with the preschool children. In level 
three, primarily eleventh graders, students seek to evaluate their teaching style, make observations, and assess the learning progress of preschool children. They also learn to reflect on their learning, teaching pedagogy, and overall teaching experience.

In level four, primarily twelfth graders, students learn to oversee the entire program, evaluating preservice teachers, and acting as student administrators of the preschool. The students in level four also participate in the preschool student advisory board. Selected students work as a team to make essential decisions regarding preschool operations, ordering of necessary materials and supplies, and maintaining the program's financial procedures (See appendix E for a description of each level's expectations). Students work in mixed-leveled groups (levels 2-4) of four to five members, and follow a daily job rotation which includes four roles: transition, lesson planning, teaching, and book work (See appendix B, C, D, and E for a description of roles, schedule, and daily job rotations). The roles are carried out using a rotation schedule where student roles are rotated each day, they attend class (See appendix $\mathrm{C}$ for sample rotation calendar).

In these roles, students demonstrate agency and self-regulatory behaviors, modeled by more knowledgeable students in their groups as well as the teacher. Students leverage their background knowledge, learn new pedagogical knowledge, discover, and observe, put a plan into action, report findings, determine the next steps, and finally reflect on their experience. These agentic behaviors and tasks create a predictable environment where students can focus on outcomes through a social clinical teaching practice experience. 


\section{SCHOOL A ECE 1 Relevant Framework Overview}

The social structure created for the program allows for high school students to make individual choices and group decisions that may influence the culture and community of the program. The community of practice framework is a socially designed and purposefully created environment centered on clinical teaching practice, reflection, and student learning through constant rotations of agentic opportunity. Using specific criteria, the interventions provided to the students within the framework allow students to make meaning from the context, but mostly the application of knowledge and reflection through clinical teaching practice. Using a community of practice framework, students make decisions and choices derived from the opportunities provided through the lesson planning experience, teaching practice, reflection, and command in leadership roles in a situated experience. Students in level four, who are mostly seniors, are expected to make decisions and choices for the betterment of the culture of the class. They are provided opportunities for planning, investigating, analyzing, problem-solving, and reflecting. The

present study analyses the motivation to act agentically, which may be the building block to teacher identity in high school students. The following are examples of tasks, given to students, that require these skills and may motivate them to act agentically: curricular decisions when lesson planning for preschool children; choices in materials used when teaching; evaluations of peer grouping and peer classwork; academic and summative input during school-wide presentations and initiatives; changes to the preschool daily schedules, monthly menu and administrative procedures; analysis of peer observation experiences; and decision regarding parent involvement and education. Although the environment is socially structured and has expectations and roles, students have the 
control to make these changes and decisions that can and have changed the program. These changes happen within the community of the program and foster a culture of agency and practice.

\section{SCHOOL A ECE 1 Framework Criteria}

The teaching criteria include professional development, knowledge intervention, and state and national assessments. The framework includes a professional development criterion comprised of knowledge in the practices and assessments of the state's Department of Children and Families (DCF); Child Development Associate (CDA); the Florida Early Learning and Development Standards (FELDS); and the National Association for Education of Young Children (NAEYC) standards, the CTE standards, and the National Academy Foundation (NAF) standards and requirements. For example, NAF provides standards that establish a college and career-ready criteria for the students in the academy. Most of the students in the early childhood program take part in different features of the Academy of Education at SCHOOL A, therefore, as part of their NAF certification, the students participate in professionalism workshops, corporate field trips and complete paid, summer internships in local daycare centers. The DCF and CDA establish a criterion that not only provides students with certifications to use after they graduate high school, but they also provide resources for background knowledge that they will need to apply in the preschool lab with the children. Lastly, the NAEYC and the FELDS provide state and national standards for high-quality childcare and education. Although many of these standards overlap, SCHOOL A ECE 1's framework is designed to help students work to understand and apply a criterion to their clinical teaching practice. The framework provides a predictable norm for students to operate, learn, and 
practice. Students who perform well in the framework often have some self-regulatory skills, can work cooperatively in groups, and are motivated to be in the class. The present study sought to find the motivational constructs, dimensions of teacher identity, and overall achievement that exists in students who meet the criteria of the clinical teaching practice framework.

In SCHOOL A ECE 1's framework, the time spent in clinical teaching practice includes observation and practice opportunities. In level 1, students are provided 50 hours of observation time in the school year to complete observational and behavioral assignments. In level two thru four, the students are in clinical teaching practice for 160 hours per school year, totaling 530 hours of on-campus clinical teaching practice and observations. Also, students participate in an optional paid internship provided by the district and NAF. Students are required to complete a five-week internship totaling 150 more hours of clinical experience, totaling 680 hours of possible on and off-campus clinical teaching practice. Table 3.3 illustrates the amount of time spent in clinical practice for all three programs in the current study. Although SCHOOL A BIO 1 does not participate in teaching practice, they do have clinical practice opportunities in the health field. 
Table 3.3

Time spent in clinical practice (on and off-campus)

\begin{tabular}{lccc}
\hline Vocational Program & $\begin{array}{c}\text { Total time spent in } \\
\text { on-campus clinical } \\
\text { practice }\end{array}$ & $\begin{array}{c}\text { Total time spent in } \\
\text { off-campus } \\
\text { clinical practice }\end{array}$ & $\begin{array}{c}\text { Total time spent in clinical } \\
\text { practice after completing } \\
\text { all four levels of the } \\
\text { program }\end{array}$ \\
\hline SCHOOL A ECE 1 & 530 hours & 150 hours & 680 hours \\
SCHOOL B ECE 2 & 0 hours & 480 hours & 480 hours \\
SCHOOL A BIO 1 & 320 hours & 300 hours & 620 hours
\end{tabular}

Note: On-campus hours are completed on the high school campus. Off-campus hours are completed at locations in the community.

\section{SCHOOL B ECE 2}

Because SCHOOL B ECE 2 is in the same district as SCHOOL A ECE 1, they share many of the same state criteria. They also share the same professional development obligations and certification requirements. The early childhood course at SCHOOL B does not have an on-campus preschool. The students must go off-campus to a local daycare to complete the required 480 contact hours with preschool children. These hours are completed on the student's own time. Students have to make arrangements for transportation to and from the daycare. The teacher is able to take students on field trips to complete some of the hours. The teacher uses the state curricular frameworks and provides students with reading and writing lessons using the teacher preparation content. The environment encourages collaborative work, and the teacher uses project-based learning to teach difficult concepts. The course focus is content-based, and clinical teaching practice is unstructured. The students have opportunities to lesson plans, observe and assess the students, but consistency is difficult. The teacher holds debriefing discussions, and the students can discuss their experiences, thoughts, and reflections. 
Using project-based learning, discussions, reading and writing assignments, textbook connections, and differentiated instruction, the teacher provides students with content knowledge in teacher preparation.

\section{SCHOOL A BIO 1}

Because SCHOOL A BIO 1 is in the same school as SCHOOL A ECE 1, both academies share many of the same benefits. The school's culture is one of content and practice, and all of the students in the school are in one or two academies. The students in the biomedical academy are thinking about entering the health science field. Many of them are taking nursing courses, and some are in the paramedic and firefighter program. The students in these courses are also provided with on and off-campus opportunities for practice. The academy is divided into four levels. Students complete 80 hours of oncampus clinical teaching practice at each level, totaling 320 hours. The level three and four students participate in a required off-campus clinical teaching practice at local doctors' offices and hospitals, totaling 300 hours. At completion, these students accomplish 620 hours of clinical teaching practice. The purpose of the inclusion of the biomedical academy in the current study is to analyze if students in CTE courses share similar motivational constructs. The group helped to understand the content's role in the formation of teacher identity.

Florida has a large and growing Career and Technical Education (CTE) program. Data from the 2017-2018 school year reported that Florida had 348,686 students enrolled in CTE programs (Florida Department of Education, 2018). The Florida Department of Education reports 30,022 students enrolled in the CTE Education and Training cluster, 
which includes the Early Childhood strand; specifically, the strand alone had 18,939 students and rated in the top five job preparation programs in the state (http://www.fldoe.org/core/fileparse.php/5652/urlt/Education.pdf). The state's graduation rate for program completers (students who complete all four levels of the program) is $97 \%$, with $82 \%$ of graduates who are employed or attend college after high school (Florida Department of Education, 2018).

The present study used data from two CTE Early Childhood public, high school programs in a large, diverse public-school district in the southeastern part of the U.S. In 2016, the county had 345,000 students, 40,000 employees, and 392 schools. The diverse district consists of students who speak 56 different languages and represent 160 countries. With 52,367 CTE job preparation programs, the school district has the most CTE programs in the state (U.S. Department of Education CTE).

Both high schools have Early Childhood programs, SCHOOL A ECE 1 established six years before the present study, and SCHOOL B ECE 2 founded 10+ years before. SCHOOL A ECE 1 has an on-campus preschool; SCHOOL B ECE 2 had an oncampus preschool, but it was subsequently closed down three years before the current study after a new principal did not want to offer the program at the school. Both schools share the same minority rate of $98 \%$; both schools have a mostly Hispanic population. The schools also share a similar economic status; both schools are Title 1 schools, SCHOOL A having $84 \%$ of students receiving free or reduced lunch, SCHOOL B having $81 \%$. Neither is a charter or magnet school, but SCHOOL B has a biomedical magnet program. SCHOOL A holds a school grade of a $\mathrm{B}$, and SCHOOL B holds a school grade of C. The schools are also similar in school enrollment population; in 2018, SCHOOL A 
had 2741 students enrolled, and SCHOOL B had 2186 students enrolled. The Early Childhood program at SCHOOL A has 356 total students enrolled, and SCHOOL B has 217 students in their program. SCHOOL A has a dropout rate of .8, while SCHOOL B has a rate of 1.7. In 2018, SCHOOL A had $88 \%$ of their seniors graduate, and SCHOOL B had $87 \%$. SCHOOL A has 11 career CTE programs, while SCHOOL B has 6. Finally, SCHOOL A has an attendance record of 95\%, while SCHOOL B holds a 92\% (Miami Dade County Public Schools, 2018).

At the school level, the programs share several similarities and differences. Both programs enroll students using similar state programs of study. Similarities include core class requirements by grade level, which consist of Language Arts, Math, Social Studies, Science, and appropriate elective classes. Both schools enroll students into the academy/program by grade level; $9^{\text {th }}$ graders enter level $1,10^{\text {th }}$ graders enter level $2,11^{\text {th }}$ graders enter level 3 , and $12^{\text {th }}$ graders complete at level 4 . Some students decide to join the program later and can double their levels in one school year. SCHOOL A also offers two education-specific dual enrollment courses (6 college credits) through a state university, which include Introduction to Education and Teaching Diverse Populations. Also, the academy framework in SCHOOL A provides students an opportunity for paid internships and professional training through the National Academy Foundation (NAF). In the year of the current study, SCHOOL A accomplished the distinguished academy award given by NAF after an academy meets a rigorous criterion.

The Early Childhood program at SCHOOL A ECE 1 is set up differently than SCHOOL B ECE 2. Both have four levels, as mandated by the state, but each level is grouped homogeneously in different class periods. SCHOOL A ECE 1 has two 
classrooms, one is the preschool lab, and the other is where the level 1 students have class. The level one students rotate in and out of the lab for their observation assignments. Since SCHOOL B ECE 2 does not have a preschool, they do not have job rotations that include teaching, maintenance, book work, and lesson planning and do not participate in on-campus clinical teaching practice.

SCHOOL A ECE 1 and SCHOOL B ECE 2 share many similar factors in state curriculum and program goals, but also have several differences in instructional practices. The instructional framework for SCHOOL A ECE 1 is a collaborative, regulated environment where students constructively teach, reflect, and collaborate. The intentional, clinical teaching structure of the practice framework includes an intervention meant to pull students forward in all academic areas, specifically, in new pedagogical knowledge, application of knowledge, and reflection. New pedagogical knowledge includes explicit literacy lessons in reading and interpreting state course standards, preparing for state technical certification exams, real-world teaching activities, projectbased learning, vocabulary instruction, writing clear and appropriate lesson objectives, creating valid assessments of those objectives, writing clear lesson plans, writing reflectively about a teaching experience, taking part in discussions about teaching and learning, and using developmentally appropriate techniques for classroom management. Application of knowledge includes opportunities for self-regulation during class duties, roles, and responsibilities such as lesson planning, instructing the preschool children, and making necessary program decisions. The intervention also encompasses a reflective aspect where students ruminate on their experiences, observations, and their learning. 
Students learn as a community of agents, using their prior knowledge and experiences to improve their teaching skills.

The instructional practices for SCHOOL B ECE 2 include the use of some of the strategies suggested by the research for CTE (Reese, 2011), but there is little observable evidence of a framework that intentionally connects new knowledge, application, and reflection through clinical teaching practice. The instruction primarily includes lecture, project-based learning, and direct instruction to teach students what they need to know to pass the state and district exams. Other teaching practices include group projects, teacher modeling, vocabulary activities, and activities using the textbook. Textbook assignments include reading, summarizing, and answering comprehension questions at the end of the chapter.

\section{Participants}

The population chosen for the current study was a convenience sample of students who have chosen to take the CTE elective courses; they were a logical test group that already exists. These students have shown some level of interest in the courses and programs. It is not known if these students have an interest in education or biomedical as career choices. The students were between ninth and 12th grade, and ranged in age from 14 to 18 . All participants were enrolled in at least one out of four levels of the Early Childhood Education courses or biomedical at the time of the current study. There were 356 students enrolled in the Early Childhood program in SCHOOL A ECE 1 and 217 students enrolled in the program at SCHOOL B ECE 2 at the time of the current study. A total sample size of 237 students from SCHOOL A ECE 1 participated in the current study: 81 level 1 students, 64 level 2 students, 46 level 3 students, and 42 level 4 
students. One ECE teacher, besides the teacher-researcher, agreed to be a part of the study. A total sample size of 123 students from SCHOOL B ECE 2 participated in the study: 66 level 1 students, 24 level 2 students, 22 level 3 students, and 11 level 4 students. There was only one teacher who taught ECE in SCHOOL B, and she agreed to participate in the study. There was a total of 541 students enrolled in the biomedical program at the time of the study. A total sample size of 238 students from the biomedical program participated in the current study: 17 level 1 students, 81 level 2 students, 63 level 3 students, and 77 level 4 students. There was a total of 5 teachers in the biomedical academy, but only two teachers agreed to participate in the study (See Appendix F for more school participant information).

\section{Procedures and Data Collection}

The participants were not randomly assigned in the nonequivalent group design, noting that there were significant differences between the groups (e.g., program total students participating or participant levels). It is recognized that, although the two ECE programs have many similarities, they also have significant differences, such as teaching styles, program frameworks, and the total time spent in on-campus clinical teaching practice. To increase the internal validity of the study, the teacher-researcher selected two programs with similarities to help to reduce the possibility of other confounding variables out of the control of the teacher-researcher. A third group was added to determine if the content being taught has any relationship to motivation or teacher identity.

When collecting data, the two instruments were given to each student through a web-based service, Google Forms. On the basis of the observation of the teacherresearcher, high school students feel comfortable giving their answers through their own 
devices that they have accessible. Any participant without a device used one of the classroom computers provided in the room, or a laptop was made available. An administrator who was not the teacher-researcher gave the survey in each setting to reduce bias. The teacher-researcher trained the administrator on how to access and provide the survey to the participants. No grade or reward was given for completing the survey, and participation was entirely voluntary. Before administrating the instruments, an introductory letter from the teacher-researcher was given to each participant asking for their cooperation. The letters explained the study and its importance. The students were asked to review and sign an assent form and parents were asked to review and sign a consent form. Students completed the survey in about 20 minutes.

\section{Data Analysis}

The data were analyzed using SPSS. Fundamental frequencies and descriptive analysis were run for the three programs and the four levels. Some of the analysis run only included the ECE programs because the research questions sought to find the effects of early clinical teaching practice, which the biomedical courses do not have. Descriptive information and frequencies for the instrument scales were collected for each dimension of each instrument (Teacher Identity and MLSQ), as well as for the independent variables (vocational program and program levels). There were some missing data that resulted from students changing schools after the surveys were performed. Some GPA and attendance records were not accessible because of permission restrictions. Cronbach's alpha was calculated to determine the internal consistency of the instrument scales. A two-way MANOVA was used to test if their enrollment in a particular vocational program, which included a higher percentage of time spent in clinical teaching practice, 
affected motivational constructs measured by the MSLQ and the dimensions of teacher identity as measured by the Teacher Identity survey. A two-way MANOVA was also used to determine there were significant differences between the program level the student was in and the dependent factors. A Post Hoc test analyzed the differences between the levels. Analysis of variance (ANOVA) was performed on each dependent variable as a follow-up test for MANOVA but only including the two ECE programs. This, along with $t$-tests, was performed to determine if there were differences between the two ECE programs. Also, a dependent sample $t$-test was performed to compare program completer $\left(12^{\text {th }}\right.$-grade students in level 4) participant's baseline $9^{\text {th }}$ grade, mid-year GPA and attendance record of unexcused absences, with their $12^{\text {th }}$ grade, mid-year GPA and attendance record of unexcused absences, to see if there were any changes in averages and overall student achievement after participating in a teacher preparation program. For this study, a significance level of .05 was set.

\section{Summary}

A quasi-experimental design was utilized to examine the interactions between motivational constructs, teacher identity, student achievement, and the amount of time spent in early clinical teaching practice. Two control groups were chosen to strengthen the validity of the study and examine generalizations of students in vocational programs. The framework used in the intervention group in the study (SCHOOL A ECE 1), incorporates an opportunity for early clinical teaching practice that involves learning new knowledge, application of knowledge, and reflection. The intervention takes place at the high school's on-campus preschool lab. The control group SCHOOL B ECE 2 differs in that it does not have an on-campus preschool, and limited opportunity for clinical 
teaching practice is available for students. In order to fulfill the 480-hour requirement for CDA certification, the students must find an off-campus location to have contact with children 3-5 years old. The experiences vary and are not part of a clinical teaching practice framework (involving perpetual lesson planning, teaching, and reflecting). Both programs share district and school-related similarities, including curricular and certification requirements; they differ in structure. The second control group, SCHOOL A BIO 1, is also a vocational, CTE program, but does not have a teacher education component. They also use a clinical framework component, where students learn and apply new knowledge on and off school campus. The second control group was included to examine student motivation in vocational programs across different contents. The biomedical control group also helped to determine if teacher identity was content-specific or if it was an inherent quality.

The participants were students who chose to take Early Childhood Education courses or biomedical courses as elective classes. The students involved were between $9^{\text {th }}$ and $12^{\text {th }}$ grade and were either in level 1,2 3 or 4 of their respective programs. The participants were a convenience sample. SCHOOL A ECE 1 had 237 participants, and SCHOOL B ECE 2 had 123 participants, and SCHOOL A BIO 1 had a total of 238 participants in this study. Participation was entirely voluntary. Participants were given two questionnaires. The MSLQ and a Teacher Identity survey were made available to the participants through Google Forms, a web-based survey service. Participants were not randomly assigned. 
A quantitative, quasi-experimental design was chosen to complete the study in order to analyze the data and create a foundation for future CTE Education and Training programs. The descriptive data analyzed included frequencies and means. Next, a twoway MANOVA was used to analyze is the participant's enrollment in any of the vocational programs affected any of the motivational constructs of teacher identity. A MANOVA was also used to determine if the level the participant is in affected motivation and teacher identity; a post hoc test was used to analyze the differences between these levels. Next, an ANOVA was performed as a follow-up test to the MANOVA to evaluate the data of each dependent variable. All tests were rerun, along with $t$-tests, to quantify the differences between the two early childhood programs, excluding the biomedical control group. Omitting the biomedical control group from the analysis gave a more exact comparison between the two programs. Finally, $t$-tests were run to compare student GPA and attendance data to examine changes in averages after participating in a teacher preparation program. The biomedical control group was excluded from the analysis because the research questions sought to determine the effects on GPA an attendance after early clinical teaching practice. 


\section{CHAPTER 4}

\section{RESULTS}

The purpose of the current study was to address students' motivation, teacher identity, and student achievement after participating in early clinical teaching practice. This chapter contains the results of the data collected in the current study. The research questions will be answered with the individual results. For each research question, descriptive and frequency information for each dependent variable is presented. Next, MANOVA multivariate test results are discussed as well as each univariate $\mathrm{F}$ test for each motivational construct. Multivariate MANOVA results for the teacher identity are given, and univariate $\mathrm{F}$ tests for each dimension is shown. Then, ANOVA results will be compared, and Post Hoc data will be examined. GPA and attendance data are presented, and $t$-test results are given. Finally, MANOVA and ANOVA results, including only the two ECE programs, will be discussed to draw a direct comparison between the two programs.

To begin, the present study examined differences in motivational constructs and dimensions of teacher identity between three groups. The first group is the intervention group, SCHOOL A ECE $1(\mathrm{n}=233)$. SCHOOL A ECE 1 follows an instructional framework that applies new pedagogical knowledge and reflection through 680 hours of on-campus, early clinical teaching practice. The second group, SCHOOL B ECE 2 (n = 123), follows the state's curricular framework through 480 hours of unstructured, offcampus, observation hours. The third group, SCHOOL A BIO $1(\mathrm{n}=123)$, follows an instructional framework similar to SCHOOL A ECE 1 but applies new knowledge through 620 hours of on and off-campus, clinical medical practice. 
The following were the research questions:

1. What is the impact of a Career and Technical Education program, including time spent in early clinical teaching practice, on student motivation as measured by the Motivated Strategies for Learning Questionnaire (MSLQ), in three programs and across four levels?

2. What is the effect of a Career and Technical Education program, including time spent in early clinical teaching practice, on teacher identity as measured by the Teacher Identity Survey, in three programs and across four levels?

3. What is the effect of a Career and Technical Education program, including time spent in early clinical teaching practice, on program completers,' mid-year, twelfth-grade average GPA as compared to their mid-year ninthgrade average GPA?

4. What is the impact of a Career and Technical Education program, including time spent in early clinical teaching practice, on program completers', mid-year, twelfth-grade average attendance record as compared to their mid-year ninth-grade average attendance record?

Two instruments and the collection of hard data were used to examine these research questions. To answer questions one, the Motivated Strategies for Learning Questionnaire (MSLQ) was given using a 7-point Likert scale to examine the effects of a vocational program that included early clinical teaching practice on the motivational constructs. To answer research question two, a Teacher Identity Survey was given using a 4-point scale to examine the effect of a vocational program that included early clinical 
teaching practice on the dimensions of teacher identity. To answer question three, the mid-year, GPA average of the program completers (12th graders who were in level 4) was compared to their mid-year, GPA average from their $9^{\text {th }}$-grade year to examine if there were any changes in their GPA average after participating in a vocational program that involved early clinical teaching practice. To answer the final research question, the mid-year, attendance average of unexcused absences (12th graders who were in level 4) was compared to their mid-year, attendance average of unexcused absences from their $9^{\text {th }}$-grade year to examine if there were any changes in their attendance average of unexcused absences after participating in a vocational program that involved early clinical teaching practice.

The sample size included 594 high school students, $9^{\text {th }}-12^{\text {th }}$ grade, level 1-4, enrolled in at least one of the three vocational programs in the present study (see Appendix F). Students in the intervention group, SCHOOL A ECE 1, experienced the highest number of hours in early clinical teaching practice. The MSLQ was used to measure what effect, if any, did the intervention have on the motivation of students in SCHOOL A ECE 1, when compared to the control groups, SCHOOL B ECE 2 and SCHOOL A BIO 1. SCHOOL B ECE 2 differs in course structure and framework and does not have an on-campus preschool but teaches the same content. SCHOOL A BIO 1 share many of the same practices, including a high number of clinical teaching practices, but in a health science content. The portion of the MSLQ given to the participants included the following five constructs: intrinsic goal orientation, extrinsic goal orientation, task value effect, learning belief control, and self-efficacy for learning and performance. 


\section{Data Description}

\section{Research Question 1 Results}

What is the impact of a CTE program, including time spent in early clinical teaching practice, on student motivation as measured by the Motivated Strategies for Learning Questionnaire (MSLQ), in three programs and across four levels?

The first research question was designed to investigate whether there was a significant effect of motivation on students who were enrolled in a high school, CTE, vocational, teacher preparation program, that had an on-campus preschool and had the opportunity to immediately apply new pedagogical knowledge through the time spent in early clinical teaching practice. A two-way MANOVA was performed to examine if motivational constructs were effects of participation in these vocational programs and, if so, at what program level. The five MSLQ subscales were taken as dependent variables, and vocational program and program level were taken as the independent variables.

A two-way MANOVA was conducted to determine if the five motivational constructs of the MSLQ (intrinsic goal orientation, extrinsic goal orientation, task value, self-efficacy for learning and performance, and control of learning beliefs) differed significantly according to which vocational program (SCHOOL A ECE 1, SCHOOL B ECE 2, SCHOOL A BIO 1) they were enrolled and at what level (levels 1-4) of the program they were in. A statistically significant MANOVA effect was obtained between vocational programs, Pillais Trace $=.08, F(10,1158)=5.09, p<.01$. The multivariate effect size was estimated at .04, which suggests that $4 \%$ of the variance in the dependent variable was accounted for by vocational program. A significant difference was also illustrated in the MANOVA for the effect of program level on the motivational constructs 
of the MSLQ, Pillais Trace $=.06, F(15,1740)=2.23, p<.05$. The multivariate effect size was estimated at .02 , which suggests that $2 \%$ of the variance in the dependent variable was accounted for by vocational program. These results showed that students in these vocational programs had motivation scale scores that differed depending on the vocational program and what program level they are in. The small effect size may be because of the small, unequal sample size within the groups. Analysis of variance (ANOVA) was conducted on each dependent variable on the MSLQ as a follow-up test for MANOVA. The purpose is to identify the motivational constructs that differ significantly according to vocational program as well as by program level.

Table 4.1

Multivariate test results for independent variables: Vocational Program and Program Levels on MSLQ

\begin{tabular}{|c|c|c|c|c|c|c|}
\hline Effect & $\begin{array}{l}\text { Pillai’s } \\
\text { Trace } \\
\text { Value }\end{array}$ & $F$ & $\begin{array}{c}\text { Hypothesis } \\
\text { df }\end{array}$ & $\begin{array}{l}\text { Error } \\
\quad d f\end{array}$ & Sig. & $\begin{array}{c}\text { Partial } \\
\text { Eta } \\
\text { Squared }\end{array}$ \\
\hline $\begin{array}{l}\text { Vocational } \\
\text { Program }\end{array}$ & .08 & 5.09 & 10 & 1158 & .000 & .04 \\
\hline Program Level & .06 & 2.22 & 15 & 1740 & .004 & .02 \\
\hline $\begin{array}{l}\text { Vocational } \\
\text { Program * Program } \\
\text { Level }\end{array}$ & .06 & 1.13 & 30 & 2910 & .286 & .01 \\
\hline
\end{tabular}

Note: $p<.05$

Univariate ANOVA revealed no significant difference in the first motivational construct, intrinsic goal orientation, according to vocational program $[F(2,582)=.46, p$ $=.63]$. A test of between-subjects effect found a marginally significant difference in intrinsic goal orientation according to program level $[F(3,582)=2.6, p=.05]$. The multivariate effect size was estimated at .01 , which suggests that $1 \%$ of the variance in the dependent variable was accounted for by program levels. In all three programs, level 
4 students had the highest means of intrinsic goal orientation. A pairwise comparison found a significant difference between level 4 students and level 1 students $(p=.01)$ and level 4 students and level 2 students ( $p=.02$ ), but no significant difference was found between level 4 students and level 3 students. A perpetual increase of mean in relation to intrinsic goal orientation was noted from level 1 to level 4.

Table 4.2

ANOVA Between-Subjects Effects of Intrinsic Goal Orientation

\begin{tabular}{lccccc}
\hline Source & $d f$ & MS & $F$ & $p$ & $\begin{array}{c}\text { Effect } \\
\text { Size }\end{array}$ \\
\hline Vocational Program & 2 & .509 & .46 & .631 & .002 \\
Program Level & 3 & 2.825 & 2.56 & .054 & .013 \\
Vocational Program $*$ & 6 & .158 & .14 & .990 & .001 \\
Program Level & 582 & 1.10 & & & \\
Error & & & & & \\
\hline
\end{tabular}

Note: $p<.05$

Table 4.3

ANOVA Vocational Program Comparisons of Intrinsic Goal Orientation

\begin{tabular}{lrcr}
\hline Group & $n$ & Mean & \multicolumn{1}{c}{$S D$} \\
\hline SCHOOL A ECE 1 & 233 & 5.291 & 1.14 \\
SCHOOL B ECE 2 & 123 & 5.316 & .96 \\
SCHOOL A BIO 1 & 238 & 5.459 & 1.00 \\
\hline
\end{tabular}


Table 4.4

ANOVA Program Level Comparisons of Intrinsic Goal Orientation

\begin{tabular}{lrcc}
\hline & \multicolumn{3}{c}{ Vocational Program } \\
\cline { 2 - 4 } Group & SCHOOL A & SCHOOL B & SCHOOL A \\
& ECE 1 $M$ & ECE 2 $M$ & 5.294 \\
\hline Level 1 & 5.176 & 5.235 & 5.330 \\
Level 2 & 5.168 & 5.319 & 5.504 \\
Level 3 & 5.404 & 5.341 & 5.594 \\
Level 4 & 5.575 & 5.750 & 5.459 \\
Total $M$ & 5.290 & 5.316 & \\
\hline
\end{tabular}

Univariate ANOVA revealed no significant difference in the second motivational construct, extrinsic goal orientation according to vocational program $[F(2,582)=.78, p$ $=.46]$, or program level $[F(3,582)=38, p=.78]$ between the three groups. Although the difference was not significant, the mean for level 4 students in SCHOOL A ECE 1 was highest for external goal orientation of all three groups $M=5,976(S D=.90)$.

Table 4.5

ANOVA Between-Subjects Effects of Extrinsic Goal Orientation

\begin{tabular}{lccccc}
\hline Source & $d f$ & MS & $F$ & $p$ & $\begin{array}{c}\text { Effect } \\
\text { Size }\end{array}$ \\
\hline Vocational Program & 2 & .873 & .78 & .459 & .003 \\
Program Level & 3 & .427 & .38 & .767 & .002 \\
Vocational Program * & 6 & 1.509 & 1.34 & .235 & .014 \\
Program Level & 582 & 1.121 & & & \\
Error & & & & & \\
\hline
\end{tabular}

Note: $p<.05$ 
Table 4.6

ANOVA Vocational Program Comparisons of Extrinsic Goal Orientation

\begin{tabular}{lrrr}
\hline Group & $n$ & Mean & \multicolumn{1}{c}{$S D$} \\
\hline SCHOOL A ECE 1 & 233 & 5.976 & .90 \\
SCHOOL B ECE 2 & 123 & 5.272 & 1.32 \\
SCHOOL A BIO 1 & 238 & 5.750 & .95 \\
\hline
\end{tabular}

Table 4.7

ANOVA Program Level Comparisons of Extrinsic Goal Orientation

\begin{tabular}{lccc}
\hline & \multicolumn{3}{c}{ Vocational Program } \\
\cline { 2 - 4 } Group & SCHOOL A & SCHOOL B & SCHOOL A \\
& ECE 1 $M$ & ECE 2 $M$ & 5.868 \\
\hline Level 1 & 5.611 & 5.814 & 5.803 \\
Level 2 & 5.621 & 5.458 & 5.575 \\
Level 3 & 5.598 & 5.739 & 5.750 \\
Level 4 & 5.976 & 5.272 & 5.730 \\
Total $M$ & 5.677 & 5.683 & \\
\hline
\end{tabular}

Univariate ANOVA revealed a marginally significant difference in the third motivational construct, task value effect according to vocational program $[F(2,582)=$ $5.3, p=.005, \eta 2=.02]$, and program level $[F(3,582)=5.8, p=.001, \eta 2=.03] . \mathrm{A}$ pairwise comparison found a significant difference between SCHOOL B ECE $2 M$ $=6.146(S D=.85)$, and SCHOOL A ECE $1 M=5.992(S D=1.03)$ at $p=.051$. There was also a significant difference between SCHOOL A ECE $1 M=5.992(S D=1.03)$ and SCHOOL A BIO $1 M=6.364(S D=.82)$, resulting in SCHOOL A ECE 1 having the lowest means of all three programs for task value effect. In regard to program levels, a 
pairwise comparison found a significant difference between level 4 students and level 1 students $(p=.000)$, and level 4 students and level 2 students $(p=.001)$, but no significant difference was found between level 4 students and level 3 students. There was also a significant difference between level three students and level 1 students $(p=.02)$ and level 2 students $(p=.05)$. There were no significant differences between level 1 and 2 students in regard to task value effect.

Table 4.8

ANOVA Between-Subjects Effects of Task Value Effect

\begin{tabular}{lccccc}
\hline Source & $d f$ & MS & $F$ & $p$ & $\begin{array}{c}\text { Effect } \\
\text { Size }\end{array}$ \\
\hline Vocational Program & 2 & 4.23 & 5.25 & .005 & .018 \\
Program Level & 3 & 4.69 & 5.82 & .001 & .029 \\
$\begin{array}{l}\text { Vocational Program * } \\
\text { Program Level }\end{array}$ & 6 & .833 & 1.03 & .402 & .011 \\
Error & 582 & 1.121 & & & \\
\hline
\end{tabular}

Note: $p<.05$

Table 4.9

ANOVA Vocational Program Comparisons of Task Value Effect

\begin{tabular}{lrlr}
\hline Group & $n$ & Mean & \multicolumn{1}{c}{$S D$} \\
\hline SCHOOL A ECE 1 & 233 & 5.992 & 1.03 \\
SCHOOL B ECE 2 & 123 & 6.146 & .84 \\
SCHOOL A BIO 1 & 238 & 6.364 & .82 \\
\hline
\end{tabular}


Table 4.10

ANOVA Program Level Comparisons of Task Value Effect

\begin{tabular}{lccc}
\hline & \multicolumn{3}{c}{ Vocational Program } \\
\cline { 2 - 4 } Group & SCHOOL A & SCHOOL B & SCHOOL A \\
& ECE 1 $M$ & ECE 2 $M$ & \\
\hline Level 1 & 5.770 & 5.998 & 5.998 \\
Level 2 & 5.813 & 6.125 & 6.125 \\
Level 3 & 6.246 & 6.349 & 6.349 \\
Level 4 & 6.417 & 6.682 & 6.682 \\
Total $M$ & 5.992 & 6.146 & 6.146 \\
\hline
\end{tabular}

Univariate ANOVA revealed no significant difference in the fourth motivational construct, control of learning beliefs according to vocational program $[F(2,582)=.55, p$ $=.58]$. Although, a test of between-subjects effect found a significant difference in control of learning beliefs $[F(3,582)=4.2, p=.006, \eta 2=.02]$ according to program level. A pairwise comparison found a significant difference between level 4 students and level 1 students $(p=.004)$, and level 2 students $(p=.002)$, but no significant difference was found between level 4 students and level 3 students. Level 4 students had a significantly higher mean than level 1 and 2 students. No other significant differences were found between the other levels in regard to control of learning beliefs. 
Table 4.11

ANOVA Between-Subjects Effects of Control of Learning Beliefs

\begin{tabular}{lccccc}
\hline Source & $d f$ & MS & $F$ & $p$ & $\begin{array}{c}\text { Effect } \\
\text { Size }\end{array}$ \\
\hline Vocational Program & 2 & 5.15 & .52 & .576 & .002 \\
Program Level & 3 & 3.96 & 4.24 & .006 & .021 \\
Vocational Program * & 6 & .931 & .99 & .426 & .010 \\
Program Level & 582 & .933 & & & \\
Error & & & & & \\
\hline
\end{tabular}

Note: $p<.05$

Table 4.12

ANOVA Vocational Program Comparisons of Control of Learning Beliefs

\begin{tabular}{lrcc}
\hline Group & $n$ & Mean & $S D$ \\
\hline SCHOOL A ECE 1 & 233 & 5.702 & 1.0 \\
SCHOOL B ECE 2 & 123 & 5.574 & .96 \\
SCHOOL A BIO 1 & 238 & 5.690 & .96 \\
\hline
\end{tabular}

Table 4.13

ANOVA Program Level Comparisons of Control of Learning Beliefs

\begin{tabular}{lccc}
\hline & \multicolumn{3}{c}{ Vocational Program } \\
\cline { 2 - 4 } Group & SCHOOL A & SCHOOL B & SCHOOL A \\
& ECE 1 $M$ & ECE 2 $M$ & \\
\hline Level 1 & 5.618 & 5.553 & 5.382 \\
Level 2 & 5.570 & 5.389 & 5.525 \\
Level 3 & 5.972 & 5.568 & 5.651 \\
Level 4 & 5.768 & 6.114 & 5.964 \\
Total $M$ & 5.702 & 5.574 & 5.690 \\
\hline
\end{tabular}


Univariate ANOVA revealed a significant difference in the fifth motivational construct, self-efficacy for learning and performance according to vocational program $[F$ $(2,582)=4.1, p=.02, \eta 2=.01]$. There was no significant difference found in selfefficacy for learning and performance and program level $[F(3,582)=.51, p=.68]$. A pairwise comparison found a significant difference between SCHOOL A BIO 1 (M $=5.908(S D=.91)$, and SCHOOL A ECE $1 M=6.132(S D=.84)$ at $p=.006$. There was also a significant difference between SCHOOL B ECE $2 M=6.139(S D=.68)$ and SCHOOL A BIO $1 M=5.908(S D=.91)$, resulting in SCHOOL A BIO 1 having the lowest means of all three programs for self-efficacy for learning and performance.

Table 4.14

ANOVA Between-Subjects Effects of Self-Efficacy for Learning and Performance

\begin{tabular}{lccccc}
\hline Source & $d f$ & MS & $F$ & $p$ & $\begin{array}{c}\text { Effect } \\
\text { Size }\end{array}$ \\
\hline Vocational Program & 2 & 2.88 & 4.11 & .017 & .014 \\
Program Level & 3 & .358 & .510 & .676 & .003 \\
Vocational Program * & 6 & .707 & 1.01 & .420 & .010 \\
Program Level & 582 & .933 & & & \\
Error & & & & & \\
\hline
\end{tabular}

Note: $p<.05$

Table 4.15

ANOVA Vocational Program Comparisons of Self-Efficacy for Learning and Performance

\begin{tabular}{lrcc}
\hline Group & $n$ & Mean & $S D$ \\
\hline SCHOOL A ECE 1 & 233 & 60133 & .84 \\
SCHOOL B ECE 2 & 123 & 6.139 & .67 \\
SCHOOL A BIO 1 & 238 & 5.908 & .91 \\
\hline
\end{tabular}


Table 4.16

ANOVA Program Level Comparisons of Self-Efficacy for Learning and Performance

\begin{tabular}{lccc}
\hline & \multicolumn{3}{c}{ Vocational Program } \\
\cline { 2 - 4 } Group & SCHOOL A & SCHOOL B & SCHOOL A \\
& ECE 1 $M$ & ECE 2 $M$ & 6.007 \\
\hline Level 1 & 5.993 & 6.171 & 5.864 \\
Level 2 & 6.084 & 6.083 & 5.847 \\
Level 3 & 6.370 & 6.034 & 5.982 \\
Level 4 & 6.217 & 6.284 & 5.908 \\
Total $M$ & 6.133 & 6.139 & \\
\hline
\end{tabular}

$T$-test analysis was also performed to directly compare the means for each motivational construct for the two early childhood programs, in isolation, excluding SCHOOL A BIO 1. There was a significant difference in the means for intrinsic goal orientation between SCHOOL A ECE 1 and SCHOOL B ECE $2(t 283.503=-.248, p=$ .804). The average mean for SCHOOL B ECE 2 was $\mathrm{M}=5.316(S D=.9659)$, higher than SCHOOL A ECE $1 \mathrm{M}=5.2880(S D=1.13)$. There was a significant difference in the means for extrinsic goal orientation between SCHOOL A ECE 1 and SCHOOL B ECE $2(t 211.680=-.053, p=.958)$. The average mean for SCHOOL B ECE 2 was $\mathrm{M}=$ $5.6829(S D=1.22)$, higher than SCHOOL A ECE $1 M=5.6762(S D=1.01)$. There was a significant difference in the means for task value effect between SCHOOL A ECE 1 and SCHOOL B ECE $2(t 291.950=-1.46, p=.145)$. The average mean for SCHOOL B ECE 2 was $M=6.1463(S D=.85)$, higher than SCHOOL A ECE $1 M=5.9982(S D=$ 1.02). There was no significant difference in the means for control of learning beliefs $(t 358=1.12, \mathrm{p}=.264)$. There was a significant difference in the means for self-efficacy 
for learning and performance between SCHOOL A ECE 1 and SCHOOL B ECE 2 $(t 295.202=-.009, p=.993)$. The average mean for SCHOOL B ECE 2 was $M=6.1392$ $(S D=.67)$, higher than SCHOOL A ECE $1 M=6.1385(S D=.84)$. These results show that the participants from SCHOOL B ECE 2 show higher means in all motivational constructs than SCHOOL A ECE 1, except control of learning beliefs. According to Levene's Test for equality of variances, this study violates the assumption of homogeneity based on SPSS; these results include data of equal variances not assumed.

Table 4.17

Independent Samples t-test and group statistics for motivational scales of the MSLQ by Vocational Program

\begin{tabular}{|c|c|c|c|c|c|c|c|}
\hline $\begin{array}{c}\text { Motivational } \\
\text { Construct }\end{array}$ & $\begin{array}{l}\text { Vocational } \\
\text { Program }\end{array}$ & $n$ & $M$ & $S D$ & $t$ & $d f$ & $p$ \\
\hline \multirow{2}{*}{$\begin{array}{l}\text { Intrinsic Goal } \\
\text { Orientation }\end{array}$} & $\begin{array}{c}\text { SCHOOL A } \\
\text { ECE } 1\end{array}$ & 237 & 5.288 & 1.13 & $-.248 *$ & 283.503 & .804 \\
\hline & $\begin{array}{l}\text { SCHOOL B } \\
\text { ECE } 2\end{array}$ & 123 & 5.316 & .97 & & & \\
\hline \multirow{2}{*}{$\begin{array}{l}\text { Extrinsic Goal } \\
\text { Orientation }\end{array}$} & $\begin{array}{c}\text { SCHOOL A } \\
\text { ECE } 1\end{array}$ & 237 & 5.676 & 1.01 & $-.053 *$ & 211.68 & .958 \\
\hline & $\begin{array}{l}\text { SCHOOL B } \\
\text { ECE } 2\end{array}$ & 123 & 5.683 & 1.22 & & & \\
\hline \multirow{2}{*}{$\begin{array}{l}\text { Task Value } \\
\text { Effect }\end{array}$} & $\begin{array}{c}\text { SCHOOL A } \\
\text { ECE } 1\end{array}$ & 237 & 5.998 & 1.03 & $-1.46^{*}$ & 291.95 & .145 \\
\hline & $\begin{array}{l}\text { SCHOOL B } \\
\text { ECE } 2\end{array}$ & 123 & 6.146 & .84 & & & \\
\hline \multirow{2}{*}{$\begin{array}{l}\text { Control of } \\
\text { Learning } \\
\text { Beliefs }\end{array}$} & $\begin{array}{c}\text { SCHOOL A } \\
\text { ECE } 1\end{array}$ & 237 & 5.698 & 1.01 & 1.12 & 358 & .264 \\
\hline & $\begin{array}{c}\text { SCHOOL B } \\
\text { ECE } 2\end{array}$ & 123 & 5.574 & .96 & & & \\
\hline \multirow{2}{*}{$\begin{array}{l}\text { Self-Efficacy } \\
\text { for Learning } \\
\text { and } \\
\text { Performance }\end{array}$} & $\begin{array}{c}\text { SCHOOL A } \\
\text { ECE } 1\end{array}$ & 237 & 6.139 & .84 & $-.009 *$ & 295.20 & .993 \\
\hline & $\begin{array}{l}\text { SCHOOL B } \\
\text { ECE } 2\end{array}$ & 123 & 6.139 & .67 & & & \\
\hline
\end{tabular}




\section{Research Question 2 Results}

What is the effect of a CTE program, including time spent in early clinical teaching practice, on teacher identity as measured by the Teacher Identity Survey, in three programs and across four levels?

The second research question was designed to examine if there was a significant effect of teacher identity development in students who were enrolled in a high school CTE, vocational, teacher preparation program, that had an on-campus preschool and had the opportunity to immediately apply new pedagogical knowledge through the time spent in early clinical teaching practice. A two-way MANOVA was performed to examine if four dimensions of teacher identity were effects of participation in these vocational programs and, if so, at what program level. The four teacher identity dimensions were taken as dependent variables, and vocational program and program level were taken as the independent variables.

A two-way MANOVA was conducted to determine if the four dimensions of teacher identity (recognition, interest, performance, and competency) differed significantly according to which vocational program (SCHOOL A ECE 1, SCHOOL B ECE 2, SCHOOL A BIO 1) they were enrolled and at what level (levels 1-4) of the program they were in. A statistically significant MANOVA effect was obtained between vocational programs, Pillais Trace $=.18, F(8,1156)=14.13, p<.05$. The multivariate effect size was estimated at .09, which suggests that $9 \%$ of the variance in the dependent variable was accounted for by vocational program. A significant difference was also illustrated in the MANOVA for the effect of program level on the dimensions of teacher identity, Pillais Trace $=.04, F(12,1737)=2.0, p<.05$. The multivariate effect size was 
estimated at .01 , which suggests that $1 \%$ of the variance in the dependent variable was accounted for by vocational program. These results showed that students in these vocational programs had teacher identity scale scores that differed depending on the vocational program and what program level they are in. The small effect size may be because of the small, unequal sample size within the groups. Analysis of variance (ANOVA) was conducted on each dependent variable on the teacher identity framework as a follow-up test for MANOVA. The purpose is to identify the dimensions of teacher identity that differ significantly according to vocational program as well as by program level.

Table 4.18

Multivariate test results for independent variables: Vocational Program and Program Levels on Teacher Identity Survey

\begin{tabular}{lcccccc}
\hline Effect & $\begin{array}{c}\text { Pillai's } \\
\text { Trace } \\
\text { Value }\end{array}$ & $F$ & $\begin{array}{c}\text { Hypothesis } \\
\mathrm{df}\end{array}$ & $\begin{array}{c}\text { Error } \\
d f\end{array}$ & $\begin{array}{c}\text { Sig. } \\
\text { Partial } \\
\text { Eta } \\
\text { Squared }\end{array}$ \\
\hline $\begin{array}{l}\text { Vocational } \\
\text { Program }\end{array}$ & .18 & 14.12 & 8 & 1156 & .000 & .09 \\
$\begin{array}{l}\text { Program Level } \\
\begin{array}{l}\text { Vocational } \\
\text { Program * Program } \\
\text { Level }\end{array}\end{array}$ & .04 & 1.96 & 12 & 1737 & .024 & .01 \\
\end{tabular}

Note: $p<.05$

Univariate ANOVA revealed significant differences in the first dimension of teacher identity, recognition according to vocational program $[F(2,580)=.41 .8, p=$ $.000, \eta 2=.13$ ]. A pairwise comparison found significant differences between SCHOOL A ECE $1 M=2.985(S D=.81)$ and SCHOOL B ECE $2 M=2.653(S D=.83)$ at $p=.000$. as well as with SCHOOL A BIO $1 M=2.228(S D=.80)$ at $p=.05$. These results show that SCHOOL A ECE 1 has a higher teacher identity recognition mean than the two 
control groups. There is also a significant difference between SCHOOL B ECE $2 M$ $=2.653(S D=.83)$ and SCHOOL A BIO1 $M=2.228(S D=.80)$. These results show that SCHOOL A BIO 1 has the lowest mean for teacher identity recognition.

Table 4.19

ANOVA Between-Subjects Effects of Teacher Identity Recognition

\begin{tabular}{lccccc}
\hline Source & $d f$ & MS & $F$ & $p$ & $\begin{array}{c}\text { Effect } \\
\text { Size }\end{array}$ \\
\hline Vocational Program & 2 & 26.28 & 41.84 & .000 & .13 \\
Program Level & 3 & 3.49 & 5.56 & .001 & .03 \\
$\begin{array}{l}\text { Vocational Program * } \\
\text { Program Level }\end{array}$ & 6 & 1.91 & 3.04 & .006 & 0.3 \\
Error & 580 & .63 & & & \\
\hline
\end{tabular}

Note: $p<.05$

Table 4.20

ANOVA Vocational Program Comparisons of Teacher Identity Recognition

\begin{tabular}{lccc}
\hline Group & $n$ & Mean & $S D$ \\
\hline SCHOOL A ECE 1 & $233_{\mathrm{b}, \mathrm{c}}$ & 2.98 & .81 \\
SCHOOL B ECE 2 & $122_{\mathrm{a}, \mathrm{c}}$ & 2.6 & .83 \\
SCHOOL A BIO 1 & $237_{\mathrm{a}, \mathrm{b}}$ & 2.22 & .80
\end{tabular}

Note: Shared subscripts represent statistically significant differences: $p<.05$

A test of between-subjects' effects also found a significant difference in teacher identity recognition according to program level across the three groups $[F(3,580)=5.56$, $p=.001, \eta 2=.03]$. A significant difference was found between level 4 and level 1 students $(p=.005)$ and level 2 students $(p=.001)$. There was a also a significant difference found between level 3 students and level 1 students $(p=.03)$ and level 2 students $(p=.005)$. There was no significant difference found between level 3 and level 
4 students. Level 4 students had the highest mean for teacher identity recognition of all for levels. A test of between-subjects' effects also found an interaction between the two independent variables (vocational program and program level) and this interaction effect is significant on teacher identity recognition $[F(6,580)=3.0, P=.006, \eta 2=.03)$.

Table 4.20.1

ANOVA Program Level Comparisons of Teacher Identity Dimension: Recognition

\begin{tabular}{lccc}
\hline & \multicolumn{3}{c}{ Vocational Program } \\
\cline { 2 - 4 } Group & SCHOOL A & SCHOOL B & SCHOOL A \\
& ECE 1 $M$ & ECE 2 $M$ & BIO 1 $M$ \\
\hline Level 1 & 2.781 & 2.443 & 2.559 \\
Level 2 & 2.891 & 2.573 & 2.138 \\
Level 3 & 3.255 & 3.083 & 2.152 \\
Level 4 & 3.226 & 3.273 & 2.312 \\
Total $M$ & 2.985 & 2.654 & 2.228 \\
\hline
\end{tabular}

Univariate ANOVA revealed significant differences in the second dimension of teacher identity, interest according to vocational program $[F(2,580)=40.3, p=.000, \eta 2$ $=.12]$. A pairwise comparison found significant differences between SCHOOL A ECE 1 $M=3.169(S D=.74)$ and SCHOOL B ECE $2 M=2.797(S D=.85)$ at $p=.000$, as well as with SCHOOL A BIO $1 M=2.416(S D=.84)$ at $p=.04$. These results show that SCHOOL A ECE 1 has a higher teacher identity interest mean than the two control groups. There is also a significant difference between SCHOOL B ECE $2 M=2.797$ (SD $=.85)$ and SCHOOL A BIO1 $M=2.416(S D=.84)$ at $p=.000$. These results show that SCHOOL A BIO 1 has the lowest mean for teacher identity interest. 
Table 4.21

ANOVA Between-Subjects Effects of Teacher Identity Interest

\begin{tabular}{lccccc}
\hline Source & $d f$ & MS & $F$ & $p$ & $\begin{array}{c}\text { Effect } \\
\text { Size }\end{array}$ \\
\hline Vocational Program & 2 & 25.27 & 40.33 & .000 & .12 \\
Program Level & 3 & 2.96 & 4.72 & .003 & .02 \\
$\begin{array}{l}\text { Vocational Program } \\
\text { Program Level }\end{array}$ & 6 & 1.50 & 2.40 & .029 & 0.2 \\
Error & 580 & .63 & & & \\
\hline
\end{tabular}

Note: $p<.05$

Table 4.22

ANOVA Vocational Program Comparisons of Teacher Identity Interest

\begin{tabular}{lccc}
\hline Group & $n$ & Mean & $S D$ \\
\hline SCHOOL A ECE 1 & $233_{\mathrm{b}, \mathrm{c}}$ & 3.20 & .74 \\
SCHOOL B ECE 2 & $122_{\mathrm{a}, \mathrm{c}}$ & 2.80 & .86 \\
SCHOOL A BIO 1 & $237_{\mathrm{a}, \mathrm{b}}$ & 2.40 & .83
\end{tabular}

Note: Shared subscripts represent statistically significant differences: $p<.05$

A test of between-subjects' effects also found a significant difference in teacher identity interest according to program level $[F(3,580)=4.7, p=.003, \eta 2=.02]$. A significant difference was found between level 4 and level 1 students $(p=.005)$ and level 2 students $(p=.000)$. There was a also a significant difference found between level 3 students and level 2 students $(p=.04)$. There was no significant difference found between level 3 and level 4 students. A test of between-subjects' effects also found a significant interaction between the independent variables (vocational program and program level) and teacher identity interest $[F(6,580)=2.3, p=.03, \eta 2=.02)$. 
Table 4.22.1

ANOVA Program Level Comparisons of Teacher Identity Dimension: Interest

\begin{tabular}{lccc}
\hline & \multicolumn{3}{c}{ Vocational Program } \\
\cline { 2 - 4 } Group & SCHOOL A & SCHOOL B & SCHOOL A \\
& ECE 1 $M$ & ECE 2 $M$ & BIO 1 $M$ \\
\hline Level 1 & 3.065 & 2.599 & 2.691 \\
Level 2 & 3.070 & 2.750 & 2.313 \\
Level 3 & 3.337 & 3.107 & 2.321 \\
Level 4 & 3.339 & 3.500 & 2.542 \\
Total $M$ & 3.170 & 2.797 & 2.417 \\
\hline
\end{tabular}

Univariate ANOVA revealed significant differences in the third dimension of teacher identity, performance according to vocational program $[F(2,580)=55.1, p=$ $.000, \eta 2=.16]$. A pairwise comparison found significant differences between SCHOOL A ECE $1 M=3.049(S D=.84)$ and SCHOOL B ECE $2 M=2.5164(S D=.92)$ at $p=$ .002 , as well as with SCHOOL A BIO $1 M=2.080(S D=.91)$ at $p=.000$. These results show that SCHOOL A ECE 1 has a higher teacher identity performance mean than the two control groups. There is also a significant difference between SCHOOL B ECE $2 M$ $=2.5164(S D=.92)$ and SCHOOL A BIO1 $M=2.080(S D=.91)$ at $p=.000$. These results show that SCHOOL A BIO 1 has the lowest mean for teacher identity performance. 
Table 4.23

ANOVA Between-Subjects Effects of Teacher Identity Performance

\begin{tabular}{lccccc}
\hline Source & $d f$ & MS & $F$ & $p$ & $\begin{array}{c}\text { Effect } \\
\text { Size }\end{array}$ \\
\hline Vocational Program & 2 & 41.23 & 55.08 & .000 & .16 \\
Program Level & 3 & 2.50 & 3.30 & .020 & .02 \\
Vocational Program * & 6 & 2.84 & 3.8 & .001 & 0.4 \\
Program Level & 580 & .75 & & & \\
Error & & & & & \\
\hline
\end{tabular}

Note: $p<.05$

Table 4.24

ANOVA Vocational Program Comparisons of Teacher Identity Performance

\begin{tabular}{lccc}
\hline Group & $n$ & Mean & $S D$ \\
\hline SCHOOL A ECE 1 & $233_{\mathrm{b}, \mathrm{c}}$ & 3.05 & .84 \\
SCHOOL B ECE 2 & $122_{\mathrm{a}, \mathrm{c}}$ & 2.52 & .91 \\
SCHOOL A BIO 1 & $237_{\mathrm{a}, \mathrm{b}}$ & 2.08 & .92
\end{tabular}

Note: Shared subscripts represent statistically significant differences: $p<.05$

A test of between-subjects' effects also found a significant difference in teacher identity performance according to program level $[F(3,580)=3.3, p=.02, \eta 2=.02]$. A pairwise comparison found a significant difference between level 4 and level 1 students $(p=.005)$ and level 2 students $(p=.009)$. There were no other significant differences between the other levels. A test of between-subjects' effects also found a significant interaction between the independent variables (vocational program and program level) and teacher identity performance $[F(6,580)=3.8, P=.001, \eta 2=.04)$. 
Table 4.24.1

ANOVA Program Level Comparisons of Teacher Identity Dimension: Performance

\begin{tabular}{lccc}
\hline & \multicolumn{3}{c}{ Vocational Program } \\
\cline { 2 - 4 } Group & SCHOOL A & SCHOOL B & SCHOOL A \\
& ECE 1 $M$ & ECE 2 $M$ & BIO 1 $M$ \\
\hline Level 1 & 2.809 & 2.258 & 2.471 \\
Level 2 & 3.109 & 2.458 & 2.081 \\
Level 3 & 3.207 & 3.000 & 1.913 \\
Level 4 & 3.250 & 3.272 & 2.130 \\
Total $M$ & 3.049 & 2.516 & 2.080 \\
\hline
\end{tabular}

Univariate ANOVA revealed significant differences in the fourth dimension of teacher identity, competence according to vocational program $[F(2,581)=41.0, p=$ $.000, \eta 2=.12]$. A pairwise comparison found significant differences between SCHOOL A ECE $1 M=3.112(S D=.73)$ and SCHOOL B ECE $2 M=2.704(S D=.82)$ at $p=.008$, as well as with SCHOOL A BIO $1 M=2.376(S D=.84)$ at $p=.000$. These results show that SCHOOL A ECE 1 has a higher teacher identity competence mean than the two control groups. There is also a significant difference between SCHOOL B ECE $2 M$ $=2.704(S D=.82)$ and SCHOOL A BIO $1 M=2.376(S D=.84)$ at $p=.000$. These results show that SCHOOL A BIO 1 has the lowest mean for teacher identity competence. 
Table 4.25

ANOVA Between-Subjects Effects of Teacher Identity Competence

\begin{tabular}{lccccc}
\hline Source & $d f$ & MS & $F$ & $p$ & $\begin{array}{c}\text { Effect } \\
\text { Size }\end{array}$ \\
\hline Vocational Program & 2 & 25.29 & 41.01 & .000 & .12 \\
Program Level & 3 & 1.82 & 2.95 & .032 & .02 \\
Vocational Program * & 6 & 1.25 & 2.03 & .060 & .02 \\
Program Level & 581 & .617 & & & \\
Error & & & & & \\
\hline
\end{tabular}

Note: $p<.05$

Table 4.26

ANOVA Vocational Program Comparisons of Teacher Identity Competence

\begin{tabular}{lccc}
\hline Group & $n$ & Mean & $S D$ \\
\hline SCHOOL A ECE 1 & $233_{\mathrm{b}, \mathrm{c}}$ & 3.11 & .73 \\
SCHOOL B ECE 2 & $122_{\mathrm{a}, \mathrm{c}}$ & 2.70 & .82 \\
SCHOOL A BIO 1 & $237_{\mathrm{a}, \mathrm{b}}$ & 2.38 & .82
\end{tabular}

Note: Shared subscripts represent statistically significant differences: $p<.05$

A test of between-subjects' effects also found a significant difference in teacher identity performance according to program level $[F(3,581)=2.9, p=.03, \eta 2=.02]$. A pairwise comparison found a significant difference between level 4 and level 1 students $(p=.005)$ and level 2 students $(p=.03)$. There were no other significant differences between the other levels. A test of between-subjects' effects also found a marginal interaction between the independent variables (vocational program and program level) and teacher identity performance $[F(6,581)=2.0, P=.06, \eta 2=.02]$. 
Table 4.26.1

ANOVA Program Level Comparisons of Teacher Identity Dimension: Competence

\begin{tabular}{cccc}
\hline & \multicolumn{3}{c}{ Vocational Program } \\
\cline { 2 - 4 } Group & SCHOOL A & SCHOOL B & SCHOOL A \\
& ECE 1 $M$ & ECE 2 $M$ & BIO 1 M \\
\hline Level 1 & 2.920 & 2.480 & 2.588 \\
Level 2 & 3.109 & 2.792 & 2.371 \\
Level 3 & 3.246 & 3.000 & 2.291 \\
Level 4 & 3.341 & 3.272 & 2.407 \\
Total $M$ & 3.112 & 2.705 & 2.377 \\
\hline
\end{tabular}

$T$-test analysis was also performed to directly compare the means for each of the dimensions of the teacher identity framework, for the two early childhood programs, in isolation, excluding SCHOOL A BIO 1. There was a significant difference in the means for recognition between SCHOOL A ECE 1 and SCHOOL B ECE $2(t 357=3.62 p<$ $.05)$. The average mean for SCHOOL A ECE 1 was $M=2.9852(S D=.81)$, higher than SCHOOL B ECE $2 M=2.6537(S D=.83)$. There was a significant difference in the means for interest between SCHOOL A ECE 1 and SCHOOL B ECE $2(t 214.548=4.0$, $p<.05)$. The average mean for SCHOOL A ECE 1 was $M=3.1677(S D=.74)$, higher than SCHOOL B ECE $2 M=2.7971(S D=.86)$. There was a significant difference in the means for performance between SCHOOL A ECE 1 and SCHOOL B ECE 2 ( $t 357=5.6$, $p<.05)$. The average mean for SCHOOL A ECE 1 was $M=3.0549(S D=.84)$, higher than SCHOOL B ECE $2 M=2.5164(S D=.92)$. There was a significant difference in the means for competence between SCHOOL A ECE 1 and SCHOOL B ECE $2(t 358=4.8, p$ 
$=.13)$. The average mean for SCHOOL A ECE 1 was $M=3.1160(S D=.73)$, higher than SCHOOL B ECE $2 M=2.7046(S D=.82)$. These results show that SCHOOL A ECE 1 had a significantly higher mean for all the dimensions of the teacher identity framework; therefore, the participants of SCHOOL A ECE 1 have a higher teacher identity than the participants in SCHOOL B ECE 2. According to Levene's Test for equality of variances, this study violates the assumption of homogeneity based on SPSS; these results include data of equal variances not assumed.

Table 4.27

Independent Samples t-test and group statistics for dimensions of the Teacher Identity Survey by Vocational Program

\begin{tabular}{cccccccc}
\hline $\begin{array}{c}\text { Teacher } \\
\text { Identity } \\
\text { Dimension }\end{array}$ & $\begin{array}{c}\text { Vocational } \\
\text { Program }\end{array}$ & $n$ & $M$ & $S D$ & $t$ & $d f$ & $p$ \\
\hline Recognition & $\begin{array}{c}\text { SCHOOL A ECE } \\
1\end{array}$ & 237 & 2.985 & .81 & 3.62 & 357 & .000 \\
& $\begin{array}{c}\text { SCHOOL B ECE } \\
2\end{array}$ & 122 & 2.653 & .83 & & & \\
& $\begin{array}{c}\text { SCHOOL A ECE } \\
1\end{array}$ & 237 & 3.167 & .74 & $4.06^{*}$ & 214.548 & .000 \\
Interest & $\begin{array}{c}\text { SCHOOL B ECE } \\
2\end{array}$ & 122 & 2.797 & .86 & & & \\
& $\begin{array}{c}1 \\
\text { SCHOOL A ECE }\end{array}$ & 237 & 3.055 & .84 & 5.58 & 357 & .000 \\
Performance & $\begin{array}{c}\text { SCHOOL B ECE } \\
2\end{array}$ & 122 & 2.516 & .92 & & & \\
& $\begin{array}{c}\text { SCHOOL A ECE } \\
1\end{array}$ & 237 & 3.116 & 73 & 4.84 & 358 & .000 \\
Competence & SCHOOL B ECE & 123 & 2.704 & .81 & & & \\
\hline
\end{tabular}

Notes: $* p<0.05$ and violates the assumption of homogeneity according to SPSS. 


\section{Research Question 3 Results}

What is the effect of a CTE program, including time spent in early clinical teaching practice, on program completers, ' mid-year, twelfth-grade average GPA as compared to their mid-year ninth-grade average GPA?

The third research question was designed to examine if there was a significant difference in overall student achievement, according to their GPA, in students who were enrolled in a high school CTE, vocational, teacher preparation program, that had an oncampus preschool and the opportunity for early clinical teaching practice. A dependent $t$ test analysis was performed to directly compare the means of the average mid-year GPA of program completers' in $12^{\text {th }}$ grade and their mid-year GPA in $9^{\text {th }}$ grade. For research question 3, only the two early childhood programs were compared. The biomedical control group was excluded to assure a measurement that included participants who participate in early clinical teaching practice. There was a significant difference in the average mid-year GPA from $9^{\text {th }}$ grade to $12^{\text {th }}$ grade in SCHOOL A ECE $1(t 39=2.7, p=$ .01 ). The average mid-year GPA mean for SCHOOL A ECE 1 in $9^{\text {th }}$ grade was $M=3.0$ $(S D=.67)$, which was lower than their $12^{\text {th }}$-grade average mid-year GPA, which was $M$ $=3.2(S D=.54)$. A repeated measure mixed design analysis was also conducted and did not find significant results. 
Table 4.28

Paired Samples T-test to compare $9^{\text {th }}$ and $12^{\text {th }}$ grade GPA Mid-year for SCHOOL A ECE 1

\begin{tabular}{lccccc}
\hline Group & $n$ & $M$ & $S D$ & $\begin{array}{c}\text { Std. Error } \\
M\end{array}$ & $t$-test \\
\hline $\begin{array}{l}9^{\mathrm{TH}} \text { Grade Mid-year } \\
\text { GPA }\end{array}$ & 40 & 3.04 & .68 & .1074 & $-.2 .70^{*}$ \\
$\begin{array}{l}12^{\mathrm{TH}} \text { Grade Mid- } \\
\text { year GPA }\end{array}$ & 40 & 3.21 & .54 & .0851 & \\
& & & & & \\
\end{tabular}

Note: ${ }^{*} p<.05$

There was also a significant difference in average mid-year GPA from $9^{\text {th }}$ grade to $12^{\text {th }}$ grade in SCHOOL B ECE $2(t 7=3.7, p=.007)$. The average mid-year GPA mean for SCHOOL B ECE 2 in $9^{\text {th }}$ grade was $M=2.6(S D=.23)$, which was lower than their $12^{\text {th }}$-grade average mid-year GPA, which was $M=2.9(S D=.30)$. These results show that students in SCHOOL B ECE 2 showed some improvement in average GPA between $9^{\text {th }}$ and $12^{\text {th }}$ grade. These results show that participants of both programs showed a significant increase in GPA from $9^{\text {th }}$ to $12^{\text {th }}$ grade.

Table 4.29

Paired Samples T-test to compare $9^{\text {th }}$ and $12^{\text {th }}$-grade Mid-year GPA for SCHOOL B ECE 2

\begin{tabular}{lccccc}
\hline Group & $n$ & $M$ & $S D$ & $\begin{array}{c}\text { Std. Error } \\
M\end{array}$ & $t$-test \\
\hline $\begin{array}{l}9^{\mathrm{TH}} \text { Grade Mid-year } \\
\text { GPA }\end{array}$ & 8 & 2.60 & .23 & .0800 & $-.3 .72 *$ \\
$\begin{array}{l}12^{\mathrm{TH}} \text { Grade Mid- } \\
\text { year GPA }\end{array}$ & 8 & 3.00 & .30 & .1068 & \\
& & & & & \\
Note: ${ }^{*} p<.05$. & & & & &
\end{tabular}




\section{Research Question 4 Results}

What is the impact of a CTE program, including time spent in early clinical teaching practice, on program completers', mid-year, twelfth-grade average attendance record as compared to their mid-year ninth-grade average attendance record?

The fourth research question was designed to examine if there was a significant difference in student average unexcused absences from the school day, according to their attendance record, for students who were enrolled in a high school CTE, vocational, teacher preparation program, that had an on-campus preschool and the opportunity for early clinical teaching practice. A dependent $t$-test analysis was performed to directly compare the means of the average mid-year unexcused absences from the school day, of program completers' in $12^{\text {th }}$ grade, and their mid-year unexcused absences from the school day in $9^{\text {th }}$ grade. For research question 4 , only the two early childhood programs were compared. The biomedical control group was excluded to assure a measurement that included participants who participate in early clinical teaching practice. A separate dependent $t$-test also showed a significant difference in average mid-year unexcused absences from the school day from $9^{\text {th }}$ grade to $12^{\text {th }}$ grade in SCHOOL A ECE $1(t 39=$ $2.1, p=.04)$. The average mid-year unexcused absences from the school day mean for SCHOOL A ECE 1 in $9^{\text {th }}$ grade was $M=.88(S D=.1 .2)$, which was lower than their $12^{\text {th }}$-grade average mid-year GPA which was $M=1.40(S D=.1 .6)$. These results show that students in SCHOOL A ECE 1 had a higher mean of unexcused absences from the school day in $12^{\text {th }}$ grade than in the $9^{\text {th }}$. There was no significant difference in average mid-year unexcused absences from the school day from $9^{\text {th }}$ grade to $12^{\text {th }}$ grade in SCHOOL B ECE $2(t 7=1.7, p=.125)$. 
Table 4.30

Paired Samples T-test to compare $9^{\text {th }}$ and $12^{\text {th }}$-grade Mid-year unexcused absences from the school day for SCHOOL A ECE 1

\begin{tabular}{lccccc}
\hline Group & $n$ & $M$ & $S D$ & $\begin{array}{c}\text { Std. Error } \\
M\end{array}$ & $t$-test \\
\hline $\begin{array}{l}9^{\mathrm{TH}} \text { Grade Mid-year } \\
\begin{array}{l}\text { Unexcused } \\
\text { Absences }\end{array}\end{array}$ & 40 & .88 & 1.24 & .197 & $-.2 .12^{*}$ \\
$\begin{array}{l}12^{\mathrm{TH}} \text { Grade Mid- } \\
\text { year Unexcused } \\
\text { Absences }\end{array}$ & 40 & 1.40 & 1.59 & .253 & \\
& & & & & \\
\hline
\end{tabular}

Note: ${ }^{*} p<.05$.

Table 4.31

Paired Samples T-test to compare $9^{\text {th }}$ and $12^{\text {th }}$-grade Mid-year unexcused absences from the school day for SCHOOL B ECE 2

\begin{tabular}{lccccc}
\hline Group & $n$ & $M$ & $S D$ & $\begin{array}{c}\text { Std. Error } \\
M\end{array}$ & $t$-test \\
\hline $\begin{array}{l}9^{\mathrm{TH}} \text { Grade Mid-year } \\
\begin{array}{l}\text { Unexcused } \\
\text { Absences }\end{array}\end{array}$ & 8 & 1.13 & 1.13 & .398 & .125 \\
$\begin{array}{l}12^{\mathrm{TH}} \text { Grade Mid- } \\
\text { year Unexcused } \\
\text { Absences }\end{array}$ & 8 & 3.00 & 2.73 & .964 & \\
& & & & & \\
\hline
\end{tabular}

Note: $* p<.05$.

\section{Data Analysis and Summary}

To summarize the results of the present study, a Pearson correlation test was done to examine the relationships between the overall dependent variables, including the mean teacher identity scale, mean motivational scale, current mid-year GPA and current mid- 
year attendance record (unexcused absences), and the independent variable, program levels. The independent variable, vocational program, is not included in the analysis because of the way it is labeled in SPSS: SCHOOL A ECE 1 is program 1, SCHOOL A BIO 1 is program 2, and SCHOOL B ECE 2 is program 3. These labels are not levels and are only labeled for identification.

There were positive and negative correlations found between the dependent variables, as well as within the program levels. The correlation tables summarize these results. Overall, there was a positive correlation between student motivation and program level, $r=.15, n=594, p=.000$. The result across all three vocational programs showed that as students move up in program level each academic year, their motivation increased. The results also demonstrate that students are motivated overall in the vocational programs and that the students that stay in the programs (choosing to take the next level), continue to be motivated in the class. A positive correlation was also found between motivation in the course and the mid-year average GPA, $r=.09, n=576, p=.04$, indicating that students who are motivated in the courses across all three programs are also showing higher achievement according to their average mid-year GPA. No significant correlation was found between attendance and teacher identity within the two groups. A positive correlation was found between motivation and teacher identity, $r=$ $.28, n=597, p=.000$, indicating that as students show an increase of motivation, they also show an increase in teacher identity. Although, the ANOVA comparing teacher identity means across all three groups indicated that the students in SCHOOL A BIO 1 had the lowest mean of teacher identity of the three groups. To directly compare the correlations of teacher identity between the two early childhood programs, a separate 
Pearson correlation was performed. The table that follows presents a summary of the results. When excluding the biomedical control group, the results indicate a stronger correlation between teacher identity and motivation, $r=.41, n=360, p=.000$, GPA, $r=$ $.20, n=344, p=.000$ and program level $, r=.32, n=356, p=.000$. No significant correlation was found between attendance and teacher identity within the two groups. Across the three groups, positive correlations were found between GPA and program levels, $r=.30, n=575, p=.000$ and negative correlations were found between GPA and attendance record (unexcused absences), $r=-.31, n=575, p=.000$. The result indicates that as student GPA increases by level, the number of unexcused absences decreases. These results may explain the increases, overall, in motivation and achievement across all three programs.

Table 4.32

Correlations, including all three groups, of motivation, mean, teacher identity mean, current mid-year GPA, and current mid-year Attendance (number of unexcused absences).

\begin{tabular}{|c|c|c|c|c|}
\hline $\begin{array}{c}\text { Overall } \\
\text { Motivation } \\
\text { in the course }\end{array}$ & $\begin{array}{l}\text { Overall } \\
\text { Teacher } \\
\text { Identity }\end{array}$ & $\begin{array}{c}\text { Current mid- } \\
\text { year GPA }\end{array}$ & $\begin{array}{l}\text { Current mid- } \\
\text { year } \\
\text { attendance } \\
\text { record } \\
\text { (unexcused } \\
\text { absences) }\end{array}$ & Program Level \\
\hline
\end{tabular}

\begin{tabular}{|c|c|c|c|c|c|}
\hline $\begin{array}{l}\text { Overall Motivation in } \\
\text { the course }\end{array}$ & - & & & & \\
\hline $\begin{array}{l}\text { Overall Teacher } \\
\text { Identity }\end{array}$ & $.28^{* *}$ & - & & & \\
\hline Current mid-year GPA & $.09^{*}$ & -.04 & - & & \\
\hline $\begin{array}{l}\text { Current mid-year } \\
\text { attendance record } \\
\text { (unexcused absences) }\end{array}$ & -.08 & .07 & $-.31^{* *}$ & - & \\
\hline Program Level & $.15^{* *}$ & .04 & $.30^{* *}$ & -.01 & - \\
\hline
\end{tabular}


Note: ${ }^{* *} p<.01,{ }^{*} p<.05$

Table 4.33

Correlations, including only the two early childhood programs, of motivation, mean, teacher identity mean, current mid-year GPA, and current mid-year Attendance (number of unexcused absences).

\begin{tabular}{|c|c|c|c|c|}
\hline $\begin{array}{c}\text { Overall } \\
\text { Motivation } \\
\text { in the course }\end{array}$ & $\begin{array}{l}\text { Overall } \\
\text { Teacher } \\
\text { Identity }\end{array}$ & $\begin{array}{l}\text { Current Mid- } \\
\text { year GPA }\end{array}$ & $\begin{array}{l}\text { Current mid- } \\
\text { year } \\
\text { attendance } \\
\text { record } \\
\text { (unexcused } \\
\text { absences) }\end{array}$ & Program Level \\
\hline
\end{tabular}

\begin{tabular}{|c|c|c|c|c|}
\hline $\begin{array}{l}\text { Overall Motivation in } \\
\text { the course }\end{array}$ & - & & & \\
\hline $\begin{array}{l}\text { Overall Teacher } \\
\text { Identity }\end{array}$ & $.41^{* *}$ & - & & \\
\hline Current Mid-year GPA & $.11^{*}$ & $.21^{* *}$ & - & \\
\hline $\begin{array}{l}\text { Current mid-year } \\
\text { attendance record } \\
\text { (unexcused absences) }\end{array}$ & -.06 & -.00 & .04 & - \\
\hline Program Level & $.15^{* *}$ & $.32^{* *}$ & $.28^{* *}$ & .04 \\
\hline
\end{tabular}

Note: ${ }^{* *} p<.01,{ }^{*} p<.05$

Chapter 4 exemplified a quantitative, quasi-experimental design to explore the interactions and relationships between motivational constructs, dimensions in teacher identity, and student achievement when participating in vocational courses, specifically in a teacher preparation course that provides a framework that includes time in clinical teaching practice. The correlations presented to confirm the results from the MANOVA 
and ANOVA tests run to examine the significant differences between the dependent variables, the three vocational programs, and the four levels in each program. Overall, there were significant differences found in motivation across the three programs, but a closer look examined each motivational construct, and the significant differences were found in the task value effect and self-efficacy for learning and performance. SCHOOL A BIO 1 showed a higher task value effect than both SCHOOL A ECE 1 and SCHOOL B ECE 2.

On the other hand, SCHOOL A BIO 1 had the lowest mean of the three groups when it came to self-efficacy for learning and performance. Most of the significant differences with motivation occurred within the levels of the program. As discussed in this chapter, a significant difference was found between the program levels in each motivational construct, except external goal orientation and self-efficacy for learning and performance.

Several analyses of data showed SCHOOL A ECE 1 to have the highest mean of the three programs when it comes to teacher identity. SCHOOL B ECE 2 had the secondhighest and SCHOOL A BIO 1 had the lowest. Significant differences were found in both independent variables: vocational programs and program levels. Because the biomedical program scored the lowest in the teacher identity analysis, a $t$-test was run to compare the two early childhood programs directly. The results show a significant difference in all four dimensions of teacher identity: recognition, interest, performance, and competence. The $t$-test confirmed the results of the ANOVA and showed SCHOOL A ECE 1 to have the highest mean for teacher identity. 
A dependent $t$-test was performed to directly compare the mid-year GPA of the $12^{\text {th }}$-grade participants, in level 4 , with their $9^{\text {th }}$-grade mid-year GPA to see if any change occurred in their GPA since participating in early clinical teaching practice. Because the biomedical program does not participate in early clinical teaching practice, they were excluded from the analysis. A significant difference was found between the $9^{\text {th }}$-grade mid-year GPA and the $12^{\text {th }}$-grade mid-year GPA in both programs. The participants in SCHOOL A ECE 1 and SCHOOL B ECE 2 showed improvement from their mid-year $9^{\text {th }}$ grade GPA to their mid-year $12^{\text {th }}$ grade GPA.

A dependent $t$-test also compared the mid-year attendance record of the two ECE programs to examine if early clinical teaching practice affects the number of unexcused absences participants had in $9^{\text {th }}$ grade and $12^{\text {th }}$ grade. SCHOOL A ECE 1 showed a higher mean of unexcused absences in the $12^{\text {th }}$ grade than in the $9^{\text {th }}$ grade. The test found no significant difference in the comparison of unexcused absences in the students from SCHOOL B ECE 2. 


\section{CHAPTER 5}

\section{DISCUSSION AND CONCLUSION}

In this chapter, the researcher provides a summary of the investigation. The chapter begins with a review of the problem of the teacher shortage as a consequence of teacher attrition rates and a reduced interest in the teaching career. The teacher-researcher also reviews the purpose and relevance of the scope of the current study. Then, a review of the findings relevant to each of the four research questions informing the present dissertation will be discussed. The results are linked to the problem strands addressed in chapter two, and relevant implications are discussed. Finally, the chapter concludes with the limitations of the study, recommendations for high school teacher preparation programs, and suggestions for future research.

The present study examined the effect and impact of time in early clinical teaching practice on high school students' motivation, teacher identity, and overall achievement based on GPA and school attendance. The students in the intervention group, SCHOOL A ECE 1, were part of a CTE high school teacher preparation program that used a community of practice framework that included about 680 hours of early clinical teaching practice in the four years of the program. The present study's purpose was to identify and examine motivating factors in the development of teacher identity, through a social learning lens, that would empower high school students, not only to enter a teaching career but be resilient enough to grow as a teacher, using their malleable teaching identity as motivation.

The teaching career is in a constant state of flux. Sutcher et al. (2016) argue that the political demands of the field of education make it difficult to keep passionate and 
effective teachers in the classroom, especially in urban, low-income communities. Thirty percent of new teachers leave the classroom in the first five years, and attrition rates soar to $50 \%$ of new teachers who work in high poverty schools (Guha et al., 2017). Much of the research blames low quality or outdated teacher preparation programs (Guha et al., 2017; Ingersoll \& Smith, 2003; Lee, 2018). Researchers call for a restructuring and strengthening of teacher preparation programs as well as refocusing effort from recruitment to retainment (Lee, 2018). The Teacher Education's Blue-Ribbon Report (2010) called for more clinical experiences and the building of pipelines that encourage students to teach in their communities, especially if they are from high poverty areas. To include teacher preparation at the high school level, CTE systems included an Education and Training cluster into many high school vocational programs; although, there is limited research on the cluster (Advance CTE, 2019; DeFeo, 2015; Loera et al., 2013). The current instructional framework for the Early Childhood program under the Education and Training cluster in CTE, includes opportunities for the observation of preschool children, encouraging schools to provide opportunities for high school students the chance to interact with preschool children on and off-campus. However, a clinical practice framework that connects content, pedagogical knowledge, and practice are not in place. The present study sought to explore the factors that exist in an existing high school early childhood program framework, where early clinical teaching practice was paramount.

First, the current study explored the motivational constructs that impact the students in the intervention program including time in early clinical teaching practice, when compared to two other vocational programs; one that shares the same content but 
has no, on-campus, practice framework, and the other that shares a similar practice philosophy but different content. Second, the study explored the effect of the practice intervention on perceived teacher identity and the relationships with motivation and student achievement. Third, the study explored the impact of time spent in early clinical teaching practice on GPA in the high school students who were on track to complete the early childhood program. Finally, the study explored if there was an effect on student attendance by comparing program completers $12^{\text {th }}$-grade attendance (amount of unexcused absences) with their $9^{\text {th }}$-grade attendance, to determine if their participation in the teaching programs had any effect on attendance.

In the present research, a social learning lens was used to examine high school students' perspective of teaching during their participation in a community of practice. The current study sought to widen the scope of teacher preparation from a university model to the possibility of a high school model. Friesen and Besley (2013) found that early teacher identity is developed through opportunities for teaching practice. Ivanova and Skara-Mincane (2016) found that participants recognized, for the first time, their teacher identity during clinical teaching practice. The current study proposes that, through early clinical teaching practice, the development of teacher identity can begin at the high school level and may potentially motivate students to enter the field and prepare them to remain in a teaching career.

A quantitative, quasi-experimental design was chosen for this research to create a foundational premise for future research in the Education and Training CTE cluster. Because there is limited research in the CTE, Education and Training cluster, at the high school level, there is a gap in the literature regarding the development of teacher identity 
and motivation as well as the connections with overall student achievement. It is also unknown if there is an impact on student motivation and teacher identity after time spent in early clinical teaching practice. Also, there is a gap in the research regarding a community of practice framework to prepare future teachers starting in high school. To begin to resolve these gaps, the present research design allowed for the use of comparison groups to compare instructional frameworks and the pre and post examination of GPA and attendance records. A quasi-experimental design also allowed for groups that were already established and not randomly selected. The teacher-researcher believes that, although the sample sizes are unequal and small, they are representative of the larger population of high school students in these programs (Black, 2001). A post-positivist framework was used to evaluate a best practice for CTE, high school, teacher preparation programs. The use of surveys and questionnaires was appropriate for the present research. It provided sufficient data to analyze and uncover the effect of early clinical practice on high school students in teacher preparation programs (Butin, 2009).

\section{Participants}

When choosing an early childhood program to use as a comparison group, the teacher-researcher considered a program of similar program size and instructional framework, including the availability of an on-campus preschool and similar clinical teaching practice framework. To create a study that would provide robust results that would expose more of the confounding variables that may exist, a comparison program was chosen that did not have an on-campus preschool and employed a different instructional framework. The schools are similar in population size, as well as in ethnicity and economic need demographics; although, the program size of SCHOOL B ECE 2 is 
significantly smaller than SCHOOL A ECE 1 . The program at SCHOOL A ECE 1 maintains a steady enrollment across all four levels. In contrast, the program at SCHOOL B ECE 2 has a lower enrollment of level 1 students and struggles to maintain enrollment at each level. The difference created an unequal sample throughout the study, leading to small effects and correlation sizes. Table 5.1 illustrates the differences in the number of participants per level by the program. Although the teacher-researcher noticed the difference early on, the decline in enrollment in SCHOOL B ECE 2 is an essential factor to discuss when discussing connections with future teacher attrition rates.

Table 5.1

Number of participants per level, per program.

\begin{tabular}{cccc}
\hline & \multicolumn{3}{c}{ Vocational Programs } \\
\cline { 2 - 4 } Levels & SCHOOL A ECE 1 & SCHOOL B ECE 2 & SCHOOL A BIO 1 \\
\hline 1 & 81 & 66 & 17 \\
2 & 64 & 24 & 81 \\
3 & 46 & 22 & 63 \\
4 & 42 & 11 & 77 \\
\hline
\end{tabular}

\section{Research Questions}

Chapter two discussed the research for clinical teaching practice. There is a gap in the research when it comes to how much clinical teaching practice is needed to properly prepare preservice teachers for the reality of teaching (Retallick \& Miller, 2010).

Researchers do not dispute that experience in the field is essential and necessary for preservice teachers, but they found that programs with a narrow focus fail to adequately prepare future teachers (Retallick \& Miller, 2010; Zeichner, 2010). Two instruments were 
used in the present study, the first measured motivational constructs in three vocational programs across four levels. The second instrument measured dimensions of teacher identity in these same programs and levels. Finally, student achievement data were collected and analyzed to determine if there is a change in achievement in the students participating in these vocational programs.

\section{Answering Research Question 1}

Understanding the motivational constructs that encourage high school students to stay in a teacher preparation program may help to broaden the scope to include high school students in teacher preparation research. The Motivated Strategies for Learning Questionnaire explored these motivational constructs in the three programs across the four levels: intrinsic goal orientation, extrinsic goal orientation, task value effect, selfefficacy for learning and performance, and control of learning beliefs. The results in the present study showed a significant difference between the programs and between the levels, but not in all constructs.

Intrinsic Goal Orientation. According to Pintrich (1991), goal orientation refers to the reasons behind a student's participation and engagement in a particular assignment. The test examines the students' overall goal orientation in the course; intrinsic goal orientation refers to the innate reasons a student participates in a learning context: out of curiosity, to master a skill, or to accept a challenge. The results of the questionnaire showed no significant difference between the three vocational programs when it came to intrinsic goal orientation, suggesting that content or time in clinical practice may not affect a student's intrinsic goal orientation. A significant difference was found between 
the levels across the three programs. The level four students showed the highest means of intrinsic goal orientation of the four levels across the three programs, and a significant difference was found between level four and level one and level two students. These results suggest that students are intrinsically motivated to remain in the vocational programs. Also, a perpetual increase of mean is noted across the four levels in all three programs. These results support the findings of Holmes et al. (2019), where they revealed that intrinsic motivation was an essential factor in teachers remaining in the profession. Still, their study also found that other external factors can become more influential, leading some teachers to leave the profession. The researchers found that changes in the work environment, including the fostering of teacher growth, a positive work environment, and a focus on student success, would increase intrinsic motivation, and teachers would be more likely to remain in the classroom. Rueda and Dembo (1995) add that if the context encourages these intrinsic motives, the students will be more motivated to learn. The results showed no significant difference between the three programs; it must be noted that, according to the present study, the students who remained in the SCHOOL B ECE 2 program (level 4 students) were the students who had the highest level of intrinsic goal orientation but represented $9 \%$ of the participant sample for the program. This further confirms that students who are highly intrinsically motivated are more resilient to other external factors that encouraged others to leave the program.

Extrinsic Goal Orientation. Extrinsic goal orientation involves motivators such as grades, performance, rewards, and others judgment and approval. The student is not motivated by the task or the course itself but out of what external reward they receive (Pintrich, 1991). The questionnaire results showed no significant difference between the 
three vocational programs or between the four levels when it came to extrinsic goal orientation. A closer analysis did reveal that the students in SCHOOL A ECE 1 and SCHOOL A BIO 1 had higher means for external motivation than intrinsic motivation in level 4 students. These students have had the most time spent in clinical practices. These two programs share a comparable clinical practice philosophy that reflects a social, practice-based learning environment. These results suggest that the environment may have a strong influence on external motivators in the programs. According to Hammerness et al. (2005), preparation programs need to consider the learning environment; context has a powerful impact on the formation of identity. SCHOOL A ECE 1 participants showed a higher teacher identity across all four dimensions when compared to SCHOOL B ECE 2. These results suggest that the learning environment helps to develop teacher identity through the external motivators experienced through the goals of clinical practice. According to Olsen (2008), extrinsic motivators act together as a teacher reacts to their environment, formulating their teacher identity. The teacherresearcher perceives some of the student external motivators in SCHOOL A ECE 1 to include grades, rewards, teacher approval, group member approval, group member expectations, leadership roles, and approval and attention of the children.

Task Value Effect. Task value refers to how important, useful, or interesting the student thinks an assignment is. Task value asks the question, why am I doing this? According to Pintrich (1991), students with high task value are more involved in their learning in the course and are, overall, more interested and find more use out of what they are learning. Pintrich and Schrauben (1992) mention that task value is different from intrinsic or extrinsic goals; they believe that goals motivate students throughout the 
learning process, but values in a learning context determine the amount of effort given to learning. Wigfield and Eccles (1992) agree but mention that their research has shown that task value falls as students become older; as students age, achievement has a stronger influence than effort.

In the present study, the results revealed a significant difference between the vocational programs and between the levels. The intervention group, SCHOOL A ECE 1, had the lowest mean for the task value effect of the three groups. These results suggest that students may not be understanding why they are learning in the course. According to Rajuan et al. (2008), there is a gap between what preservice teachers describe they are learning in clinical practice and what mentor teachers "prescribe as learning in teacher education" (p. 134). Their study revealed that because teaching is a real-world practice, "implicit orientations that reflect different perspectives towards teaching are seldom made explicit” (p.134). This supports the results of the present study. From a social learning perspective, the values and beliefs of the context may be conflicting with the individual students' values and beliefs about teaching and learning. Further study using qualitative analysis would benefit the present research to understand what high school students in SCGOOL A ECE 1 value and believe during clinical practice. The differences in the instructional framework may explain why students in SCHOOL A ECE 1 see less value in the learning taking place than the students in SCHOOL B ECE 2 or SCHOOL A BIO 1. It is important to note that although SCHOOL A ECE 1 received the lowest mean, task value perpetually increased at each level, as it did the other two groups. Also, the means of all three groups for task value were the highest of all of the motivational 
constructs. These results suggest that students are valuing what they are learning in these vocational courses.

One significant difference in the framework of SCHOOL A ECE 1 is that students learn more through the practice of teaching than through content. Learning in a community of practice happens in a social structure, which is different from a traditional classroom. The environment of SCHOOL A ECE 1 is competitive, rigorous, and challenging in a different way than in a traditional classroom. According to Wenger (1998), learning occurs between student agency and the social structure of the classroom. He adds that meaning is negotiated through the practice, roles, and values within the context (Wenger, 1998). The environment also challenges self-efficacy, which is directly related to task value. According to Ambrose et al. (2010), if students value a goal but do not have the self-efficacy to accomplish it, they can be "fragile" and will make excuses for poor performance. However, if students do not see the value of a goal but have high efficacy, they may give minimum effort and will "evade" work (p. 81). Although these results conflict with the results from the teacher identity survey, where SCHOOL A ECE 1 showed a perception of higher competence and performance than the other two groups, Pintrich and Schrauben (1992) found that "perceptions of the value of a task do not have a direct influence on performance" (p. 172). These results show that time in early clinical practice does not make an impact on task value effects.

Control of Learning Beliefs. According to Pintrich (1991), control of learning refers to students' belief that the effort they put into learning will have a positive result. The motivational construct connects effort and success. In other words, if the students feel they have control over their performance, they will put forth more effort. The current 
study found no significant difference between the three vocational programs when it came to control of learning beliefs, but a significant difference was noted between the levels. Level four students had higher means than level one and two students, but no significant difference was found with level three students. These results support the findings of Drysdale and McBeath (2018), which found that students who put forth the effort to understand content at a deeper level are usually intrinsically motivated. Level four students across all three programs were more intrinsically motivated when compared to the other levels. The results in the current study suggest that time in clinical teaching practice does not affect control of learning beliefs when compared to other programs. Although, time within a program may lead to a feeling of control of their own learning and an increase of intrinsic motivation.

Self-Efficacy of Learning and Performance. In the MSLQ, two aspects of learning expectancy are assessed as expectancy for success and self-efficacy. According to Pintrich (1991), expectancy for success refers to expected achievement in a specific task. Self-efficacy relates to one's perceived ability to accomplish the task. Selfjudgement and confidence are strongly related to self-efficacy (Pintrich, 1991). The results of the current study found a significant difference between the groups. SCHOOL A BIO 1 had the lowest mean for self-efficacy of learning beliefs. Of the three groups, SCHOOL A BIO 1 has the most rigorous content. These results suggest that the students in SCHOOL A BIO 1 have less self-efficacy than the students in the other two groups.

The results of the MSLQ revealed that time in clinical teaching practice does not impact the motivational constructs evaluated in the questionnaire. The tests run to examine the motivational constructs do not show evidence of a significant difference 
between the three programs in relation to time spent in early clinical teaching practice. A $t$-test was run to compare the data with only the two ECE groups, which yielded the same results. This supports a study by Defeo (2015), which found that students' motivation to take a vocational class was more general and not specific to the practices of the courses. The highest percentage of students in his study said that they were interested in the subject area or the career field itself. The results of the current study show that, although the data demonstrate an increase in motivation at each level, time in early clinical practice was not the key motivator in these vocational programs.

\section{Answering Research Question 2}

Research supports the idea that the development of teacher identity is critical in the early stages of teacher preparation (Day et al., 2008; Chong et al., 2011; Olsen, 2008). A review of the literature found that teacher identity is an important, on-going, unstable phenomenon that is always shifting as a consequence of internal and external factors involving the person and the context (Gee, 2001; Olsen, 2008). The results of the current study found that SCHOOL A ECE 1 had significant differences in all four dimensions of the teacher identity framework: recognition, interest, performance, and competence when compared to the other two groups in the current study. There were also significant differences between the levels within the programs.

Recognition. The results showed that SCHOOL A ECE 1 had a higher mean for the teacher identity dimension of recognition than SCHOOL B ECE 2 and SCHOOL A BIO 1. SCHOOL B ECE 2 also had a higher mean than SCHOOL A BIO 1. This finding shows that time spent in early clinical practice contributes to the development of teacher identity in high school students when it comes to the dimension of recognition. These 
results support Olsen's (2008) research and his findings that, even before preservice teacher begin a teacher preparation program, students are sometimes recognized by family and friends as future teachers because of their interaction with smaller children in their personal lives, resulting in a sense of teacher identity in relation to recognition. However, these results also show that time spent in clinical teaching practice fosters and develops the recognition dimension of teacher identity. In SCHOOL A ECE 1, recognition also comes from the teacher, their peers, and the preschool children, as well as from grades, rewards, and leadership opportunities.

A significant difference was also found between the levels of vocational programs. The level four students in SCHOOL A ECE 1 had a significant difference from levels one and two but not level three students. The difference between the levels may have to do with a shift of roles from level three to level four. Level four students may experience a shift in identity at level 4 because most are moved up to group or class leaders. They shift from teaching the preschool children in level three to being recognized as a leader by their peers. The present study was done in the Fall of the school year, and level four students are just learning their new roles and responsibilities, it may have been too early in the school year for the students to recognize themselves as a leader within their peers. The study done by Chong et al. (2011) supports this result, finding that, in a new role, "professional identity would still be in its infancy," but the researchers believe that with time and the development of efficacy in the role, teacher identity will grow (p. $60)$.

Interest. Regarding interest in teaching, the study found a significant difference between the three programs when it comes to interest in a teaching career. SCHOOL A 
ECE 1 had the highest mean regarding the interest of the three programs; SCHOOL A BIO 1 had the lowest. Students in both ECE programs show interest in becoming a teacher, whereas the students in the biomedical program do not. These results show that time spent in early clinical practice contributes to teacher identity of high school students when it comes to the interest dimension of teacher identity. According to DeFeo (2015), students who enter vocational courses in high school are able to identify their interests in specific careers on the basis of their interests that they have narrowed down over time. Students between the ages of 14-18 are in the exploratory and specification phase of career choice. If students lose interest in the content, they lose interest in their career choice (DeFeo, 2015). A disinterest in the content helps to explain the decrease in enrollment at each level for all three programs.

A significant difference was also found between the levels. Again, level 4 students had a significantly higher teacher identity, when it came to interest than level one or level two students. No significant difference was found between level three and level four students. This also is supported by DeFeo's (2015) research in that as students lose interest in the field, they choose a different vocational track. As a result, level four students are the students who have the highest interest and who have remained in the programs. These results also show that innate interest in the content of the course is linked to teacher identity. Olsen (2008) emphasizes that students who are innately interested in the course come into the program with some teacher identity. He claims internal interest may be a consequence of gender practices of pretend play as children or their values and beliefs about teachers. Students in the biomedical program have less 
interest in the teaching content; therefore, they have less teacher identity when it comes to interest.

Performance. A significant difference was found between SCHOOL A ECE 1 and the other two groups when it came to the performance dimension of teacher identity. SCHOOL A ECE 1 had a significantly higher mean than the students in SCHOOL B ECE 2 and SCHOOL A BIO 1 when it came to performance. SCHOOL B ECE 2 also had a significant difference with SCHOOL A BIO 1. SCHOOL A BIO 1 had the lowest mean of the three groups. These results show that time spent in early clinical practice contributes to the development of a teacher identity when it comes to performance. The increase in teacher identity may be because of the predetermined criteria and framework in place of the program at SCHOOL A ECE 1. Students have predetermined daily roles, procedures, and goals. According to Rueda and Dembo (1995) found that if a student understands what they are supposed to do to accomplish a goal, they will be more motivated. The intervention group in the present study follows a set of performance goals illustrated in Appendix B, C, D and E. Hakim (2015) supports the claim by Rueda and Dembo and found that students will successfully execute a task if they understand the performance goals. He claims that performance should be measured by the learner's success in learning, in a given time, by a specific criterion (Hakim, 2015).

A significant difference was also found between the levels of students in the three programs regarding the performance dimension of teacher identity. Level four students had a significantly higher mean for performance than level one and level two students. No difference was found between the level four and level three students; the difference may be as a consequence of the shift in roles for level four students in SCHOOL A ECE 
1 , from teachers to group leaders. The shift also causes fewer external motivators since they are starting a new role and see a decrease in self-efficacy. Fernandez et al. (2012) found that performance-oriented students tend to seek more approval and feedback than goal-oriented students. The results showed that the level four students in level four in SCHOOL A ECE 1 were more extrinsically motivated than any of the other groups, across the three vocational programs. These results may indicate that the community of practice framework results in more external motivators, such as approval from the teacher and their peers.

Competence. A significant difference was found between the three programs in regard to the teacher identity dimension, competence. SCHOOL A ECE 1 showed a significantly higher mean than the other two programs in the competence domain. These results show that time spent in early clinical teaching practice contributes to the competence dimension of the teacher identity framework. According to Hakim (2015), competency and performance are related in a particular context. He believes that the two concepts have a causal relationship: competency being a "tool" for performance (p. 1). Hakim mentions four types of competence required for teaching students: pedagogical competence, personal competence, professional competence, and social competence. The present study shows that the high school students in SCHOOL A ECE 1, are beginning to develop the competency dimension of their teacher identity through time spent in clinical teaching practice.

The $t$-tests performed in the present study included only the two ECE groups, in order to have a more direct comparison of the means, excluding the biomedical group. 
The tests confirmed the ANOVA results presented. SCHOOL B ECE 2 students had a higher level of motivation, and the students from SCHOOL A ECE 1 had a higher level of teacher identity.

\section{Answering Research Question 3 and 4}

Student Achievement: GPA and Attendance. Students in SCHOOL A ECE 1 showed a significant improvement in GPA from their $9^{\text {th }}$-grade year to their $12^{\text {th }}$-grade year. SCHOOL B ECE 2 received the same result. The students in both programs saw an increase in GPA between the two grades. These results show that early clinical teaching practice does not contribute to an increase in GPA but learning about teaching might influence achievement. An influence on achievement may be a consequence of seeing the world from a teacher's perspective, through content learned, might improve learning skills and strategies. According to Rueda and Dembo (1995), as students grow older, their view of achievement changes; they begin to focus more on the ability than effort. The change of perspective supports the results of the present study regarding achievement. The students in SCHOOL A ECE 1 showed a higher mean in competence and performance, and that may be where their self-efficacy exists. SCHOOL B ECE 2 student's self-efficacy may exist in the content taught in class. The students of SCHOOL A feel more able to perform and have a higher expectancy for achievement. Also, according to Rueda and Dembo, when students feel more in control of their learning, they achieve more. The results of the identity survey showed that students in SCHOOL A ECE 1 feel that they have more control over their learning. The control experienced may be a consequence of their skill and practice as a teacher; studying to be a teacher may be improving their GPA. According to Bragg and Ruud (2007), an increase in GPA is seen 
in students who participate in CTE courses. This increase is also seen in their enrollment into two-year college enrollment. This supports the results of increase of GPA in the students in the ECE program at both schools.

A significant difference was found in the attendance records of the students in SCHOOL A ECE 1 . According to the $12^{\text {th }}$-grade attendance record of unexcused absences, students had significantly more unexcused absences from the school day in the $12^{\text {th }}$ grade than in the $9^{\text {th }}$ grade. The students in SCHOOL B ECE 2 had no significant differences found in their attendance records for unexcused absences in the school day.

\section{Implications}

There was a positive relationship between motivation, identity, and achievement in the intervention group of the present study. The results of the current study support the application of a community of practice framework in a high school teacher preparation program. The results of this study also support the existing literature on motivation development in a sociocultural setting as well as identity formation derived from clinical teaching practice. Schools can use the framework applied in SCHOOL A ECE 1 when developing their early childhood programs, using a community social structure that includes an on-campus preschool. The inclusion of the framework will increase teacher identity in high school students and will motivate some students to remain in the program.

\section{Discussion}

The present study drew on social learning theories to explore how a high school vocational teacher preparation program can begin to create preservice teachers that are 
resilient and effective. The current study used an intervention group that managed a community of practice framework that included a social structure for knowledge, practice, reflection, and identity development (Wenger, 1998). The social structure of the intervention group used standards and procedures to help students make meaning out of teaching experiences. In this context, students worked in groups to negotiate meaning from a "living experience" (Wenger, 1998, p. 229). The current study applied Wenger's suggestion to use the context/environment as a point of entry into understanding the social learning occurring in the teacher preparation program. By using a sociocultural approach, researchers can begin to study clinical practice environments beginning with a younger population. The study sought to explore the role of motivation, teacher identity, and overall achievement in a community of practice. The participants were from lowincome areas and were mostly minorities. The participants included higher achieving as well as low achieving students. These students choose to come together to take a vocational course that will help prepare them for their future careers.

The results of the present study were conflicting. The research on motivation is torn, and it became apparent in the present study. Analyzing motivation from a sociocultural perspective is unconventional. When considering Vygotsky's work, students learn when in a social context, where cognition and social experiences influence learning. When a community of practice becomes a system of teaching and learning, motivation, identity, and achievement become part of the culture. Students become part of the culture and become agentic participants of the community. Many preservice teachers feel that the most essential aspect of their teacher preparation program was their field experience, but many feel that they were not ready for the realities of teaching. 
Teaching in itself is a culture; the school where the teachers work is a culture, but a short field experience opportunity does not give the preservice teacher time to delve into that culture and experience teaching and learning through it. The results of the present study reflect and propose an earlier start to a teaching culture learning environment, beginning at the high school level.

The results of the current study found no significant difference in the motivational constructs between the intervention group and the two control groups. All of the groups showed evidence of motivation, but one was not significantly more than the other. When analyzing the results form a sociocultural view, the motivation in the intervention group does not belong to the individual but to the community of the class. When comparing the enrollment rates of both ECE programs, SCHOOL A ECE 1 maintained enrollment more steadily than SCHOOL B ECE 2 . The difference may be because, although they feel the same motivation as individual high school students, they are motivated by the progress of the program, because they are part of the culture, they return. The collective motivation then leads them to develop a teacher identity within the context of a community.

Using a community of practice framework for a high school teacher preparation program allows the high school students to learn through play. Vygotsky studied how children learned through play in social environments and how children learned from and with each other. Students in the intervention group learn through playing with different teaching identities. By providing them with an early teaching practicum, the framework allows these older students to explore teaching through pretend play; even though they are actually teaching, they do it without the fear of failure. The experimentation also exposes the student to the possibility of a career in education, social work, or mental 
health. Chong et al. (2011) believe that how preservice teachers react in these experiences will determine how resilient they are in the real world of teaching.

\section{Recommendations for Future Research}

As the teacher-researcher, studies that explore the framework applied at SCHOOL

A ECE 1 qualitatively would give a more robust understanding of the motivation, identity, and achievement factors. Because these types of programs must be structured around the culture of the teachers, students, and school, studies of these programs should be done in different settings and demographics. It is not known how many of the students who complete the program have become teachers, and if they are still teaching. A longitudinal study that follows these program completers would benefit the research.

There is also a gap in CTE research when it comes to the success of these programs in the Education and Training clusters, more research on the benefits and successes of these programs would help districts and principles understand their dynamics. Also, longitudinal research on a high school-university pipeline program would benefit the field of education and attrition research. In addition, as a result of the current study, interesting gender data has come to light. The males that remained in SCHOOL A ECE 1 showed a high level of teacher identity. An exploratory study analyzing the motivations and identity development of males in high school teacher preparation programs would also benefit and add to the CTE research. Finally, a longitudinal study can be completed to measure the academic achievement of the preschool children in these programs. The results of the present study will add to the research in early childhood as well as CTE. 


\section{Limitations}

A limitation of the current study involved the unequal number of students at SCHOOL B ECE 2. The imbalance may have affected the representation of the mean scores of certain levels and effect sizes. Also, the teacher-researcher is the teacher of the intervention program. Although the intervention in the target group was already in place, results may have been impacted. 


\section{REFERENCES}

Achieve, Advance CTE, the Council of Chief State Officers and Education Strategy Group. (2019). The State of Career Technical Education: Improving Data Quality and Effectiveness. Retrieved from https://careertech.org/resource/state-cte-improvingdata-quality-effectiveness

Ambrose, S. A., Bridges, M. W., DiPietro, M., Lovett, M. C., \& Norman, M. K. (2010). How learning works: Seven research-based principles for smart teaching. John Wiley \& Sons.

Arrington, K. (2000). Middle grades career planning programs. Journal of Career Development, 27(2), 103-109.

Baker, R. S., \& Milner, J. O. (2006). Complexities of collaboration: Intensity of mentors' responses to paired and single preservice teachers. Action in Teacher Education, 28(3), 61-72.

Bandura, A. (1991). Social cognitive theory of self-regulation. Organizational behavior and human decision processes, 50(2), 248-287.

Bandura, A. (2000). Self-efficacy: The foundation of agency. Control of human behavior, mental processes, and consciousness: Essays in honor of the 60th birthday of August Flammer, 16.

Bandura, A. (2001). Social cognitive theory: An agentic perspective. Annual review of psychology, 52(1), 1-26.

Beauchamp, C., \& Thomas, L. (2009). Understanding teacher identity: An overview of issues in the literature and implications for teacher education. Cambridge journal of education, 39(2), 175-189.

Beijaard, D., Meijer, P. C., \& Verloop, N. (2004). Reconsidering research on teachers' professional identity. Teaching and teacher education, 20(2), 107-128. https://openaccess.leidenuniv.nl/bitstream/handle/1887/11190/10_404_07.pdf?se que

Berry, B., \& Shields, P. M. (2017). Solving the teacher shortage: Revisiting the lessons we've learned. Phi Delta Kappan, 98(8), 8-18.

Black, T. R. (2001). Understanding social science research. Sage.

Bragg, D. D., \& Ruud, C. M. (2007). Career Pathways, Academic Performance, and Transition to College and Careers: The Impact of Two Select Career and 
Technical Education (CTE) Transition Programs on Student Outcomes. In Brief. Office of Community College Research and Leadership.

Bullough Jr, R. V., Young, J., Erickson, L., Birrell, J. R., Clark, D. C., Egan, M. W., ... \& Smith, G. (2002). Rethinking field experience: Partnership teaching versus single-placement teaching. Journal of teacher education, 53(1), 68-80.

Butin, D. W. (Ed.). (2009). The education dissertation: A guide for practitioner scholars. Corwin Press.

Carlsson, R., Lindqvist, P., \& Nordänger, U. K. (2019). Is teacher attrition a poor estimate of the value of teacher education? A Swedish case. European Journal of Teacher Education, 1-15.

Clift, R. T., \& Brady, P. (2005). Research on methods courses and field experiences. Studying teacher education: The report of the AERA panel on research and teacher education, 309424.

Chong, S., Low, E. L., \& Goh, K. C. (2011). Emerging Professional Teacher Identity of Pre-Service Teachers. Australian Journal of Teacher Education, 36(8), 50-64.

Coburn, C. E., \& Stein, M. K. (2006). Communities of practice theory and the role of teacher professional community in policy implementation. New directions in education policy implementation: Confronting complexity, 25-46.

Cochran-Smith, M., Villegas, A. M., Abrams, L., Chavez Moreno, L., Mills, T., \& Stern, R. (2016). Research on teacher preparation: Charting the landscape of a sprawling field. Handbook of research on teaching, 5, 439-547.

Collins, E., \& Green, J. L. (1992). Learning in classroom settings: Making or breaking a culture. Redefining student learning: Roots of educational change, 85-98.

Cooper, K., \& Olson, M. R. (1996). The multiple 'I's' of teacher identity. Changing research and practice: Teachers' professionalism, identities and knowledge, 7889.

Day, C., Kington, A., Stobart, G., \& Sammons, P. (2006). The personal and professional selves of teachers: Stable and unstable identities. British educational research journal, 32(4), 601-616.

Darling-Hammond, L. (2006). Constructing 21st-century teacher education. Journal of Teacher Education, 57(3), 300-314.

DeFeo, D. J. (2015). Why are you here? CTE students' enrollment motivations and career aspirations. Career and Technical Education Research, 40(2), 82-98. 
Den Brok, P., Wubbels, T., \& Van Tartwijk, J. (2017). Exploring beginning teachers' attrition in the Netherlands. Teachers and Teaching, 23(8), 881-895.

Dillabough, J. A. (1999). Gender politics and conceptions of the modern teacher: Women, identity, and professionalism. British journal of sociology of education, 20(3), 373-394. https://www.tandfonline.com/doi/pdf/10.1080/01425699995326? casa token=brx GWde2CykAAAAA:r7nITdG7vpiHgq ox9TzMcwDDjaN 81vOtYeaF04wmT9I CBjfD-6aV08 i75d_yTKS7AVKwL7tok1w

Ducharme, E. R., \& Ducharme, M. K. (1996). Needed research in teacher education. Handbook of research on teacher education, 2, 1030-1046.

Dweck, C. S., \& Leggett, E. L. (1988). A social-cognitive approach to motivation and personality. Psychological review, 95(2), 256.

Emirbayer, M., \& Mische, A. (1998). What is agency? 1. American journal of sociology, 103(4), 962-1023.

https://www.jstor.org/stable/pdf/10.1086/231294.pdf?casa token $=$ ohYn0HR4590 AAAAA:oLkzV1gBdLn5fyRhUW64nHf2TWAC-FQBPKCCxr5smYtite Ivhk1DIkzTCwbPlVbiTsgiPIR7jpugpQXf19LJPyhAeiPtjTub5hGIUER91Y1dJ0fai $\underline{f}$

Fernández, A. P., Anaya, D., \& Suárez, J. M. (2012). Motivation features and motivational self-regulatory strategies in the middle school students. Revista de psicodidáctica, 17(1). https://www.redalyc.org/html/175/17523162008/

Florida Department of Economic Opportunity (2018). Employment Projection Data. Retrieved from http:/www.floridajobs.org/workforce-statistics/datacenter/statistical-programs/employment-projections

Florida Department of Education (2018). Career and Professional Education Act Enrollment and Performance Report, 2017-18. Retrieved from http://www.fldoe.org/core/fileparse.php/9904/urlt/1718capepr.pdf

Florida Department of Education (2020). Teacher Shortage Area Report, 2019-2020. Retrieved from file://C:/Users/Lagui.DESKTOPA2K9IUM/Downloads/ViewTSAReport.pdf

Freese, A. R. (2006). Reframing one's teaching: Discovering our teacher selves through reflection and inquiry. Teaching and teacher education, 22(1), 100-119.

Glazer, J. (2018). Learning from those who no longer teach: Viewing teacher attrition through a resistance lens. Teaching and Teacher Education, 74, 62-71. 
Guha, R., Hyler, M. E., \& Darling-Hammond, L. (2017). The power and potential of teacher residencies. Phi Delta Kappan, 98(8), 31-37.

Hartnell-Young, E. (2006). Teachers roles' and professional learning in communities of practice supported by technology in schools. Journal of technology and teacher education, 14(3), 461-480.

Hickey, D. T., \& Zuiker, S. J. (2005). Engaged participation: A sociocultural model of motivation with implications for educational assessment. Educational Assessment, 10(3), 277-305.

Hughes, K. L., \& Karp, M. M. (2006). Strengthening Transitions by Encouraging Career Pathways: A Look at State Policies and Practices. CCRC Brief Number 30. Community College Research Center, Columbia University.

Holmes, B., Parker, D., \& Gibson, J. (2019). Rethinking Teacher Retention In Hard-ToStaff Schools. Contemporary Issues in Education Research (CIER), 12(1), 27-32.

Hull, C. L. (1943). Principles of behavior: An introduction to behavior theory. New York: Appleton-Century-Crofts.

Ingersoll, R. M., \& Smith, T. M. (2003). The wrong solution to the teacher shortage. Educational leadership, 60(8), 30-33.

Ivanova, I. Skara-Mincane, R. (2016). Development of Professional Identity during Teacher's Practice. Social and Behavioural Sciences. 232, 529 - 536.

Ivanova, I., \& Skara-MincLne, R. (2016). Development of Professional Identity During Teacher's Practice. Procedia-Social and Behavioral Sciences, 232, 529-536. https://ac.els-cdn.com/S1877042816313064/1-s2.0-S1877042816313064main.pdf? tid $=68$ ec $72 \mathrm{~b} 6-679 \mathrm{~b}-48 \mathrm{dc}-\mathrm{a} 439-$

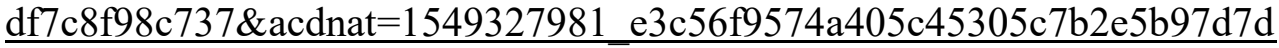

Järvelä, S., \& Salovaara, H. (2004). The interplay of motivational goals and cognitive strategies in a new pedagogical culture: A context-oriented and qualitative approach. European psychologist, 9(4), 232-244.

Korinek, L., \& deFur, S. H. (2016). Supporting student self-regulation to access the general education curriculum. TEACHING exceptional children, 48(5), 232-242.

Korthagen, F. A. (2004). In search of the essence of a good teacher: Towards a more holistic approach in teacher education. Teaching and teacher education, 20(1), 77-97. 
Lauriala, A., \& Kukkonen, M. (2005). Teacher and student identities as situated cognitions. Connecting policy and practice: Challenges for teaching and learning in schools and universities, 199-208.

Lee, R. E. (2018). Breaking Down Barriers and Building Bridges: Transformative Practices in Community-and School-Based Urban Teacher Preparation. Journal of Teacher Education, 69(2), 118-126

Lent, R. W., Brown, S. D., \& Hackett, G. (1994). Toward a unifying social cognitive theory of career and academic interest, choice, and performance. Journal of vocational behavior, 45(1), 79-122. https://www.sciencedirect.com/science/article/abs/pii/S000187918471027X

Levine, A. (2006). Educating schoolteachers. Education Schools Project.

Linnenbrink, E. A., \& Pintrich, P. R. (2001). Multiple goals, multiple contexts: The dynamic interplay between personal goals and contextual goal stresses.

Loera, G., Nakamoto, J., Oh, Y. J., \& Rueda, R. (2013). Factors that promote motivation and academic engagement in a career technical education context. Career and Technical Education Research, 38(3), 173-190.

Mead, G. H. (1934). Mind, self and society (Vol. 111). University of Chicago Press.: Chicago.

Miami Dade County Public Schools (2018). ARDA: Assessment, Research, and Data Analysis. 2017-18 Cross-Sectional Dropout Rates. Retrieved from http://oada.dadeschools.net/SchoolPerformanceData/SchoolPerformanceData.asp

Miltiadou, M., \& Savenye, W. C. (2003). Applying social cognitive constructs of motivation to enhance student success in online distance education. $A A C E$ journal, 11(1), 78-95.

National Commission on Teaching \& America's Future. (1996). What matters most: Teaching for America's future. New York, NY: Author.

National Council for Accreditation of Teacher Education. (2010). Transforming teacher education through clinical practice: A national strategy to prepare effective teachers. Report of the Blue Ribbon Panel on Clinical Preparation and Partnerships for Improved Student Learning. ERIC Clearinghouse.

Nolen, S. B. (2007). Young children's motivation to read and write: Development in social contexts. Cognition and instruction, 25(2-3), 219-270. 
Nguyen, H. T. M., \& Yang, H. (2018). Learning to become a teacher in Australia: a study of pre-service teachers' identity development. The Australian Educational Researcher, 45(5), 625-645.

Olsen, B. (2008). How reasons for entry into the profession illuminate teacher identity development. Teacher education quarterly, 35(3), 23-40.

Pillen, M. T., Den Brok, P. J., \& Beijaard, D. (2013). Profiles and change in beginning teachers' professional identity tensions. Teaching and Teacher Education, 34, 8697.

Pintrich, P. R. (1991). A manual for the use of Motivated Strategies for Learning Questionnaire (MSLQ).

Pintrich, P. R., \& Schrauben, B. (1992). Students' motivational beliefs and their cognitive engagement in classroom academic tasks. Student perceptions in the classroom, 7, 149-183.

Rajuan, M., Beijaard, D., \& Verloop, N. (2008). What Do Student Teachers Learn? Perceptions of Learning in Mentoring Relationships. New Educator, 4(2), 133151. Retrieved from http://search.ebscohost.com.ezproxy.fiu.edu/login.aspx?direct=true\&db=eric\&A $\mathrm{N}=\mathrm{EJ} 811767 \&$ site $=$ eds-live

Redding, C., \& Henry, G. T. (2018). Leaving school early: An examination of novice teachers' within-and end-of-year turnover. American Educational Research Journal, 0002831218790542.

Reese, S. (2011). CTE and the Common Core State Standards. Techniques: Connecting Education and Careers (J1), 86(7), 16-20. Retrieved from https://files.eric.ed.gov/fulltext/EJ964076.pdf

Reeve, J. (2013). How students create motivationally supportive learning environments for themselves: The concept of agentic engagement. Journal of Educational Psychology, 105(3), 579. file:///C:/Users/Lagui.DESKTOPA2K9IUM/Downloads/Reeve2013.pdf

Retallick, M. S., \& Miller, G. (2010). Teacher Preparation in Career and Technical Education: A Model for Developing and Researching Early Field Experiences. Journal of Career and Technical Education, 25(1), 62-75.

Ronfeldt, M., \& McQueen, K. (2017). Does new teacher induction really improve retention?. Journal of Teacher Education, 68(4), 394-410. 
Rosenberg, M. \& Sowders, S (2019). Recruiting Washington Teachers: 2018-19 Annual Report. PESB - Professional Educator Standards Board. Retrieved from http://pathway.pesb.wa.gov/future-educators/rwt/reports

Rueda, R., \& Dembo, M. (1995). Motivational processes in learning: A comparative analysis of cognitive and sociocultural frameworks. In M. Maehr \& P. Pintrich (Eds.), Advances in motivation and achievement: Culture, Motivation, and Achievement (Vol. 9). (Pp. 255-289). Greenwich, Connecticut: JAI Press.

Schunk, D. H. (1989). Social cognitive theory and self-regulated learning. In Selfregulated learning and academic achievement (pp. 83-110). Springer, New York, NY.

Schunk, D. H. (2012). Learning theories an educational perspective sixth edition. Pearson.

Schunk, D. H., \& Meece, J. L. (2012). Student perceptions in the classroom. Routledge.

Schunk, D. H., Meece, J. R., \& Pintrich, P. R. (2012). Motivation in education: Theory, research, and applications. Pearson Higher Ed.

Stipanovic, N., Lewis, M. V., \& Stringfield, S. (2012). Situating programs of study within current and historical career and technical educational reform efforts. International Journal of Educational Reform, 21(2), 80-97. http://www.nrcete.org/sites/default/files/external-reports-files/12008 ijer_v21_no2 fnls_2.pdf\#page $=4$

Super, D. E. (1980). A life-span, life-space approach to career development. Journal of vocational behavior, 16(3), 282-298.

Sutcher, L., Darling-Hammond, L., \& Carver-Thomas, D. (2016). A coming crisis in teaching. Teacher supply, demand, and shortages in the US.

Sutcher, L., Darling-Hammond, L., \& Carver-Thomas, D. (2019). Understanding Teacher Shortages: An Analysis of Teacher Supply and Demand in the United States. education policy analysis archives, 27(35).

Sutherland, L., Howard, S., \& Markauskaite, L. (2010). Professional identity creation: Examining the development of beginning preservice teachers' understanding of their work as teachers. Teaching and teacher education, 26(3), 455-465.

State Department of Economic Opportunity, Bureau of Labor Market Statistics (2016). 
Ting, S. R., Leung, Y. F., Stewart, K., Smith, A. C., Roberts, G. L., \& Dees, S. (2012). A Preliminary Study of Career Education in Middle School. Journal of Career and Technical Education, 27(2), 84-97.

Thamotharan, V. \& Hazari, Z. (2017, May). Science and Math Teaching Identity, Persistence and Constructivist Teaching Beliefs. 2017 UTeach Conference.

Thamotharan, V. \& Hazari, Z. (2018, Jan). Predicting Persistence through Science Teaching Identity. 2018 Association of Science Teacher Educators Conference.

U.S. Department of Education CTE (n.d.). Florida CTE Fact Sheet. Retrieved from https://cte.careertech.org/sites/default/files/Florida_CTE_Factsheet_2017.pdf

Vagi, R., Pivovarova, M., \& Miedel Barnard, W. (2019). Keeping our best? A survival analysis examining a measure of preservice teacher quality and teacher attrition. Journal of Teacher Education, 70(2), 115-127.

Volet, S. E., \& Järvelä, S. E. (2001). Motivation in learning contexts: Theoretical advances and methodological implications. Pergamon Press.

Walker, R. A., Pressick-Kilborn, K., Arnold, L. S., \& Sainsbury, E. J. (2004). Investigating Motivation in Context: Developing Sociocultural Perspectives. European Psychologist, 9(4), 245-256. https://doiorg.ezproxy.fiu.edu/10.1027/1016-9040.9.4.245

Wenger, E.(1998). Communities of practice: Learning, meaning and identity. Journal of Mathematics Teacher Education, 6(2), 185-194.

Wigfield, A., \& Eccles, J. S. (1992). The development of achievement task values: A theoretical analysis. Developmental review, 12(3), 265-310.

Wilson, K., \& Narayan, A. (2016). Relationships among individual task self-efficacy, self-regulated learning strategy use and academic performance in a computersupported collaborative learning environment. Educational Psychology, 36(2), 236-253.

Wilson, K., \& Narayan, A. (2016). Relationships among individual task self-efficacy, self-regulated learning strategy use and academic performance in a computersupported collaborative learning environment. Educational Psychology, 36(2), 236-253.

Wirth, A. G. (1980). Education in the technological society. Lanham, MD; University Press of America. 
Yazan, B. (2018). A conceptual framework to understand language teacher identities. Journal of Second Language Teacher Education, 1(1), 21-48.

Zeichner, K. (2010). Rethinking the connections between campus courses and field experiences in college-and university-based teacher education. Journal of teacher education, 61(1-2), 89-99.

Zimmerman, B. J. (1989). A social cognitive view of self-regulated academic learning. Journal of educational psychology, 81(3), 329.

Zimmerman, B. J. (2002). Becoming a self-regulated learner: An overview. Theory into practice, 41(2), 64-70. 


\section{APPENDICES \\ APPENDIX A: Survey Instruments \\ Motivated Strategies for Learning Questionnaire Manual DEMOGRAPHIC INFORMATION}

1. Gender (circle one). Male Female

2. What year did you graduate from high school?

3. Class level (circle one).

Freshman Sophomore Junior Senior

4. Ethnic background (circle one).

$\begin{array}{llc}\begin{array}{l}\text { Afro-American } \\ \text { or Black }\end{array} & \text { Asian-Caucasian } & \text { Hispanic Other } \\ & \text { American } & \text { or Spanish } \\ & & \text { Speaking }\end{array}$

5. How many hours per week do you work for pay?

6. How many other college level courses have you had in this subject area?

7. How many classes are you taking this term?

8. How many hours a week do you study for this course?

9. Reasons for taking this class (circle yes or no for each item).
a. fulfills distribution requirement
Yes
No
b. content seems interesting
Yes
No
c. is required of all students at college
Yes
No
d. will be useful to me in other courses
Yes
No
e. is an easy elective
Yes
No
f. will help improve my academic skills
Yes
No
g. is required for major (program)
Yes
No
h. was recommended by a friend
Yes
No
i. was recommended by a counselor
Yes
No
j. will improve career prospects
Yes
No
k. fit into my schedule
Yes
No 


\section{Part A. Motivation}

The following questions ask about your motivation for and attitudes about this class. Remember there are no right or wrong answers, just answer as accurately as possible. Use the scale below to answer the questions. If you think the statement is very true of you, circle 7; if a statement is not at all true of you, circle 1. If the statement is more or less true of you, find the number between 1 and 7 that best describes you.

$\begin{array}{llllllc}1 & 3 & 4 & 5 & 6 & \begin{array}{c}7 \\ \text { very true } \\ \text { of me }\end{array} \\ \begin{array}{l}\text { not at all } \\ \text { true of me }\end{array} & & & & & \end{array}$

1. In a class like this, I prefer course material $\quad \begin{array}{llllllll}1 & 2 & 3 & 4 & 5 & 6 & 7\end{array}$ that really challenges me so I can learn new things.

2. If I study in appropriate ways, then I will be able to learn the material in this course.

3. When I take a test I think about how poorly I am doing compared with other students.

4. I think I will be able to use what I learn in this course in other courses.

5. I believe I will receive an excellent grade in this class.

$\begin{array}{lllllll}1 & 2 & 3 & 4 & 5 & 6 & 7\end{array}$

6. I'm certain I can underst nd the most

$\begin{array}{lllllll}1 & 2 & 3 & 4 & 5 & 6 & 7\end{array}$
difficult material presented in the readings for this course.

7. Getting a good grade in this class is the most satisfying thing for me right now.

$\begin{array}{lllllll}1 & 2 & 3 & 4 & 5 & 6 & 7\end{array}$

8. When I take a test I think about items on other parts of the test I can't answer. 
not at all

true of me very true of me

9. It is my own fault if I don't learn the material in this course.

10. It is important for me to learn the course material in this class.

11. The most important thing for me right now is improving my overall grade point average, so my main concern in this class is getting a good grade.

12. I'm confident I can learn the basic concepts taught in this course.

13. If I can, I want to get better grades in this class than most of the other students.

14. When I take tests I think of the consequences of failing.

15. I'm confident I can understand the most complex material presented by the instructor in this course.

16. In a class like this, I prefer course material that arouses my curiosity, even if it is difficult to le rn.

17. I am very interested in the content area of this course.

18. If I try hard enough, then I will understand the course material.

19. I have an uneasy, upset feeling when I take an exam.

$$
\begin{array}{lllllll}
1 & 2 & 3 & 4 & 5 & 6 & 7
\end{array}
$$$$
\begin{array}{lllllll}
1 & 2 & 3 & 4 & 5 & 6 & 7
\end{array}
$$

$\begin{array}{lllllll}1 & 2 & 3 & 4 & 5 & 6 & 7\end{array}$ $\begin{array}{lllllll}1 & 2 & 3 & 4 & 5 & 6 & 7\end{array}$

$\begin{array}{lllllll}1 & 2 & 3 & 4 & 5 & 6 & 7\end{array}$

$\begin{array}{lllllll}1 & 2 & 3 & 4 & 5 & 6 & 7\end{array}$

$\begin{array}{lllllll}1 & 2 & 3 & 4 & 5 & 6 & 7\end{array}$

$\begin{array}{lllllll}1 & 2 & 3 & 4 & 5 & 6 & 7\end{array}$

$\begin{array}{lllllll}1 & 2 & 3 & 4 & 5 & 6 & 7\end{array}$

$\begin{array}{lllllll}1 & 2 & 3 & 4 & 5 & 6 & 7\end{array}$ 
not at all

true of me very true of me

20. I'm confident I can do an excellent $\begin{array}{lllllll}1 & 2 & 3 & 4 & 5 & 6 & 7\end{array}$ job on the assignments and tests in this course.

21. I expect to do well in this class.

22. The most satisfying thing for me in this course is trying to understand the content as thoroughly as possible.

23. I think the course material in this class is useful for me to learn.

24. When I have the opportunity in this class, I choose course assignments that I can learn from even if they don't guarantee a good grade.

25. If I don't understand the course material, it is because I didn't try hard enough.

26. I like the subject matter of this course.

27. Understanding the subject matter of this course is very important to me.

28. I feel my heart beating $\mathrm{f}$ st when I take an exam.

29. I'm certain I can master the skills being taught in this class.

30. I want to do well in this class because it is important to show my ability to my family, friends, employer, or others.

$\begin{array}{ccccccc}1 & 2 & 3 & 4 & 5 & 6 & 7 \\ 1 & 2 & 3 & 4 & 5 & 6 & 7\end{array}$

$\begin{array}{lllllll}1 & 2 & 3 & 4 & 5 & 6 & 7\end{array}$

$\begin{array}{lllllll}1 & 2 & 3 & 4 & 5 & 6 & 7\end{array}$ $\begin{array}{lllllll}1 & 2 & 3 & 4 & 5 & 6 & 7\end{array}$

$\begin{array}{lllllll}1 & 2 & 3 & 4 & 5 & 6 & 7\end{array}$

$\begin{array}{lllllll}1 & 2 & 3 & 4 & 5 & 6 & 7\end{array}$

$\begin{array}{lllllll}1 & 2 & 3 & 4 & 5 & 6 & 7\end{array}$

$\begin{array}{lllllll}1 & 2 & 3 & 4 & 5 & 6 & 7\end{array}$

$\begin{array}{lllllll}1 & 2 & 3 & 4 & 5 & 6 & 7\end{array}$ 
Adapted with permission from:

Thamotharan, V. \& Hazari, Z. (2018, Jan). Predicting Persistence through Science Teaching Identity. 2018 Association of Science Teacher Educators Conference.

Thamotharan, V. \& Hazari, Z. (2017, May). Science and Math Teaching Identity, Persistence and

Constructivist Teaching Beliefs. 2017 UTeach Conference.

To what extent do you agree or disagree with the following statements?

Not at all-0, 1,2,3, Very much so-4

1. I can see myself as a teacher?

2. My family sees me as good at teaching.

3. My friends/classmates see me as good at teaching.

4. Others ask me for help in teaching.

5. I enjoy teaching others.

6. Thinking about ways to teach is fun.

7. It is interesting to observe/listen to others develop their thinking about teaching.

8. I am passionate about sharing ideas about teaching with others.

9. I know the steps necessary to teach concepts effectively.

10. I understand teaching concepts well enough to be effective when teaching a lesson. 11. When a student has difficulty understanding a concept, I usually know how to help the student understand it better.

12. I know how to turn students on to learning. 


\section{APPENDIX B}

SCHOOL A ECE 1

Instructional Framework: Description of roles and responsibilities in job rotations

\begin{tabular}{|c|c|}
\hline \multicolumn{2}{|r|}{$\begin{array}{l}\text { Student-Teachers Group Roles and Responsibilities } \\
\text { Early Clinical Practice in a Community of Practice Framework }\end{array}$} \\
\hline $\begin{array}{l}\text { Transition } \\
\text { Group }\end{array}$ & $\begin{array}{l}\text { - } \text { Planning, preparing, and serving snacks and lunch } \\
\text { - Creating a monthly menu that follows nutritional standards for a } \\
\text { preschool age child } \\
\text { - Keeping the environment clean and safe } \\
\text { - Transitioning preschool students from one situation to another } \\
\text { based on the daily schedule } \\
\text { - Learning about and participating in several types of play } \\
\text { - Observing and reflecting on experiences with children during } \\
\text { activities (especially in behaviors regarding transitioning from } \\
\text { one activity to another and during play) } \\
\text { - Planning interventions for children who have difficulty } \\
\text { transitioning } \\
\text { - Connecting these observations and experiences with the } \\
\text { information, they must learn for the Child Development Associate } \\
\text { (CDA) exam }\end{array}$ \\
\hline $\begin{array}{l}\text { TEACH } \\
\text { Group }\end{array}$ & 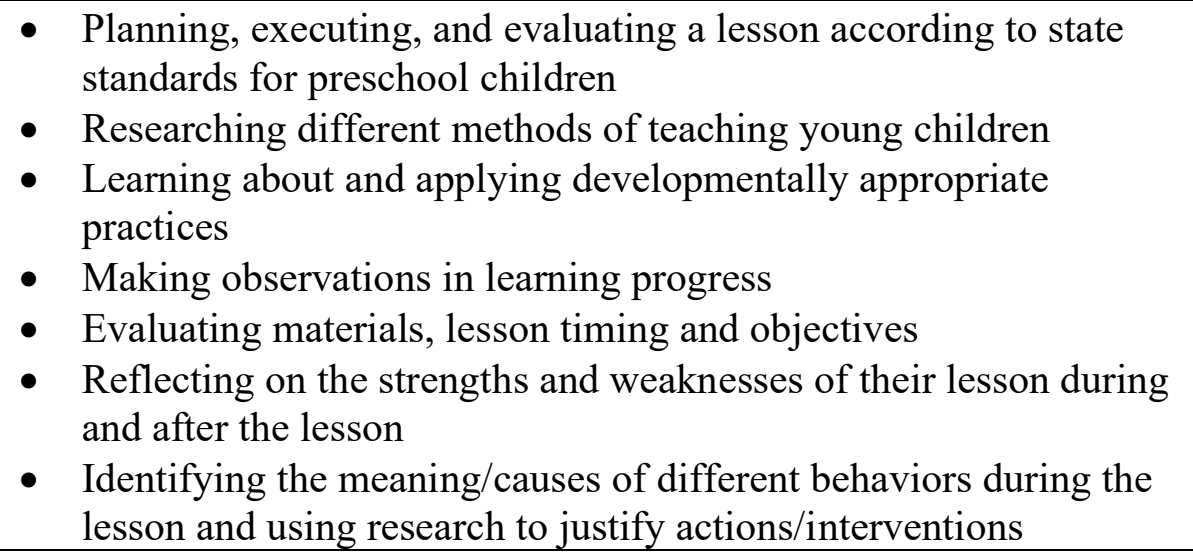 \\
\hline $\begin{array}{l}\text { Book } \\
\text { Work } \\
\text { Group }\end{array}$ & $\begin{array}{l}\text { - Researching teaching methods and strategies in preschool } \\
\text { appropriate practices } \\
\text { - Understanding teaching and learning theories and putting them } \\
\text { into practice } \\
\text { - Learning about and understanding essential factors in child } \\
\text { growth and development } \\
\text { - Investigating the rules and regulations behind childcare in the } \\
\text { state } \\
\text { - Understanding the reasons behind these laws } \\
\text { - Learning about health and nutritional needs of a preschool age } \\
\text { child }\end{array}$ \\
\hline
\end{tabular}




\begin{tabular}{|c|c|}
\hline & $\begin{array}{l}\text { - Learning to identify and report child abuse and neglect } \\
\text { - Understanding diverse types of observations and screenings }\end{array}$ \\
\hline $\begin{array}{l}\text { Lesson } \\
\text { Planning } \\
\text { Group }\end{array}$ & $\begin{array}{l}\text { - Create and develop a lesson plan which includes an objective, } \\
\text { state standards, materials, procedures, assessment, and } \\
\text { accommodations } \\
\text { - Consider roles for each member of the lesson planning group } \\
\text { - Learn to read and use the state standards and curriculum of a } \\
\text { preschool classroom } \\
\text { - Make developmentally appropriate decisions when creating and } \\
\text { developing all parts of the lesson plan } \\
\text { - Create a sample or draw a diagram of the activity in the lesson to } \\
\text { identify and remedy any weaknesses in the plan } \\
\text { - Refer to and discuss reflections from past experiences and discuss } \\
\text { improvements as well as strengths } \\
\text { - Submit a lesson plan for approval }\end{array}$ \\
\hline
\end{tabular}




\section{APPENDIX C}

\section{SCHOOL A ECE 1 Instructional Framework}

\section{Excerpt from Adolescent Group Rotation Calendar}

$\underline{\text { Key }}$

Numbers (1-4): Represent each group's number. Each group is assigned a number and has 3-4 students in each group. Students remain in this group for the school year unless a problem arises. White Square: Represents A Day on the A/B block school schedule (periods 1,3,5,7) Green Square: Represents B Day on the A/B block school schedule (periods 2,4,6,8)

TEACH: On this day that group will teach the preschool children.

BW: On this day that group will complete their assignment by the end of the period.

LP: On this day that group will lesson plan for their next teaching experience.

TR: On this day that group will transition the children from one activity to another and complete all required maintenance task.

\begin{tabular}{|c|c|c|c|c|}
\hline & $\begin{array}{l}10 / 31 \\
1 \mathrm{TEACH} \\
2 \mathrm{BW} \\
3 \mathrm{LP} \\
4 \mathrm{TR}\end{array}$ & $\begin{array}{l}\text { 11/1 } \\
1 \text { TEACH } \\
2 B W \\
3 \text { LP } \\
4 T R\end{array}$ & $\begin{array}{l}2 \\
1 \mathrm{TR} \\
2 \text { Teach } \\
3 \mathrm{BW} \\
4 \mathrm{LP}\end{array}$ & $\begin{array}{l}3 \\
1 \text { TR } \\
2 \text { Teach } \\
3 \text { BW } \\
4 \text { LP }\end{array}$ \\
\hline $\begin{array}{l}6 \\
1 \mathrm{LP} \\
2 \mathrm{TR} \\
3 \text { Teach } \\
4 \mathrm{BW}\end{array}$ & $\begin{array}{l}7 \\
1 \mathrm{LP} \\
2 \mathrm{TR} \\
3 \text { Teach } \\
4 \mathrm{BW}\end{array}$ & $\begin{array}{l}8 \\
1 \mathrm{BW} \\
2 \mathrm{LP} \\
3 \mathrm{TR} \\
4 \mathrm{TEACH}\end{array}$ & $\begin{array}{l}9 \\
1 \mathrm{BW} \\
2 \mathrm{LP} \\
3 \mathrm{TR} \\
4 \mathrm{TEACH}\end{array}$ & $10 \mathrm{NO}$ SCHOOL \\
\hline $\begin{array}{l}13 \\
1 \mathrm{TEACH} \\
2 \mathrm{BW} \\
3 \mathrm{LP} \\
4 \mathrm{TR}\end{array}$ & $\begin{array}{l}14 \\
1 \mathrm{TEACH} \\
2 \mathrm{BW} \\
3 \mathrm{LP} \\
4 T R\end{array}$ & $\begin{array}{l}15 \\
1 \text { TR } \\
2 \text { Teach } \\
3 \text { BW } \\
4 \text { LP }\end{array}$ & $\begin{array}{l}16 \\
1 \text { TR } \\
2 \text { Teach } \\
3 \text { BW } \\
4 \text { LP }\end{array}$ & $\begin{array}{l}17 \\
1 \mathrm{LP} \\
2 \mathrm{TR} \\
3 \text { Teach } \\
4 \mathrm{BW}\end{array}$ \\
\hline $\begin{array}{l}20 \\
1 \mathrm{LP} \\
2 \mathrm{TR} \\
3 \text { Teach } \\
4 \mathrm{BW}\end{array}$ & $\begin{array}{l}21 \\
1 \mathrm{BW} \\
2 \mathrm{LP} \\
3 \mathrm{TR} \\
4 \mathrm{TEACH}\end{array}$ & $22 \mathrm{NO} \mathrm{SCHOOL}$ & $23 \mathrm{NO} \mathrm{SCHOOL}$ & $24 \mathrm{NO} \mathrm{SCHOOL}$ \\
\hline
\end{tabular}


APPENDIX D

SCHOOL A ECE 1 Instructional Framework

Daily Schedule and General Routines 


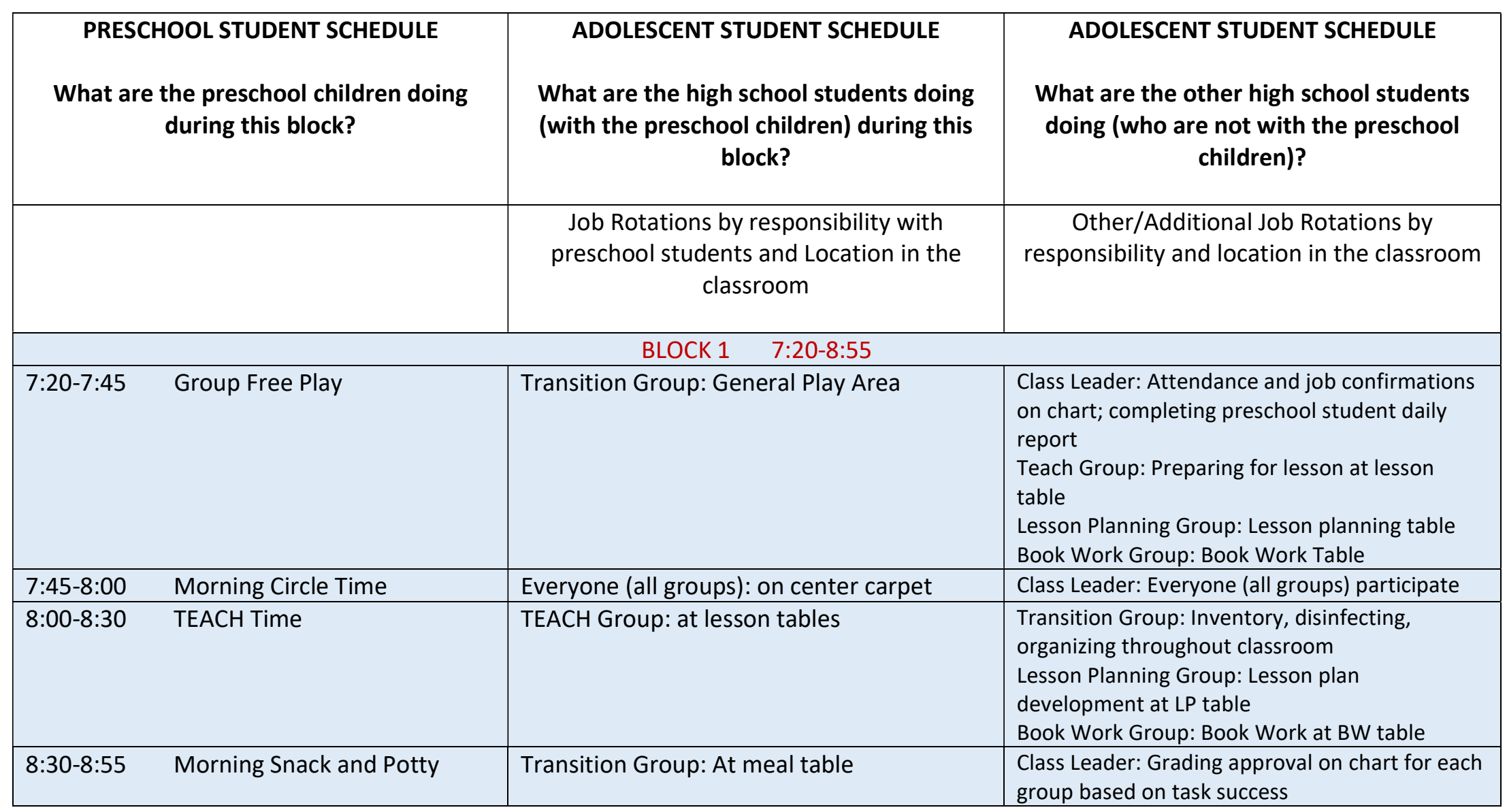




\begin{tabular}{|c|c|c|}
\hline & & $\begin{array}{l}\text { Teach Group: Reset activity area and begin } \\
\text { writing reflection at computer station } \\
\text { Lesson Planning Group: Lesson plan approval at } \\
\text { LP table } \\
\text { Book Work Group: Book Work approval and } \\
\text { submission at BW table }\end{array}$ \\
\hline \multicolumn{3}{|c|}{ BLOCK $2 \quad 8: 55-10: 25$} \\
\hline 8:55-9:15 Recess & Transition Group: Outside Playground & $\begin{array}{l}\text { Class Leader: Attendance and job confirmations } \\
\text { on chart; completing preschool student daily } \\
\text { report } \\
\text { Teach Group: Preparing for lesson at lesson } \\
\text { table } \\
\text { Lesson Planning Group and Book Work Group } \\
\text { assist transition group in playground area }\end{array}$ \\
\hline 9:20-9:30 Group Storytime & Class Leader: at center carpet & $\begin{array}{l}\text { Teach Group: Preparing for lesson at lesson } \\
\text { table } \\
\text { Lesson Planning Group: Lesson planning table } \\
\text { Book Work Group: Book Work Table }\end{array}$ \\
\hline 9:30-10:00 TEACH Time & TEACH Group: at lesson tables & $\begin{array}{l}\text { Transition Group: Inventory, disinfecting, } \\
\text { organizing throughout classroom } \\
\text { Lesson Planning Group: Lesson plan } \\
\text { development at LP table } \\
\text { Book Work Group: Book Work at BW table }\end{array}$ \\
\hline 10:00-10:25 Independent Play & Transition Group: General Play Area & $\begin{array}{l}\text { Class Leader: Grading approval on chart for each } \\
\text { group based on task success } \\
\text { Teach Group: Reset activity area and begin } \\
\text { writing reflection at computer station } \\
\text { Lesson Planning Group: Lesson plan approval at } \\
\text { LP table } \\
\text { Book Work Group: Book Work approval and } \\
\text { submission at BW table }\end{array}$ \\
\hline
\end{tabular}




\begin{tabular}{|c|c|c|}
\hline \multicolumn{3}{|c|}{ BLOCK $3 \quad 10: 25-12: 00$} \\
\hline $10: 25-10: 30$ & Transition Group: at hand washing sink & $\begin{array}{l}\text { Class Leader: Attendance and job confirmations } \\
\text { on chart; completing preschool student daily } \\
\text { report } \\
\text { Teach Group: Preparing for lesson at lesson } \\
\text { table } \\
\text { Lesson Planning Group: Lesson planning table } \\
\text { Book Work Group: Book Work Table }\end{array}$ \\
\hline 10:30-10:40 Center Activities & $\begin{array}{l}\text { Class Leader: at center carpet and various } \\
\text { locations }\end{array}$ & Transition Group: Outside clean up \\
\hline 10:45-11:15 TEACH Time & TEACH Group: at lesson tables & $\begin{array}{l}\text { Transition Group: Preparing and cooking lunch } \\
\text { Lesson Planning Group: Lesson plan } \\
\text { development at LP table } \\
\text { Book Work Group: Book Work at BW table }\end{array}$ \\
\hline 11:20-11:45 Lunch and Potty & Transition Group: At meal table & $\begin{array}{l}\text { Class Leader: Grading approval on chart for each } \\
\text { group based on task success } \\
\text { Teach Group: Reset activity area and begin } \\
\text { writing reflection at computer station } \\
\text { Lesson Planning Group: Lesson plan approval at } \\
\text { LP table } \\
\text { Book Work Group: Book Work approval and } \\
\text { submission at BW table }\end{array}$ \\
\hline 11:50-12:50 Nap Time & 12:00-12:50 Lunch & $\begin{array}{l}\text { All groups are at lunch in high school } \\
\text { cafeteria }\end{array}$ \\
\hline \multicolumn{3}{|c|}{ BLOCK $4 \quad 12: 55-2: 20$} \\
\hline 12:55-1:15 Wake Up and Play & Transition Group: General Play Area & \\
\hline 1:15-1:45 TEACH Time & TEACH Group: at lesson tables & $\begin{array}{l}\text { Transition Group: End of the day sweep, laundry } \\
\text { and final clean up } \\
\text { Lesson Planning Group: Lesson plan } \\
\text { development at LP table } \\
\text { Book Work Group: Book Work at BW table }\end{array}$ \\
\hline
\end{tabular}




\begin{tabular}{|ll|l|l|}
\hline 1:45-2:00 & Afternoon Snack and Potty & Transition Group: At meal table & $\begin{array}{l}\text { Class Leader: Grading approval on chart for each } \\
\text { group based on task success } \\
\text { Teach Group: } \text { Reset activity area and begin } \\
\text { writing reflection at computer station } \\
\text { Lesson Planning Group: Lesson plan approval at } \\
\text { LP table } \\
\text { Book Work Group: Book Work approval and } \\
\text { submission at BW table }\end{array}$ \\
\hline 2:00-2:15 & Closing Circle Time & Everyone (all groups): on center carpet & Class Leader: Everyone (all groups) participate \\
\hline 2:15-2:40 & Parent Pick Up & School released at 2:20 & $\begin{array}{l}\text { All groups are dismissed: Various students stay } \\
\text { afterschool to assist in preschool dismissal }\end{array}$ \\
\hline
\end{tabular}




\section{APPENDIX E}

Description of Student Roles and Expectation by Program Level

\begin{tabular}{|c|c|}
\hline Student level & Description and Example of Level Expectations \\
\hline 1 (Mostly $9^{\text {th }}$ graders) & $\begin{array}{l}\text { Students in level } 1 \text { have little contact with preschool children in the } \\
\text { preschool lab. Most assignments do not require them to teach, } \\
\text { observe or evaluate. Students concentrate on content, gaining } \\
\text { knowledge for future application. }\end{array}$ \\
\hline 2 (Mostly $10^{\text {th }}$ graders) & $\begin{array}{l}\text { Students in level } 2 \text { have daily contact with preschool children in the } \\
\text { preschool lab. Students are expected to participate in all the roles } \\
\text { and jobs and make basic observations and contributions to the } \\
\text { group. Students must apply the knowledge learned in level } 1 \text { when } \\
\text { lesson planning and teaching. }\end{array}$ \\
\hline 3 (Mostly $11^{\text {th }}$ graders) & $\begin{array}{l}\text { Students in level } 3 \text { have mostly contact with preschool children in } \\
\text { the preschool lab. These students take the role of lead teacher for } \\
\text { teaching experiences, make observations and evaluate themselves } \\
\text { and their students. Students work with the level } 2 \text { students to help } \\
\text { them with all roles and responsibilities. Students are expected to } \\
\text { apply prior knowledge, evaluate and reflect on teaching experience. }\end{array}$ \\
\hline 4 (Mostly $12^{\text {th }}$ graders) & $\begin{array}{l}\text { Students in level } 4 \text { manage and help oversee classroom and group } \\
\text { procedures and routines. These students evaluate the lessons and } \\
\text { teach experiences of lower level students in their group. These } \\
\text { students make suggestions and reflect on the successes and } \\
\text { weaknesses of the lesson taught by their peers. Level } 4 \text { students } \\
\text { make important decisions regarding class procedures, changes to the } \\
\text { instructional framework if needed, and reflect on academy's overall } \\
\text { strengths and weaknesses. These students participate in periodic } \\
\text { professional development during lunch or after school where they } \\
\text { learn new teaching strategies, prepare for certifications and discuss } \\
\text { concerns. }\end{array}$ \\
\hline
\end{tabular}




\section{APPENDIX F:}

School Data for SCHOOL A ECE 1, SCHOOL B ECE 2 and SCHOOL A BIO 1

\begin{tabular}{|c|c|c|c|}
\hline State Data & \multicolumn{3}{|c|}{$\begin{array}{l}\text { 2018-2019 data- } 431,730 \text { students in CTE job preparatory courses } \\
2017-2018 \text { data- } 30,022 \text { students registered in high school ET cluster } \\
\text { courses } \\
\text { ECE has enrollment of } 18,939 \text { (2017-2018) } \\
\text { Graduation rate of program completers is } 96.52 \% \\
81.50 \% \text { are employed or enrolled in postsecondary after graduation }\end{array}$} \\
\hline County Data & \multicolumn{3}{|c|}{ County has top enrollment in the state in job prep programs } \\
\hline \multirow{12}{*}{ School Data } & SCHOOL A & & SCHOOL B \\
\hline & $98 \%$ & Minority rate & $98 \%$ \\
\hline & Yes & Title 1 school & Yes \\
\hline & $84 \%$ & $\begin{array}{l}\text { Economically disadvantaged } \\
\text { rate }\end{array}$ & $81 \%$ \\
\hline & No & Charter & No \\
\hline & B & School Grade & $\mathrm{C}$ \\
\hline & 11 & Number of Career programs & 6 \\
\hline & 2741 & Enrollment & 2186 \\
\hline & 88.2 & Graduation Rate & 87.2 \\
\hline & .8 & Dropout rate & 1.7 \\
\hline & 94.7 & Attendance record & 91.99 \\
\hline & $\begin{array}{l}4 \text { block } \\
\text { schedule }\end{array}$ & Scheduling & 4 block schedule \\
\hline \multirow{14}{*}{$\begin{array}{l}\text { ECE } \\
\text { Program } \\
\text { Data }\end{array}$} & 6 years & Age of Program & $10+$ years \\
\hline & 356 & Program Enrollment Total & 217 \\
\hline & 176 & ECE Level 1 & 111 \\
\hline & 75 & ECE Level 2 & 62 \\
\hline & 64 & ECE Level 3 & 33 \\
\hline & 42 & ECE Level 4 & 11 \\
\hline & Yes & On-site Preschool & No \\
\hline & Yes & DCF/ECPC Certification & Yes \\
\hline & Yes & CDA certification & Yes \\
\hline & 2 & Number of Teachers & 1 \\
\hline & 1 & Number of Assistants & 0 \\
\hline & $\begin{array}{l}\text { Mixed Levels } \\
\text { except level } 1\end{array}$ & Student Scheduling & $\begin{array}{l}\text { All levels are } \\
\text { separated by } \\
\text { levels }\end{array}$ \\
\hline & FLDOE & Curriculum CTE Framework & FLDOE \\
\hline & Yes & Group Rotations & N/A \\
\hline
\end{tabular}




\begin{tabular}{|l|l|l|}
\hline \multirow{5}{*}{} & 10 years & Age of Program \\
\cline { 2 - 3 } & 541 & Program Enrollment Total \\
\cline { 2 - 3 } & 175 & ECE Level 1 \\
\cline { 2 - 3 } $\begin{array}{l}\text { BIO 1 } \\
\text { Program Data }\end{array}$ & 153 & ECE Level 2 \\
\cline { 2 - 3 } & 93 & ECE Level 3 \\
\cline { 2 - 3 } & Yes & ECE Level 4 \\
\cline { 2 - 3 } & Yes & Cn-site Clinical Lab \\
\cline { 2 - 3 } & 5 & Number of Teachers \\
\cline { 2 - 3 } & 0 & Number of Assistants \\
\cline { 2 - 3 } & $\begin{array}{l}\text { Mixed Levels } \\
\text { except level 1 }\end{array}$ & \\
\cline { 2 - 3 } & FLDOE & Curriculum CTE Framework \\
\hline
\end{tabular}


VITA

\section{ELIZABETH MARTIN AGUILA}

Born, Hialeah, Florida

1994-2001

B.S., Varying Exceptionalities

Florida International University

Miami, Florida

2001-2003

M.S., Exceptional Student Education

Florida International University

Miami, Florida

2001-2008

Teacher, Exceptional Student Education

Miami Dade County Public Schools

Miami, Florida

2006-2007

Teacher of the Year Award

Barbara Goleman Senior High

Miami Lakes, Florida

2008-2013

Teacher, Language Arts $9^{\text {th }}-12^{\text {th }}$ Grade

Miami Dade County Public Schools

Miami, Florida

2013-Present

Teacher, Career and Technical Education $9^{\text {th }}-12^{\text {th }}$ Grade

Preschool Director

Miami Dade County Public Schools

Miami, Florida

2016-2017

Teacher of the Year Award

Hialeah Gardens High School

Hialeah Gardens, Florida

2019-2020

Doctoral Candidate

Florida International University

Miami, Florida

\section{PUBLICATIONS AND PRESENTATIONS}

Aguila, E.M., (January, 2020). Miami-Dade's Aspiring Teachers Introduce Robotics and Coding to Preschoolers. 2020 Florida Educator Technology Conference. 
Aguila, E.M., (2019, May 23). How to Prepare Students to Learn by Teaching. Edutopia. Retrieved from https://www.edutopia.org/article/how-prepare-students-learn-teaching

Aguila, E.M., Lino, S., Rodino, G., Marroquin, C., Valle, V., (December, 2017). Developing the Early Stages of Literacy through Dialogic Reading with Bilingual Students. Paper presented at the meeting of the American Reading Forum, Sanibel, Florida. 